Aus der Abteilung Pathologie

(Prof. Dr. med. H.-J. Radzun)

im Zentrum Pathologie und Rechtsmedizin

der Medizinischen Fakultät der Universität Göttingen

\title{
Antikanzerogene Effekte von Belamcanda chinensis in Zelllinien maligner Keimzelltumoren des Hodens
}

\author{
INAUGURAL-DISSERTATION \\ zur Erlangung des Doktorgrades \\ der Medizinischen Fakultät der \\ Georg-August-Universität zu Göttingen
}

vorgelegt von

Astrid Maria Hasibeder

aus

Wien, Österreich

Göttingen 2013 
Dekan: Prof. Dr. rer. nat. H. K. Kroemer

I. Berichterstatter: PD Dr. med. S. Schweyer

II. Berichterstatter: PD Dr. med. E. Heinrich

Tag der mündlichen Prüfung: 06.11.2013 


\section{Inhaltsverzeichnis}

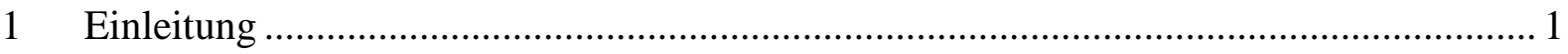

$1.1 \quad$ Maligne Keimzelltumoren des Hodens ......................................................... 1

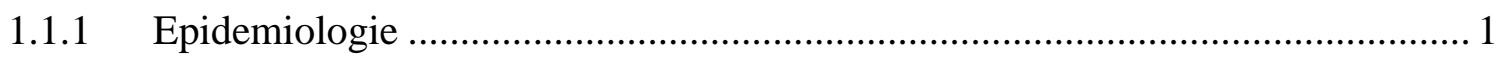

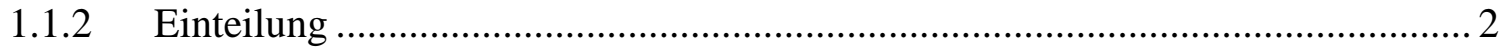

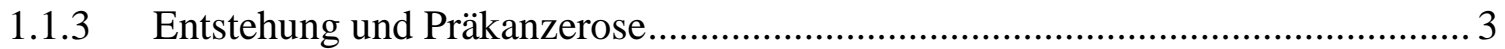

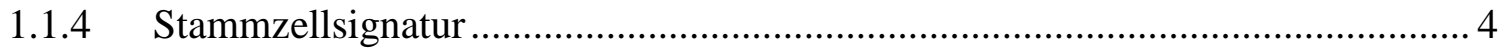

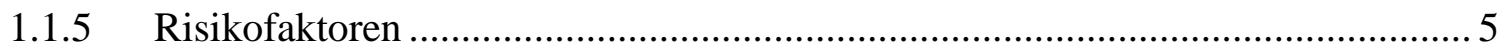

1.1.6 Klinik: Diagnostik, Therapie und Prognose ................................................ 6

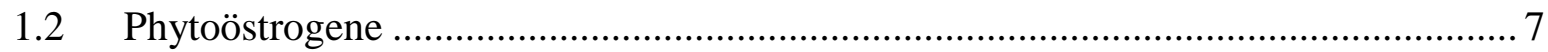

1.2.1 Belamcanda-chinensis-Extrakt und Tectorigenin ....................................... 8

1.2.2 Phytoöstrogene in der Krebsforschung ...................................................... 9

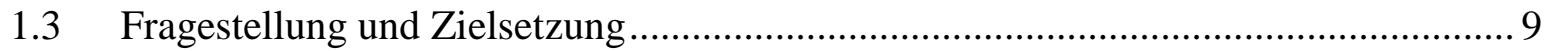

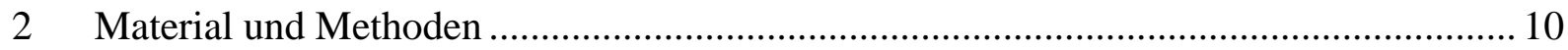

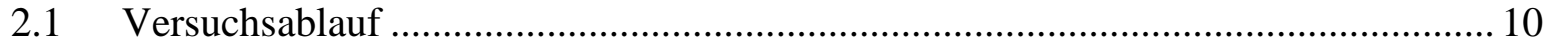

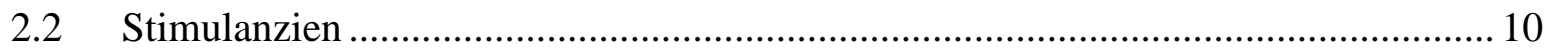

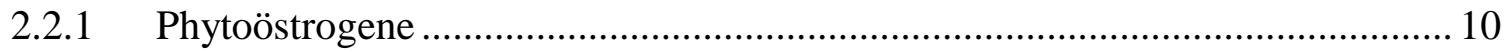

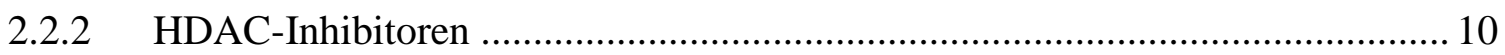

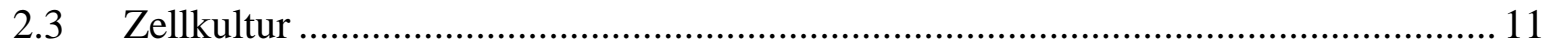

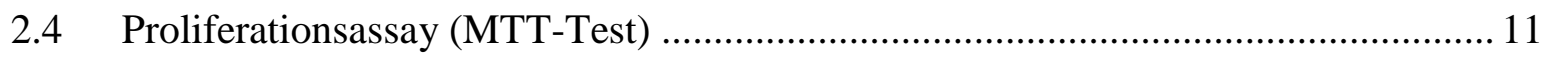

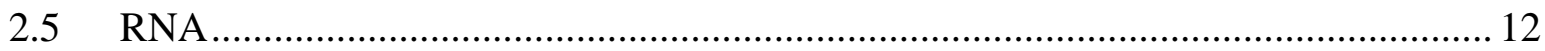

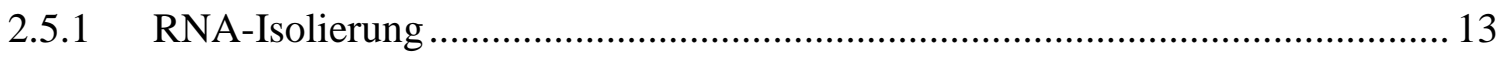

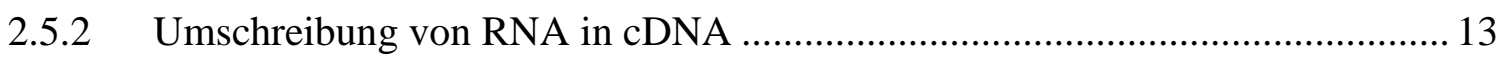

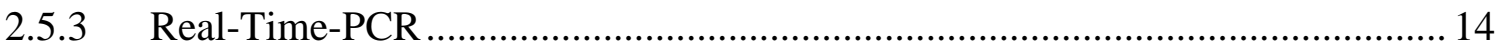

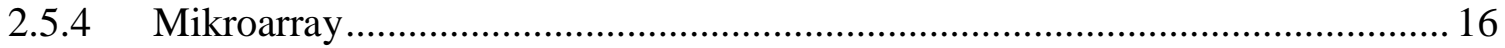

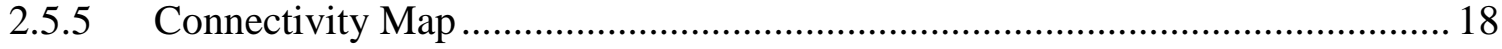

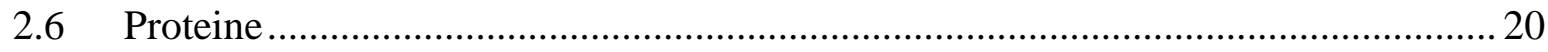

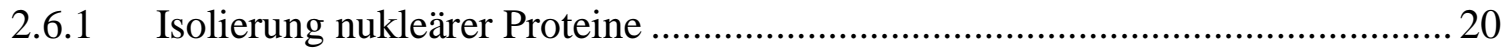

2.6.2 Quantifizierung der Proteine nach Bradford ................................................ 20

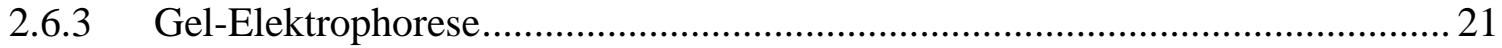

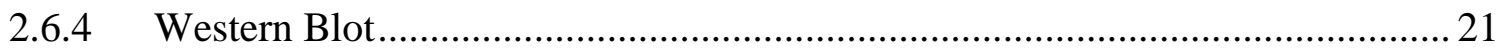




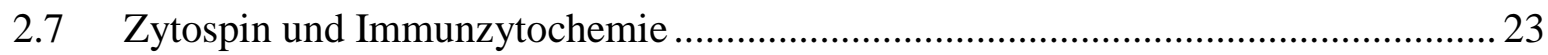

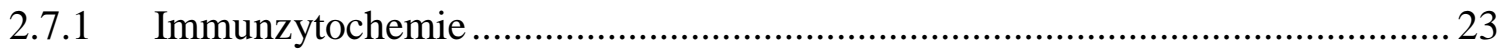

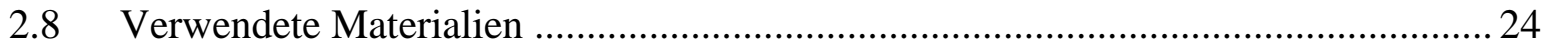

2.8.1 Chemikalien, Enzyme, Puffer, Kits ......................................................... 24

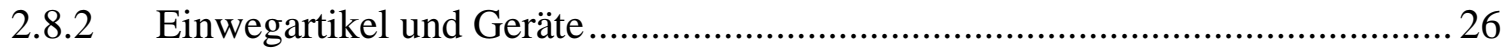

2.8.3 Selbst angesetzte Puffer und Lösungen ........................................................ 28

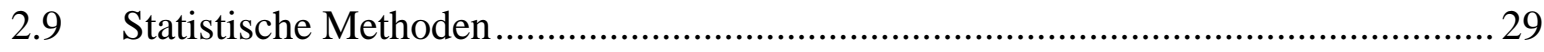

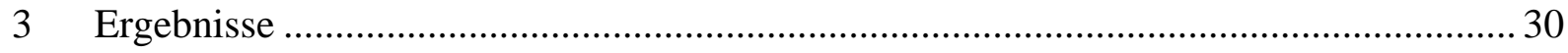

3.1 TGCT-Zelllinien unter Phytoöstrogen-Stimulation............................................ 30

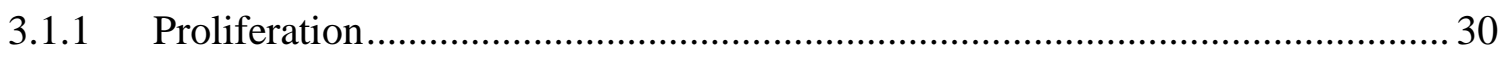

3.1.2 mRNA-Expression der Stammzellgene ...................................................... 33

3.1.3 Proteinexpression der Stammzellgene …....................................................... 37

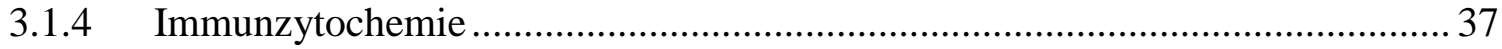

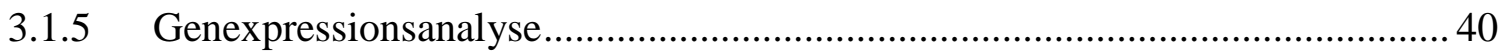

3.2 BCE: Vergleich von TGCT- und Prostatakrebszellen im Stimulationsversuch........ 43

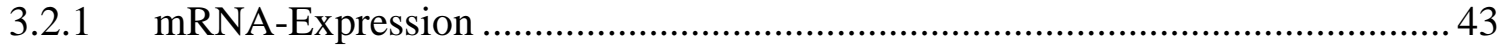

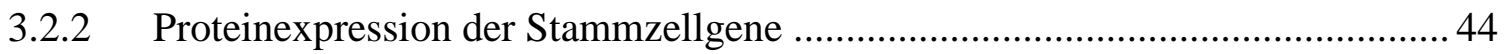

3.3 Effekte von BCE und HDAC-Inhibitoren im Vergleich .......................................46

3.3.1 mRNA-Expression der Stammzellgene .................................................... 46

3.3.2 Proteinexpression der Stammzellgene .......................................................... 46

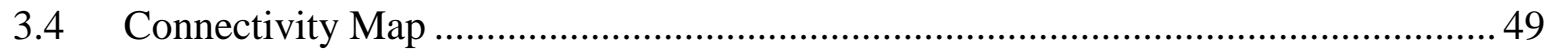

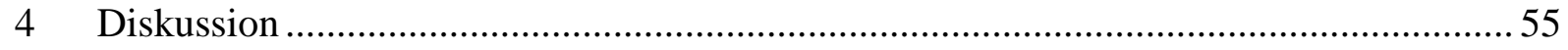

4.1 Proliferationsinhibition in TGCT-Zelllinien nach Stimulation mit Tectorigenin und

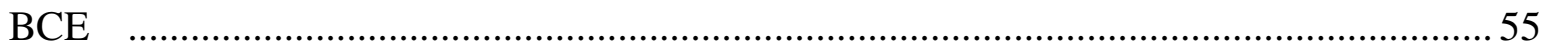

4.2 Differentielle Expression von Stammzellfaktoren in TGCT-Zelllinien unter BCEStimulation

4.3 Regulation verschiedener Differenzierungsgene in TGCT-Zelllinien nach

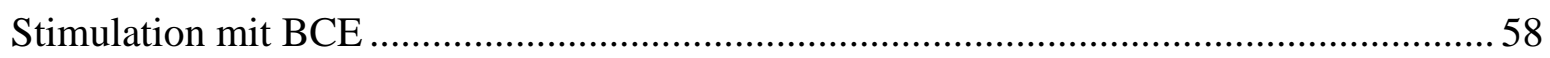

4.4 Kein Hinweis auf Hyperacetylierung von Histonen durch das BCE........................ 61

4.5 Hormonrezeptoren in TGCT-Zellen und Inhibition der Stammzellsignatur in LNCaP-Zellen nach BCE-Stimulation 


\section{Inhaltsverzeichnis}

4.6 Annäherung an den Wirkmechanismus des Belamcanda-chinensis-Extraktes mit

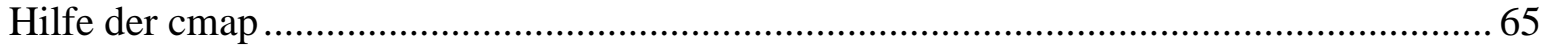

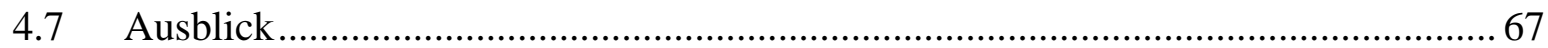

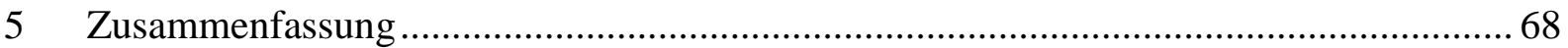

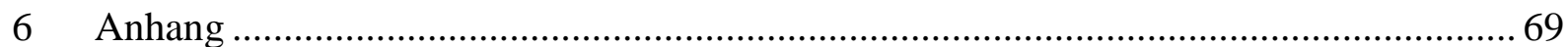

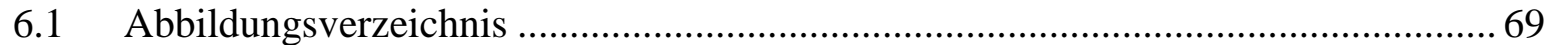

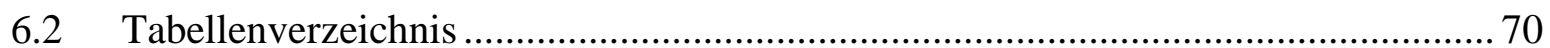

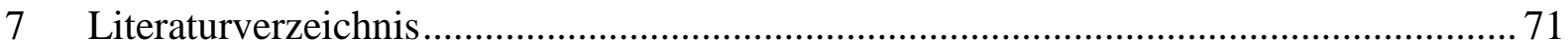




\section{Abkürzungsverzeichnis}

\begin{tabular}{|c|c|}
\hline AFP & Alpha-Fetoprotein \\
\hline AR & Androgenrezeptor \\
\hline BCE & Belamcanda-chinensis-Extrakt \\
\hline$\beta-\mathrm{HCG}$ & Beta-Untereinheit des humanen Choriongonadotropin \\
\hline BSA & Bovines Serumalbumin \\
\hline CAG & Cytosin, Adenin, Guanin \\
\hline cDNA & Complementary DNA \\
\hline CIS & Carcinoma in situ \\
\hline cmap & Connectivity Map \\
\hline $\mathrm{CO}_{2}$ & Kohlenstoffdioxid \\
\hline $\mathrm{CT}$ & Computertomographie \\
\hline DAVID & Database for Annotation, Visualization and Integrated Discovery \\
\hline DMSO & Dimethylsulfoxid \\
\hline DNA & Deoxyribonucleic acid \\
\hline dNTP & Desoxynukleotidtriphosphat \\
\hline DTT & Dithiothreitol \\
\hline $\mathrm{EC}$ & Embryonal carcinoma \\
\hline ER & Estrogen receptor \\
\hline ER- $\alpha$ & Estrogen receptor alpha \\
\hline $\mathrm{ER}-\beta$ & Estrogen receptor beta \\
\hline ES & Embryonale Stammzelle \\
\hline FCS & Fetal calf serum \\
\hline $\mathrm{HCl}$ & Chlorwasserstoff \\
\hline HDACi & Histon-Deacetylase-Inhibitor \\
\hline HEPES & 2-(4-(2-Hydroxyethyl)-1-piperazinyl)-ethansulfonsäure \\
\hline $\mathrm{H}_{2} \mathrm{O}$ bi. dest. & Doppelt destilliertes Wasser \\
\hline HRP & Horseradish peroxidase \\
\hline ICC & Immunocytochemistry \\
\hline IGCNU & Intratubular germ cell neoplasia unclassified \\
\hline
\end{tabular}


IGF Insulin-like growth factor

IGFBP3 Insulin-like growth factor-binding protein 3

IGFR1 Insulin-like growth factor receptor 1

LDH Laktatdehydrogenase

MIAME Minimum Information About a Microarray Experiment

mRNA Messenger RNA

MTT (3-(4,5-Dimethylthiazol-2-yl)-2,5-diphenyltetrazoliumbromid)

NADH Nikotinamidadenindinukleotid

NADPH Nikotinamidadenindinukleotidphosphat

OD Optische Dichte

PBS Phosphat-buffered saline

PCA Principal component analysis

PCR Polymerase chain reaction

PDEF Prostate-derived Ets transcription factor

PEB Cisplatin, Etoposid, Bleomycin

PSA Prostata-spezifisches Antigen

RNA Ribonucleic acid

rpm Revolutions per minute

RTD-PCR Real time detection PCR

RT-PCR Reverse transcriptase PCR

SDS Sodiumdodecylsulfat

siRNA Small interfering RNA

TBST Tris-buffered saline and tween

TGCT Testicular germ cell tumor(s)

TNM(S) Tumor, lymph nodes, metastasis, (serum tumor markers)

TSA Trichostatin A

UICC Union for International Cancer Control

VPA Valproat

WHO World Health Organization

Abkürzungen von Genen und Zelllinien werden im Text erklärt. 
Einleitung

\section{Einleitung}

\subsection{Maligne Keimzelltumoren des Hodens}

\subsubsection{Epidemiologie}

Die malignen Keimzelltumoren des Hodens sind die häufigsten malignen soliden Tumoren des jungen Mannes im Alter von 15-34 Jahren. Zwar sind sie auch die fünfthäufigste Krebstodesursache dieser Altersgruppe, dank der fortschrittlichen Therapiemöglichkeiten wird jedoch eine Abnahme der Mortalität seit 1971 beschrieben (Silverberg 1982).

Mit einer Inzidenz von 10,6 pro 100000 Personenjahren zählen maligne Keimzelltumoren des Hodens insgesamt zu den seltenen Krebserkrankungen in Deutschland (Stang et al. 2010), allerdings wurde eine weltweite Verdopplung der Fälle in den letzten 40 Jahren geschätzt. Von Bedeutung ist eine beachtenswerte geografische Varianz. So findet man die höchste Inzidenz in Skandinavien und der Schweiz, eine mittlere in Deutschland, den USA, Australien und Großbritannien und die niedrigste in Asien und Afrika. Aus Entwicklungsländern sind allerdings nur wenige Daten verfügbar. Interessanterweise variiert die Inzidenz auch zwischen verschiedenen ethnischen Gruppen, mit beispielsweise einer deutlich höheren Rate in der weißen als in der schwarzen amerikanischen Bevölkerung (Huyghe et al. 2003).

Die steigende Inzidenz sowie die differentielle geografische und ethnische Verteilung lassen vermuten, dass, wie bei einer Reihe weiterer maligner Tumoren, der Einfluss von Umweltfaktoren eine Rolle spielt (Belpomme et al. 2007).

Im Zusammenhang mit der unterschiedlichen geografischen Inzidenz von TGCT (testicular germ cell tumors, dt: Keimzelltumoren des Hodens) weisen internationale Daten über die Verteilung von hormonabhängigen Tumoren (Hoden, Ovar, Prostata, Brust, Uterus) darauf hin, dass es sich dabei um Tumoren des Wohlstandes handelt. Eine Hypothese ist, dass einige Komponenten der westlichen protein- und fettreichen Ernährung Menschen für diese Tumoren prädisponieren. Statistiken aus Japan zeigen eine Korrelation von Ernährung und Krebsvorkommen. Bedingt durch Veränderungen in der Ernährungsgewohnheit werden japanische Kinder immer größer. Einhergehend mit dieser Veränderung nimmt auch die Inzidenz von Ovarial- und Prostatakarzinomen sowie TGCT zu (Berg 1975). Da diese Umweltfaktoren, besonders Ernährung und Lebensstil, bis heute als Risikofaktoren für die Entstehung diverser Krebserkrankungen (mit-)verantwortlich gemacht werden, gibt es beispielsweise von der American Cancer Society Leitlinien zur Prävention, welche gesunde Ernährung und körperliche Aktivität empfehlen (Kushi et al. 2012). 
Einleitung

Andere Wissenschaftler weisen in aktuellen Publikationen allerdings darauf hin, dass es zurzeit zwei verschiedene Ansätze zur Erklärung der steigenden Anzahl von Neuerkrankungen an Malignomen gibt. Der erste Erklärungsansatz, ähnlich dem von Berg (1975), macht das ständige Wachsen und das Altern der Bevölkerung, Lifestylefaktoren wie Rauchen, Alkohol und Ernährung und den Fortschritt in der Diagnostik und in Screeningverfahren dafür verantwortlich. Im Gegensatz dazu weisen Belpomme et al. (2007) darauf hin, dass diese Argumente nicht ausreichend Erklärung liefern, da beispielsweise Lifestylefaktoren, mit Ausnahme von Zigarettenrauchen, nicht mutagen sind. Deshalb wird vermutet, dass - zusätzlich zu den bereits genannten - neue Faktoren aus der Umwelt einen erheblichen Beitrag leisten. Gemeint ist damit unter anderem die unfreiwillige Exposition gegenüber diversen Schadstoffen. Beispiele dafür sind vor allem Umweltfaktoren wie Viren, Strahlung und Chemikalien (Belpomme et al. 2007).

\subsubsection{Einteilung}

$\mathrm{Zu}$ den Hodentumoren zählen nicht ausschließlich TGCT, allerdings machen diese nach Schottenfeld et al. (1980) mindestens 95 Prozent der malignen Neoplasien des Hodens bei erwachsenen Männern aus. Bei den Nicht-Keimzelltumoren handelt es sich hauptsächlich um Keimstrang-/Gonadenstroma-Tumoren und maligne Lymphome des Hodens, welche in der Regel bei älteren Patienten auftreten (Schottenfeld et al. 1980).

Abgesehen davon, dass maligne Keimzelltumoren des Hodens eine gemeinsame Vorläuferzelle haben, werden sie nach histologischen und klinischen Kriterien in Seminome und NichtSeminome unterteilt. Zu den Seminomen zählen ausschließlich reine Tumorformen, während Nicht-Seminome unter anderem Dottersacktumor, Chorionkarzinom, embryonales Karzinom und Teratom sowie Mischformen der genannten Tumore umfassen (Hayes-Lattin und Nichols 2009).

Eine detaillierte Einteilung der Hodentumoren liefert die WHO. Nach ihrer histologischen Klassifikation von 2004 werden Hodentumoren folgendermaßen eingeteilt: (Tabelle 1) 
Einleitung

Tabelle 1: WHO Klassifikation der Hodentumoren und ihre Häufigkeit, modifiziert nach Eble et al. (2004, S. 218)

\begin{tabular}{|c|c|}
\hline $\begin{array}{l}\text { Keimzelltumoren } \\
\text { Vorläuferläsion: } \\
\text { Intratubuläre Keimzellneoplasie, IGCNU } \\
\text { Tumoren aus einem histologischen Typ (rei- } \\
\text { Seminom } \\
\text { spermatozytisches Seminom } \\
\text { embryonales Karzinom (EC) } \\
\text { Dottersacktumor } \\
\text { rophoblastische Tumoren } \\
\text { Chorionkarzinom } \\
\text { Teratome } \\
\text { Dermoidzyste } \\
\text { monodermales Teratom } \\
\text { Teratom mit somatischer Malignität } \\
\text { Tumoren aus mehreren histologischen Typen } \\
\text { (Mischformen): } \\
\text { Teratom und embryonales Karzinom } \\
\text { Chorionkarzinom und Teratom/embryonales } \\
\text { Karzinom }\end{array}$ & $\begin{array}{ll}\text { Tumoren des Keimstrang-/Gonaden- } & \\
\text { stromas } & \sim \mathbf{5 \%} \\
\text { Leydig-Zell-Tumor } & \\
\text { Sertoli-Zell-Tumor } \\
\text { Granulosazelltumor } \\
\text { Tumoren aus der Thekom-Fibrom-Gruppe } \\
\\
\text { diverse Tumoren des Hodens } \\
\text { Karzinoid-Tumor } \\
\text { Tumoren des ovarialen Epithel-Typs } \\
\begin{array}{l}\text { Nephroblastom } \\
\text { Paragangliom }\end{array} \\
\text { hämatopoetische Tumoren }\end{array}$ \\
\hline
\end{tabular}

\subsubsection{Entstehung und Präkanzerose}

Es wird angenommen, dass maligne Keimzelltumoren des Hodens aus einer gemeinsamen Vorläuferläsion hervorgehen, der intratubular germ cell neoplasia unclassified (IGCNU; Synonym: testikuläre intratubuläre Neoplasie, TIN). Da diese ähnliche Transkriptionsfaktoren wie embryonale Stammzellen exprimiert, wird vermutet, dass die Ausgangszelle eine pluripotente Gonozyte ist, welche durch Unregelmäßigkeiten in Differenzierung und Migration während der Embryogenese entartet (Hayes-Lattin und Nichols 2009). Demnach geschieht der Anstoß zur malignen Transformation wahrscheinlich in utero während der frühen Entwicklung der Keimlinien-Stammzelle. Insgesamt basiert diese Hypothese auch darauf, dass morphologische Ähnlichkeiten zwischen IGCNU-Zellen und Gonozyten bestehen. IGCNUZellen sind folglich in einer geringen Zahl bereits in präpubertären Hoden zu finden, welche morphologisch in vielerlei Hinsicht nicht nur adulten IGCNU-Zellen gleichen, sondern auch normalen infantilen Gonozyten. Während der Kindheit sind IGCNU-Zellen silent und beginnen erst in der Pubertät zu proliferieren - möglicherweise bedingt durch die hormonelle Situation - mit anschließender Progression in den sichtbaren Tumor (Hoei-Hansen et al. 2005). 
Einleitung

Untersuchungen an unerwartet verstorbenen, mutmaßlich gesunden, jungen Männern haben gezeigt, dass die Prävalenz von IGCNU etwa der von TGCT in einer Bevölkerung entspricht. Daher entwickeln sich wahrscheinlich alle Vorläuferläsionen zu Seminomen oder NichtSeminomen (Linke et al. 2005).

\subsubsection{Stammzellsignatur}

Da TGCT wahrscheinlich aus primordialen Keimzellen hervorgehen, exprimieren sie eine embryonale Stammzell(ES)-ähnliche Gensignatur. Diese verleiht ihnen - im Gegensatz zu Körperzellen - den einzigartigen Charakter, zentrale molekulare Programme, die für die Pluripotenz von Stammzellen essentiell sind, beizubehalten. Dabei spielen vor allem die Transkriptionsfaktoren NANOG, POU5F1 und SOX2 eine wichtige Rolle. Diese Transkriptionsfaktoren werden während der initialen Phase der Keimzellentwicklung im Stadium der primordialen Keimzelle erworben. Die genaue Funktion dieser Pluripotenzgene in der fetalen Keimlinie konnte allerdings noch nicht endgültig geklärt werden, da in Tierexperimenten der Knockout-Phänotyp von jedem der Transkriptionsfaktoren in Letalität im Embryonalstadium endet (Clark 2007). Knockout-Versuche an embryonalen Stammzellen allerdings führten zu unterschiedlichen Ausdifferenzierungen. Unter einer NANOG-Ausschaltung entwickelten sich diese zu viszeralem/parietalem Entoderm, während eine Ablation von POU5F1 und SOX2 zur Differenzierung in Trophektoderm führte (Avilion et al. 2003; Liu et al. 2007). Zusammen scheinen NANOG, POU5F1 und SOX2 des Weiteren an einem transkriptionellen Regelkreislauf beteiligt zu sein, der auch eine positive Feedbackschleife enthält. Dieser Regelkreislauf ist verantwortlich für die Selbsterneuerung von embryonalen Stammzellen und die Differenzierung. Besonders NANOG und POU5F1 sind an diesen Mechanismen maßgeblich beteiligt, da sie auch in pluripotenten Stammzellen in der inneren Zellmasse von Blastozysten exprimiert sind. Insgesamt führt eine Expression dieser drei Transkriptionsfaktoren folglich dazu, dass Selbsterneuerungsgene aktiviert und Differenzierungsgene reprimiert sind (Liu et al. 2007).

Ferner verbindet diese drei Stammzellfaktoren ihre kanzerogene Eigenschaft, die für die Malignität von vielen Tumoren (mit-)verantwortlich ist (Abate-Shen 2003; Park et al. 2008; Jeter et al. 2009).

Untersuchungen haben darüber hinaus gezeigt, dass diese ES-ähnliche Gensignatur in diversen schlecht differenzierten Tumoren zu finden ist. Sie gehen in den verschiedenen Geweben aus unterschiedlichen Ursprungszellen hervor und es besteht eine inverse Beziehung zwischen der Anreicherung dieser ES-ähnlichen Gensignaturen in Tumoren und dem Grad der Tumor- 
Einleitung

differenzierung. Da der Differenzierungsgrad von Tumoren durch histopathologische Kriterien definiert ist, konnte dadurch gezeigt werden, dass die Abwesenheit von gut differenzierten Gewebseigenschaften eine molekulare Ähnlichkeit zu einem undifferenzierten Stammzellstatus mit sich bringt. Zusätzlich zu den Aktivierungstargets der Pluripotenzgene NANOG, POU5F1 und SOX2 waren beispielsweise in schlecht differenzierten Mammakarzinomen meist verschiedene weitere transkriptionsregulatorische Gene ständig aktiviert (Ben-Porath et al. 2008).

Experimentell wurde unter der Wirkung von Histon-Deacetylase-Inhibitoren (HDACi) eine repressive epigenetische Modifikation in der Promoterregion von NANOG beobachtet, welche eine Inhibition der Transkripionsfaktoren NANOG, POU5F1 und SOX2 auslöste. Die Folgen der verminderten Expression der ES-ähnlichen Gensignatur waren Zellzyklusarrest und Differenzierung in alle drei Keimblätter (You et al. 2009).

\subsubsection{Risikofaktoren}

Seit Jahrzehnten besteht das Bestreben, diverse Risikofaktoren, die für die Entstehung von TGCT eine Rolle spielen, zu identifizieren. Einige sollen hier genannt werden, besonders jene, denen wegen ihrer Häufigkeit im Zusammenhang mit maligner Entartung von Hodengewebe große Bedeutung zukommt.

Als ein Hauptrisikofaktor gilt der Kryptorchismus. Bereits 1980 zeigten Studien, dass Männer mit einem Maldescensus testis ein 17-mal höheres Risiko für eine maligne Entartung des Hodens haben, verglichen mit Männern ohne Lageanomalie (Wobbes et al. 1980).

Ein signifikanter Zusammenhang besteht auch zwischen männlicher Infertilität und der Entstehung von malignen Keimzelltumoren des Hodens. Untersuchungen konnten zudem die Hypothese bestätigen, dass der Assoziation von verminderter Samenqualität und TGCT eine gemeinsame Ursache zugrunde liegt (Jacobsen et al. 2000). Weiterführende Studien schrieben schließlich infertilen Männern, die abnorme Samenqualität aufweisen, sogar ein 20-fach erhöhtes Risiko für die Entwicklung von TGCT zu (Raman et al. 2005).

Störungen in der Geschlechtsentwicklung (disorders of sex development, DSD) zählen auch zu Risikofaktoren für eine maligne Transformation des Hodens. Das spezifische Risiko ist für die einzelnen Erkrankungen dieser Gruppe jedoch sehr unterschiedlich, da ihnen heterogene genetische Ursachen zugrunde liegen (Pleskacova et al. 2010).

Diskutiert werden auch diverse pränatale Umwelteinflüsse als Risikofaktoren für Fehl- und Missbildungen an männlichen Geschlechtsorganen sowie die Prädisposition für Hodentumoren. Unter anderem wurde in diesem Zusammenhang ein besonderes Augenmerk auf den Ein- 
Einleitung

fluss von Östrogenen gelegt, da epidemiologische Studien eine Auswirkung auf die Fetalentwicklung der Gonaden nahelegten (Sharpe und Skakkebaek 1993; McLachlan et al. 1998).

\subsubsection{Klinik: Diagnostik, Therapie und Prognose}

Männer mit Hodentumoren präsentieren sich klinisch in der Mehrzahl der Fälle durch eine einseitige Schwellung des Hodens, welche nicht schmerzhaft ist. Schmerzen bestehen jedoch in Ausnahmefällen, ausgelöst beispielsweise durch schnelles Wachstum oder durch Einblutung in den Tumor innerhalb der Tunica albuginea, wodurch die Diagnosestellung erschwert werden kann (Stephen 1962).

Das im Folgenden dargestellte klinische Vorgehen bei Verdacht auf Hodenkrebs entspricht den Leitlinien aus dem Jahr 2008 der European Germ Cell Cancer Consensus Group (EGCCCG; Krege et al. 2008).

Zur Diagnostik wird üblicherweise ein Ultraschall des Hodens durchgeführt, gefolgt von einem Thoraxröntgen oder -CT und einer CT-Untersuchung von Abdomen und Becken. Neben den Routineparametern wird in der laborchemischen Untersuchung AFP (Nicht-Seminom) und $\beta$-HCG (Seminom) als Tumormarker bestimmt, bei Metastasen spielt zusätzlich LDH eine wichtige Rolle (Krege et al. 2008). Nach Abschluss der Diagnostik kann eine Stadieneinteilung (Staging) nach der UICC TNM(S)-Klassifikation zur Beurteilung des Tumors erfolgen, welche die Höhe der Serum-Tumormarker berücksichtigt (Sobin et al. 2009).

Die Therapie der ersten Wahl stellt die Orchiektomie dar, welche gleichzeitig der histologischen Tumorsicherung dient. In Einzelfällen kann eine organerhaltende Operation in Erwägung gezogen werden, die jedoch nur in erfahrenen Zentren durchgeführt werden sollte. Da bei etwa neun Prozent der Patienten im kontralateralen Hoden ein CIS vorliegt, wird empfohlen, vom kontralateralen Hoden Biopsien zu entnehmen. Das postoperative Vorgehen unterscheidet sich für Seminome und Nicht-Seminome.

Liegt ein Seminom im klinischen Stadium I vor - der Tumor ist also auf den Hoden beschränkt -, gibt es drei Optionen mit gleichwertiger Gesamtüberlebensrate. Eine Möglichkeit stellt die adjuvante Bestrahlung der infradiaphragmalen/parakavalen Lymphknoten mit einer Gesamtdosis von 20 Gy dar. Etwa äquivalent wäre eine Chemotherapie mit Carboplatin, oder als dritte Möglichkeit eine engmaschige Überwachung (Surveillance) mit weiterer Therapie nur im Rezidivfall. Bei Metastasen sind Chemo- und Radiotherapie unumgänglich.

Bei Nicht-Seminomen im klinischen Stadium I ist für das postoperative Vorgehen zusätzlich von Bedeutung, ob eine Gefäßinvasion im Primärtumorpräparat vorliegt. Ist dies der Fall, wird eine adjuvante Chemotherapie nach dem PEB-Regime (Cisplatin, Etoposid, Bleomycin) empfohlen. Liegt keine Gefäßinvasion vor, wird unter Surveillance erst bei Auftreten eines 
Einleitung

Rezidivs mit der oben genannten Chemotherapie begonnen. Bei fortgeschrittenen Stadien ist eine Chemotherapie nach dem PEB-Protokoll erforderlich. In einigen Fällen wird eine operative Sanierung von residualen Tumorherden zu einem späteren Zeitpunkt nötig (Krege et al. 2008).

Die Prognose ist von verschiedenen klinischen Kriterien abhängig und - je nachdem - durch eine 5-Jahres-Überlebensrate von 50-90 \% (schlechte - gute Prognose) gekennzeichnet (Krege et al. 2008). Allgemein kann die Prognose jedoch als sehr gut bezeichnet werden, da die Erkrankung etwa in der Hälfte der Fälle im klinischen Stadium I diagnostiziert wird und somit eine Heilungschance von $98 \%$ besteht (Classen et al. 2009).

\subsection{Phytoöstrogene}

1926 wurde zum ersten Mal beschrieben, dass pflanzliche Extrakte östrogenen Charakter und entsprechende Aktivitäten besitzen, welche seither als Phytoöstrogene bezeichnet werden. Sie können nach ihren chemischen Eigenschaften in drei Hauptklassen unterteilt werden: Isoflavone, Coumestane (zusammen als Isoflavonoide bezeichnet) und Lignane. Sie kommen allgemein in Pflanzen oder ihren Samen vor. Isoflavone, $\mathrm{zu}$ denen auch Genistein und Daidzein zählen, sind unter anderem in Hülsenfrüchtlern und Bohnen enthalten. Lignane sind in zahlreichen Früchten sowie Getreide und Gemüse vertreten, Coumestane in Sprossen und Futterpflanzen.

Möglicherweise ist auch die Verwendung bestimmter Pflanzen in der traditionellen chinesischen Medizin und allgemein in der Volksmedizin auf ihre östrogenen Effekte zurückzuführen. Phytoöstrogene sind ferner von besonderem biologischen Interesse, da sie in vitro und in vivo schwache östrogene sowie antiöstrogene Wirkungen gezeigt haben (Murkies et al. 1998).

Phytoöstrogene und Phytoöstrogentherapie erfreuen sich allerdings aus mehreren Gründen in der Forschung großer Beliebtheit: Zum einen weist die epidemiologische Verteilung bestimmter Tumoren auf einen tumorprotektiven Einfluss von verschiedenen Phytoöstrogenen hin (Adlercreutz 1995), was sie als Drogen im Rahmen von Prävention und Therapie von Malignomen interessant macht (Kennedy 1995). Dementsprechend haben sie in der Pharmaforschung bezüglich Tumoren wie Prostatakarzinom, Leukämie (s. Abschnitt 1.2.2) und Mammakarzinom (Shao et al. 1998) schon seit einiger Zeit Einzug gefunden. Zum anderen ist es ihre Popularität in der Bevölkerung, die Phytoöstrogene und allgemein Phytopharmaka in der Erforschung als (alternative) Therapieoption interessant macht. Gegenwärtig werden beispielsweise in der Gynäkologie Phytoöstrogene als Hormonersatztherapie zur Linderung kli- 
Einleitung

makterischer Beschwerden eingesetzt. Dabei hat sich herausgestellt, dass diese pflanzlichen Präparate bei Patientinnen auf größere Akzeptanz stoßen als herkömmliche synthetische Östrogene, da diese als „unnatürlich“ empfunden werden (Glazier und Bowman 2001).

\subsubsection{Belamcanda-chinensis-Extrakt und Tectorigenin}

Belamcanda chinensis gehört zu der Familie der Schwertlilien und wird auch Leopardenblume genannt (Cheers 1998). Sie ist in China, Japan und Korea beheimatet, und ihr getrockneter Wurzelstock wird in der traditionellen chinesischen Medizin eingesetzt. Zu den Indikationen zählen respiratorische und gastrointestinale Symptome, Fieber und auch gynäkologische Beschwerden wie Dysmenorrhoe. Als wirksame Bestandteile des Extraktes (Belamcandachinensis-Extrakt, BCE) wurden die Isoflavonoide Belamcandinin, Iridin, Irigenin, Tectoridin und Tectorigenin, Flavonoide und viele mehr identifiziert (Wagner et al. 1999). Eine bedeutende und viel erforschte Komponente ist Tectorigenin; sein Anteil am Gesamtextrakt beträgt etwa $5 \%$ (Thelen et al. 2005). Die genaue Zusammensetzung der Inhaltsstoffe des Extraktes aus dem Rhizom der Belamcanda chinensis ist allerdings von der Herkunft der Pflanze abhängig. In der Erforschung des pharmakologischen Potentials des Extraktes konnten in vitro unter anderem antifungale und antivirale Effekte gezeigt werden, in vivo wurden zusätzlich uterusrelaxierende und schleimlösende Erfolge erzielt (Wagner et al. 1999) (Abb. 1).

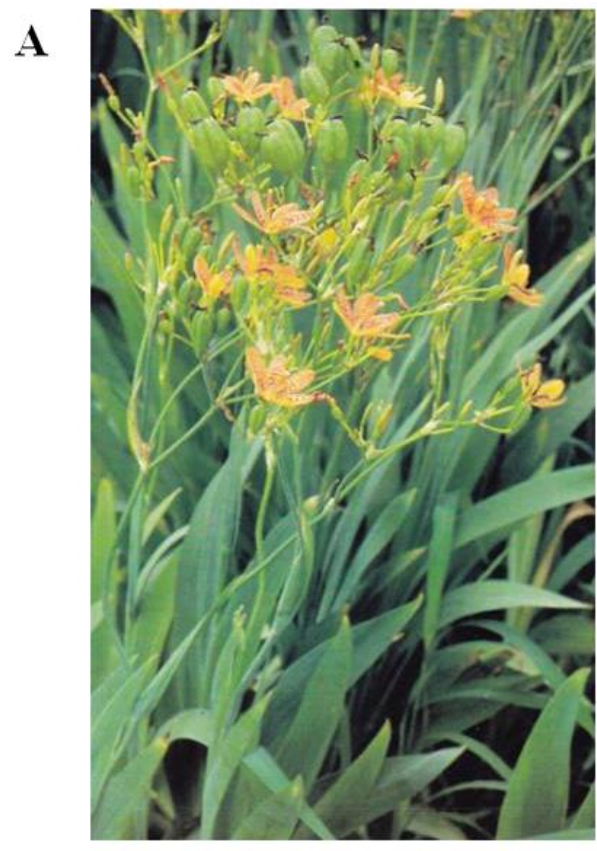

B<smiles>COc1c(O)cc2occ(-c3ccc(O)cc3)c(=O)c2c1O</smiles>

C

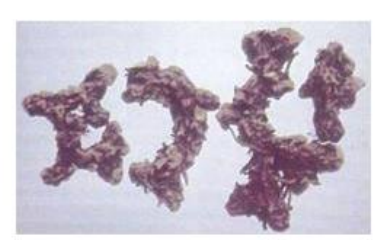

Abb. 1: Belamcanda chinensis und Tectorigenin

Wuchsform von Belamcanda chinensis (A), Strukturformel von Tectorigenin (B), Rhizom von Belamcanda chinensis (C). Abbildung aus Wagner et al. (1999, S. 1) und modifiziert nach Kang et al. $(\mathbf{2 0 0 8}, \mathrm{S} .1453)$ 
Einleitung

\subsubsection{Phytoöstrogene in der Krebsforschung}

Da diverse Phytoöstrogene wie Genistein in der Forschung enormen Anklang finden, soll im Folgenden speziell auf Isoflavonoide des BCE eingegangen werden.

Seit etwa zehn Jahren wird das Potential des BCE und seiner Komponenten als potentielles Medikament für die Tumortherapie erforscht. Dabei konnte eine Induktion von Differenzierung und Apoptose erstmals mit Tectorigenin in HL-60-Zellen, einer humanen akuten myeloischen Leukämie(AML)-Zelllinie erzielt werden. Damals wurde das Isoflavonoid aus den Wurzeln von Pueraria thunbergiana extrahiert (Lee et al. 2001). Kurze Zeit später wurde für die Isoflavonoide des BCE, ebenfalls aus dem Rhizom der Pflanze gewonnen, eine antiangiogene Aktivität beschrieben. Außerdem zeigte sich in Mäusen mit Sarkom beziehungsweise mit implantierten Lungenkarzinomzellen eine Reduktion der Tumormasse (Jung SH et al. 2003).

Auch in der Erforschung hormonabhängiger Tumoren haben diese Phytoöstrogene Einzug gefunden. In Prostatakrebszellinien hat sich eine Proliferationsinhibition gezeigt (Morrisey et al. 2004), die durch weitere Ergebnisse über die Repression von für Prostatakrebszellen markante und ausschlaggebende Strukturen wie PSA, PDEF, IGF1R (Thelen et al. 2005) und AR erweitert werden konnte (Thelen et al. 2007). Ferner wurden die Östrogenrezeptoren in dieser Tumorentität untersucht. Dabei konnte gezeigt werden, dass der als Tumorsuppressor agierende ER- $\beta$ eine Induktion erfährt, während der ER- $\alpha$, ein Transkriptions- und ProliferationsAktivator, reprimiert wird (Stettner et al. 2007).

\subsection{Fragestellung und Zielsetzung}

Belamcanda-chinensis-Extrakt und die Reinsubstanz Tectorigenin sind in der traditionellen chinesischen Medizin eingesetzte Phytoöstrogene, die in der gegenwärtigen Forschung antikanzerogene Eigenschaften gezeigt haben.

Das Ziel dieser Arbeit war es, die Effekte von Phytoöstrogenen aus dem BCE in etablierten TGCT-Zelllinien zu untersuchen. Die TGCT-Zelllinien NTERA-2 und TCam-2 (NichtSeminom- und Seminom-Zellen) wurden im Rahmen von Stimulationsversuchen unter Verwendung von Tectorigenin und BCE (i) auf zeit- und konzentrationsabhängige Veränderungen in ihrem Proliferationsverhalten und (ii) auf die Beeinflussung der Stammzellsignatur, repräsentiert durch die Transkriptionsfaktoren NANOG, POU5F1 und SOX2, untersucht. Insbesondere die Beeinflussung der Stammzellsignatur sollte Erkenntnisse darüber erzielen, ob diese als Malignitätskriterium oder Ziel für Target-Therapien von TGCT herangezogen werden können. 
Material und Methoden

\section{Material und Methoden}

\subsection{Versuchsablauf}

Die beiden TGCT-Zelllinien NTERA-2 (Nicht-Seminom-Zelllinie) und TCam-2 (SeminomZelllinie) wurden in Zellkulturexperimenten mit verschiedenen Konzentrationen von Tectorigenin und Belamcanda-chinensis-Extrakt über unterschiedliche Zeiträume stimuliert. Als zusätzliche Stimulanzien kamen die HDAC-Inhibitoren Valproat und Trichostatin A zum Einsatz. Die Proliferation und mRNA-Expression der TGCT-Zellinien wurde mittels eines Proliferationsassays (MTT-Test) beziehungsweise PCR und Mikroarrays untersucht. Die Proteinanalyse erfolgte mit Hilfe von Western Blot und immunzytochemischen Färbungen.

Im weiteren Verlauf wurde auch die Prostatakarzinomzellinie LNCaP mit BCE stimuliert und auf spezifische Veränderungen in mRNA- und Proteinexpression untersucht.

\subsection{Stimulanzien}

\subsubsection{Phytoöstrogene}

Die ersten Stimulationsversuche wurden mit dem Reinextrakt Tectorigenin unternommen. Aus Gründen der kommerziellen Verfügbarkeit musste allerdings im Verlauf der Experimente das Gesamtextrakt aus dem Rhizom von Belamchanda chinensis verwendet werden.

Tectorigenin: Tectorigenin wurde von der Firma Bionorica SE (Neumarkt) bezogen. Aufgelöst in 0,1\% DMSO wurden Konzentrationen von 100, 250 und $500 \mu \mathrm{M}$ angesetzt. Die genannten Konzentrationen wurden in Anlehnung an die Publikation von Thelen et al. (2005) ausgewählt. In der genannten Arbeit wurden unter Verwendung ähnlicher Konzentrationen inhibitorische Effekte auf pharmakotherapeutisch bedeutende Zielstrukturen in Prostatakarzinomzellen beobachtet.

Belamcanda-chinensis-Extrakt: Das Belamcanda-chinensis-Extrakt (BCE) wurde ebenso wie Tectorigenin von der Firma Bionorica SE (Neumarkt) bezogen. Das Auflösen des kristallinen Extraktes erfolgte in 0,1 \% DMSO. Die BCE-Konzentrationen von 62,5, 125, 250, 500 und $1000 \mu \mathrm{g} / \mathrm{ml}$ wurden in Anlehnung an Thelen et al. (2007) ausgewählt, die ähnliche bereits an der Prostatakrebszelllinie LNCaP getestet und etabliert haben.

\subsubsection{HDAC-Inhibitoren}

Valproat: Valproat wurde von der Firma Sigma (Steinheim) bezogen und mit sterilem Wasser in einer Konzentration von $5 \mathrm{mM}$ eingesetzt. Die Zusammensetzung wurde in Anlehnung an die Publikation von Venkataramani et al. (2010) ausgewählt. 
Material und Methoden

Trichostatin A: Auch Trichostatin A wurde von der Firma Sigma (Steinheim) bezogen. Angesetzt wurde dieses mit 0,1\% DMSO in einer Konzentration von 500 nM. Ebenso wie bei Valproat sei hier auf den etablierten Einsatz der Lösung in der Arbeit von Venkataramani et al. (2010) verwiesen.

Da die Mehrzahl der Stimulanzien 0,1 \% DMSO enthält, wurden die Kontrollzellen jeweils auch mit 0,1\% DMSO versehen, um auszuschließen, dass mögliche Veränderungen in den Zellen im Stimulationsversuch auf diese Chemikalie zurückzuführen sind.

\subsection{Zellkultur}

Um die Versuche des beschriebenen Vorhabens durchzuführen, wurden die Nicht-SeminomZelllinie NTERA-2 (Pal und Ravindran 2006) und die als Seminom charakterisierte Zelllinie TCam-2 (de Jong et al. 2008) in Kultur gehalten. Im Allgemeinen bestand das Nährmedium aus folgenden Komponenten:

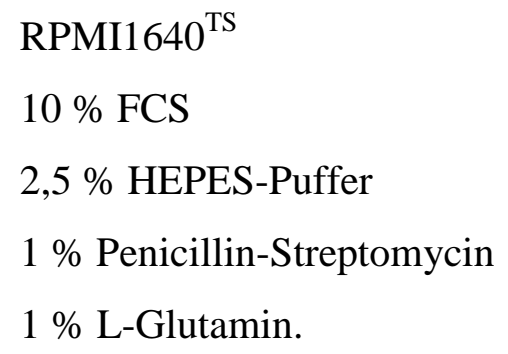

Für optimale Wachstumsbedingungen erfolgte die Kultivierung im Brutschrank bei $37^{\circ} \mathrm{C}$ und einer $\mathrm{CO}_{2}$-Zufuhr von $5 \%$. Die Zellen wurden in $10 \mathrm{ml}$ Medium in $75-\mathrm{cm}^{2}$-Zellkulturflaschen gehalten, alle zwei bis drei Tage erfolgte ein Mediumwechsel. Bei vollständiger Konfluenz wurden die Zellen trypsiniert, mit Medium gewaschen und dann in gewünschter Dichte in neuen Flaschen ebenfalls in $10 \mathrm{ml}$, mit genannten Supplementen versehenem RPMI1640 ${ }^{\mathrm{TS}}$ angesetzt. Das Waschen erfolgte durch Zentrifugieren, vier Minuten bei $1200 \mathrm{rpm}$ und Resuspension.

Alle Zellkulturarbeiten wurden stets mit sterilen Gefäßen und unter keimfreien Bedingungen unter einer Sterilbank durchgeführt, um Kontaminationen zu vermeiden.

\subsection{Proliferationsassay (MTT-Test)}

Der Proliferationsassay erfolgte mit dem Cell Proliferation Kit I (MTT) (Roche, Mannheim) laut Herstellerprotokoll. Dabei handelt es sich um einen kolorimetrischen Test für die nicht- 
Material und Methoden

radioaktive Quantifizierung von Proliferation und Lebensfähigkeit von Zellen (Mosmann 1983).

Am ersten Versuchstag wurden die Zellen auf einer 96-well-Platte angesetzt. Dabei wurden 4000 Zellen pro well ausgesät und in jeweils $100 \mu \mathrm{l}$ phenolrotfreiem RPMI1640 ${ }^{\mathrm{TS}}$ angezüchtet. Am darauffolgenden Tag konnte, nach visueller Kontrolle des Zellwachstums mit Hilfe eines Auflichtmikroskops, das Medium entfernt und die Zellen mit dem in DMSO gelösten Tectorigenin beziehungsweise BCE in den beschriebenen Konzentrationen, wieder mit $100 \mu 1$ phenolrotfreiem RPMI1640 ${ }^{\mathrm{TS}}$ stimuliert werden. Am dritten Tag wurde das Medium erneut entfernt um die Stimulationszeit einzuhalten, und für die 24-Stunden-Messung $10 \mu 1$ MTT (3-(4,5-Dimethylthiazol-2-yl)-2,5-diphenyltetrazoliumbromid) plus $100 \mu$ l Medium pro well hinzugefügt. Das Prinzip der nun eingetretenen Reaktion beruht darauf, dass metabolisch aktive Zellen das gelbe Tetrazolium-Salz MTT in violette Formazan-Kristalle umwandeln. An dieser zellulären Reaktion sind die Pyridin-Nukleotide NADH und NADPH beteiligt. Vier Stunden später konnte das Ganze zusätzlich mit $100 \mu$ l Solubilization Solution versetzt werden, wodurch die gebildeten Formazan-Kristalle aufgelöst und einen Tag später die gefärbte Lösung mit einem Microplate Reader Model 680 Series (Biometra, Göttingen) quantifiziert werden konnte. Dies erfolgte nach einer Mixzeit von fünf Sekunden bei dualen Messparametern von 550-600 nm und > $650 \mathrm{~nm}$, um den vom Hersteller empfohlenen Wellenlängenbereich von 550-690 nm abzudecken. Alle Inkubationszeiten bis zur Messung im Microplate Reader erfolgten im Brutschrank.

Für weitere Messungen wurde das Zellwachstum nach dem gewünschten Zeitraum wieder durch Entfernen des BCE-Medium-Gemisches und Hinzufügen von MTT abgestoppt und nach Durchführung des oben beschriebenen Vorganges quantitativ bestimmt.

Zur Auswertung der erhobenen Daten in Form von Extinktionswerten ist zu sagen, dass die direkte Korrelation der Extinktion oder auch optische Dichte (OD) mit der Zellanzahl durch den Hersteller des Proliferations-Kits beschrieben ist. Dabei entspricht eine hohe Extinktion indirekt einer hohen Zellzahl, da der Umsatz von Stoffwechselprodukten der lebensfähigen Zellen gemessen wird.

\subsection{RNA}

Die RNA-Analyse diente der Identifizierung von differentiell regulierten Genen in den Zelllinien nach Stimulation. 
Material und Methoden

\subsubsection{RNA-Isolierung}

Zur Analyse der RNA wurden jeweils eine Million Zellen in $5 \mathrm{ml}$ Medium in $25-\mathrm{cm}^{2}-$ Zellkulturflaschen kultiviert und stimuliert. Die Isolierung der Zellen erfolgte durch Abkratzen mithilfe von Zellschabern und zweimaliges Waschen mit PBS. Die Zellpellets wurden anschließend in $300 \mu 1$ RLT-Puffer- $\beta$-Mercaptoethanol (pro Flasche) resuspendiert. Dieses wurde zuvor im Verhältnis 100:1 (RLT-Puffer : $\beta$-Mercaptoethanol) angesetzt und auf Eis gekühlt. Nach kräftigem Vortexen wurde die Zellsuspension auf einen Shredder (Qiagen, Hilden) pipettiert und zwei Minuten bei $11000 \mathrm{rpm}$ zentrifugiert. Dadurch wurde das Zelllysat homogenisiert und die Viskosität, die durch hochmolekulare Zell-Komponenten und ZellTrümmer zustande kommt, reduziert.

Die weitere Aufreinigung der RNA erfolgte mithilfe des RNeasy Mini-Kits (Qiagen, Hilden). Dabei werden die Proben erst lysiert und dann homogenisiert. Durch das Hinzufügen von gleichen Mengen Ethanol (300 $\mu \mathrm{l}$ zu $300 \mu$ l Probe) wurden ideale Bindungskonditionen für die nachfolgenden Schritte geschaffen. Die Lysate wurden nun auf eine Silizium-Membran aufgetragen, an der die RNA-Moleküle binden, sodass alle Verunreinigungen wie etwa Salze und Proteinreste effizient abgewaschen werden konnten. Nach verschiedenen Waschschritten wurde die reine und konzentrierte RNA zuletzt mit $28 \mu 1$ Wasser unter Zentrifugation - eine Minute bei 13000 rpm - von der Membran gelöst.

Anschließend erfolgte eine quantitative und qualitative Messung der Proben im Agilent Bioanalyzer 2100 mit Hilfe des RNA 6000 Nanochip Kits (Agilent Technologies, Waldbronn) unter Anleitung des Herstellerprotokolls.

Ein Teil der RNA wurde danach für die Umschreibung in cDNA eingesetzt, der Rest konnte bei $-80^{\circ} \mathrm{C}$ gelagert werden.

\subsubsection{Umschreibung von RNA in CDNA}

Die Umschreibung von RNA in cDNA (komplementäre DNA) ist nötig, um die cDNA anschließend als Ausgangsmaterial in einer Real-Time-PCR verwenden zu können. Dieses Verfahren wird auch reverse Transkription (RT) genannt und von Enzymen (RNA-abhängige DNA-Polymerasen) katalysiert.

Unter Verwendung des Omniscript RT Kit (Qiagen, Hilden) wurde wie folgt verfahren: die RNA wurde verdünnt, indem jeweils 500 ng der quantifizierten Proben auf $13 \mu 1$ mit RNasefreiem Wasser aufgefüllt wurden. Bevor ein Mastermix angesetzt werden konnte, erfolgte eine Vorverdünnung des Random Primers (Invitrogen, Karlsruhe) - 6,6 $\mu$ l Primer mit 3,4 $\mu 1$ RNase-freiem Wasser. 
Material und Methoden

Der anschließend angesetzte Mastermix enthielt je Probe:

$2 \mu 1$ RT Puffer

$2 \mu \mathrm{l}$ Nukleotide (dNTP)

$1 \mu 1$ Random Primer (aus der Vorverdünnung)

$1 \mu 1$ Reverse Transkriptase (RT)

$1 \mu 1$ RiboLock ${ }^{\mathrm{TM}}$ RNase Inhibitor (Fermentas, St. Leon-Rot).

Die reverse Transkription erfolgte im Cycler TPersonal 48 (Biometra, Göttingen). $13 \mu$ l verdünnte RNA wurde zu Beginn fünf Minuten bei $70^{\circ} \mathrm{C}$ inkubiert. Nach Abkühlen auf $40^{\circ} \mathrm{C}$ wurde der Zyklus unterbrochen, die RNA unverzüglich auf Eis gestellt und mit $7 \mu$ RTAnsatz (Mastermix, s.o.) versehen. Anschließend konnte der Lauf fortgesetzt werden: eine Stunde bei $37^{\circ} \mathrm{C}$, mit anschließender Deaktivierung der Transkriptase durch Erhitzen für fünf Minuten auf $95^{\circ} \mathrm{C}$. Nachdem die Umschreibung erfolgt war, wurde auf $4^{\circ} \mathrm{C}$ abgekühlt, um restliche enzymatische Aktivitäten zu verhindern. Im Anschluss daran lag die RNA als cDNA vor und konnte in der Real-Time-PCR eingesetzt werden.

Für weitere Analysen wurden die erhaltenen $20 \mu \mathrm{l}$ cDNA mit $80 \mu \mathrm{l}$ RNase-freiem Wasser verdünnt.

\subsubsection{Real-Time-PCR}

Die Real-Time-PCR (Polymerase-Kettenreaktion) ist ein Verfahren zur spezifischen Vervielfältigung gewünschter DNA-Abschnitte, die zusätzlich eine Quantifizierung in Echtzeit ermöglicht. Erreicht wird dies dadurch, dass nach jedem Zyklus Fluoreszenzsignale gemessen werden, welche proportional mit der Menge der DNA zunehmen. Dieses Detektionsverfahren in Echtzeit wird daher auch als real time detection PCR (RTD-PCR) bezeichnet.

Diese Methode wurde in den genannten Experimenten eingesetzt, um Expressionsunterschiede der spezifischen Gene nach verschiedenen Behandlungen zu detektieren. Hierbei kam ein auf SYBR-Green basierendes Reagens (Eurogentec, Köln) zum Einsatz. Die Reaktionsansätze bestanden pro Probe aus: $\quad 10 \mu \mathrm{l} \mathrm{SYBR-Green}$

$$
\begin{aligned}
& 0,15 \mu 1 \text { forward Primer } \\
& 0,15 \mu 1 \text { reverse Primer } \\
& 4,7 \mu 1 \text { RNase-freies Wasser } \\
& 25 \text { ng cDNA. }
\end{aligned}
$$

Zusätzlich zu den Proben wurde bei jedem Lauf auch eine Negativkontrolle angesetzt, die statt $5 \mu \mathrm{l}$ cDNA RNase-freies Wasser enthielt. 
Material und Methoden

Da versucht wurde, für alle Primer optimale Reaktionsbedingungen zu schaffen, unterscheiden sich die RTD-PCR-Protokolle zum Teil für die verschiedenen Primer (s. Tabelle 3). Allgemein diente Lauf 1 der Denaturierung der cDNA, gefolgt von Lauf 2, der die Amplifizierung der gewünschten DNA-Abschnitte beinhaltete. Dabei erfolgte in Schritt 1 eine Denaturierung, gefolgt von Annealing (Schritt 2) und anschließender Elongation (Schritt 3). Lauf 3 diente der Fluoreszenzmessung. Abschließend wurde auf $4{ }^{\circ} \mathrm{C}$ beziehungsweise $20^{\circ} \mathrm{C}$ abgekühlt.

Als Housekeeping-Gen wurde ARP verwendet, da seine Expression nicht reguliert wird. Untersucht wurde primär die mRNA-Expression der Stammzellfaktoren NANOG, POU5F1 und SOX2. In weiteren Versuchen kamen außerdem AR, IGF1R, IGFBP3 und ER- $\beta$ zum Einsatz (Tabelle 2).

Tabelle 2: Real-Time-PCR - Sequenzen der eingesetzten Primer F: forward, R: reverse. Für ER- $\beta$ wurde ein kommerzielles System verwendet, für das die Sequenzen nicht preisgegeben werden.

\begin{tabular}{ll}
\hline Primer & Sequenz \\
\hline AR & F: 5'-AGGAACTCGATCCTATCATTGC-3' \\
& R: 5'-CTGCCATCATTCCGGAA-3' \\
ARP & F: 5'-CGACCTGGAAGTCCAACTAC-3' \\
& R: 5'-ATCTGCTGCATCTGCTTG-3' \\
ER- $\beta$ & Hs_ESR2_1_SG QuantiTect Primer Assay (Qiagen, Hilden) \\
IGF1R & F: 5'-CCGAAGGTCTGTGAGGAAGA-3' \\
& R: 5'-AATGGCGGATCTTCACGTAG-3' \\
IGFBP3 & F: 5'-GAACTTCTCCTCCGAGTCCAA-3' \\
& R: 5'-GAGTTACACGACTCAGGGTC-3' \\
NANOG & F: 5'-TTCCTTCCTCCATGGATCTG-3' \\
& R: 5'-ATCTGCTGGAGGCTGAGGTA-3' \\
POU5F1 & F: 5'-AGAAGGATGTGGTCCGAGTG-3' \\
& R: 5'-GTGAAGTGAGGGCTCCCATA-3' \\
SOX2 & F: 5'-CAAGATGCACAACTCGGAGA-3' \\
& R: 5'-CTCCGGGAAGCGTGTACTTA-3' \\
\hline
\end{tabular}


Material und Methoden

Tabelle 3: RTD-PCR-Protokolle

Lauf 1 dient der Denaturierung der cDNA, gefolgt von Lauf 2, der die Amplifizierung der gewünschten DNA-Abschnitte beinhaltete. Dabei erfolgte in Schritt 1 eine Denaturierung, gefolgt von Annealing (Schritt 2) und anschließender Elongation (Schritt 3). Lauf 3 diente der Fluoreszenzmessung. Abschließend wurde auf $4^{\circ} \mathrm{C}$ beziehungsweise $20^{\circ} \mathrm{C}$ abgekühlt.

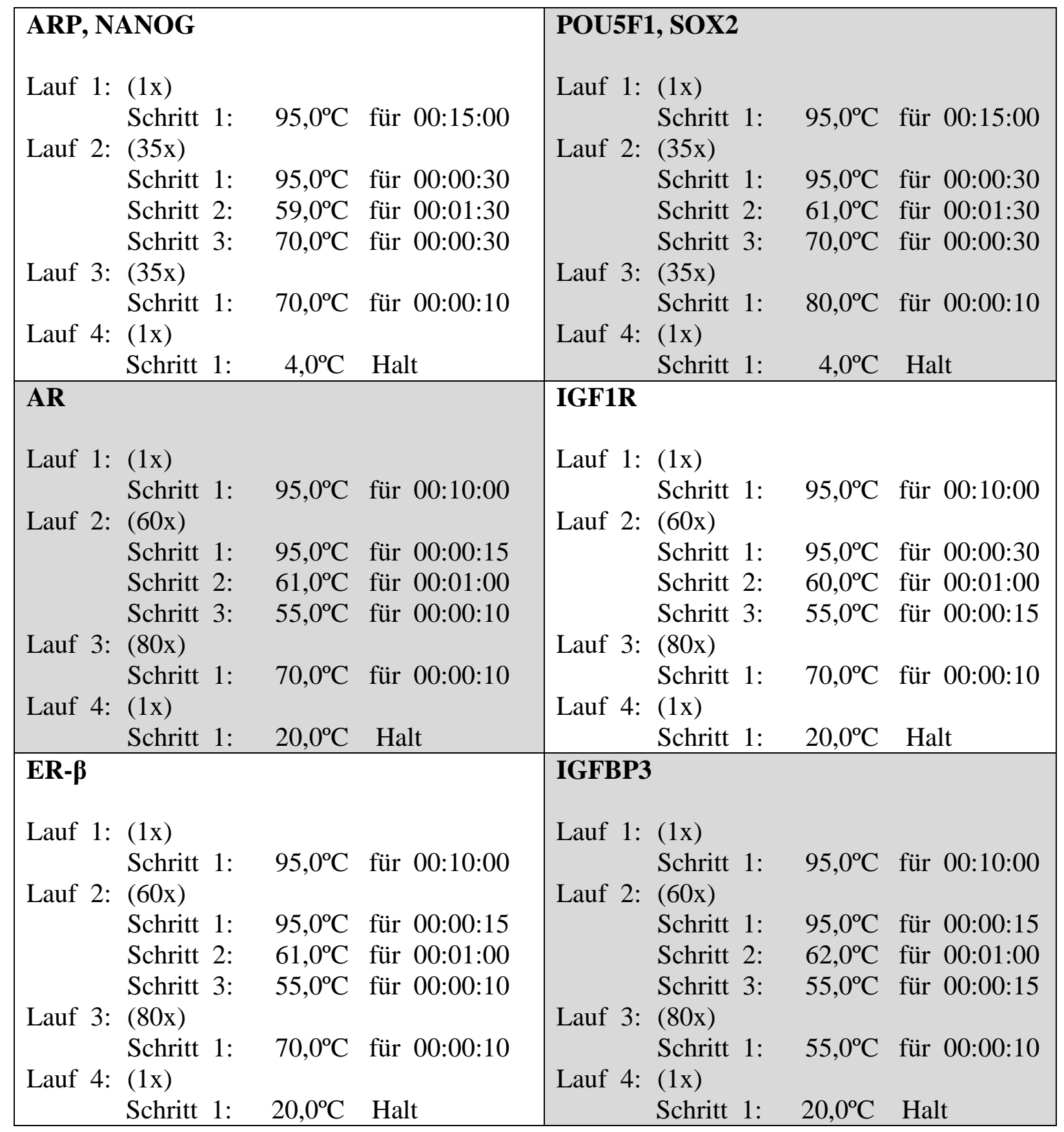

\subsubsection{Mikroarray}

Für die Probengewinnung wurden die TGCT-Zellen, wie in Abschnitt 2.5.1 beschrieben, kultiviert und stimuliert.

Die Transkriptomanalyse mittels Mikroarray-Technik erfolgte im Transkriptomanalyselabor (TAL) der Universitätsmedizin Göttingen. 
Material und Methoden

Die RNA wurde nach der Trizol-Standard-Methode (Chomczynski und Sacchi 1987) unter Verwendung des TRIzol® Reagents (Invitrogen, Karlsruhe) isoliert; dabei wurde nach dem Protokoll des Herstellers verfahren.

Für die anschließende Durchführung der Mikroarrays kam der Low RNA Input linear Amplification Kit Plus, One Color (Agilent Technologies, Weilbronn), ebenfalls entsprechend den Kit-spezifischen Anweisungen, zum Einsatz. Die RNA wurde markiert (mono-color experiment) und mit dem C.elegans 4x44K Design Array hybridisiert. Ein NanoDrop ND-1000 Spektralphotometer diente zur Messung von Quantität und Cy-dye Beimischungsraten des erzeugten Zielmaterials. Die Wasch- und Färbe-Vorgänge des Arrays wurden nach den Empfehlungen des Herstellers durchgeführt. Die Cy3-Intensität wurde unter Verwendung eines Agilent DNA Mikroarray Scanners bei fünf Mikron Auflösung durch one-color scanning detektiert. Es folgte ein visuelles Screening der gescannten Bilder auf Artefakte und eine anschließende Analyse. Die Messung der Intensität erfolgte mithilfe der Agilent Feature Extraction (FE) Software, Version 9.5, die darauffolgende Analyse mittels des Limma Package (Smyth 2004) von Bioconductor (Gentleman et al. 2004).

Die Daten in dieser Arbeit sind nach den MIAME-Richtlinien erarbeitet. Die Mikroarray Datenanalyse bestand aus folgenden Schritten: 1. Zwischen-Array Normalisierung, 2. Globales Clustern und PCA, 3. Anpassen der Daten an ein lineares Modell, 4. Detektion unterschiedlicher Genexpression und 5. Über-Repräsentations-Analyse von unterschiedlich exprimierten Genen.

Die Quantile-Normalisierung erfolgte mit Hilfe der log2-transformierten Intensitäten als Methode für die zwischen-Array Normalisierung, um sicherzustellen, dass die Intensitäten ähnliche Verteilungen zwischen den Arrays haben (Irizarry et al. 2003).

Für die Cluster-Analyse wurde ein hierarchischer Ansatz mit der Durchschnitt-Methode angewandt. Entfernungen wurden gemessen als 1 - Pearson's Correlation Coefficient. Die PCA (principal component analysis) wurde unter Verwendung der princomp Funktion in der R-Software durchgeführt. Zur Abschätzung der durchschnittlichen Gruppenwerte für jedes Gen und der differentiellen Genexpression wurde ein einfaches lineares Modell den Daten angepasst und Gruppen-Mittelwerte und Standardabweichungen für jedes Gen gewonnen. Um Gene mit signifikanten Expressionsveränderungen zwischen Gruppen zu finden, wurden - durch Moderieren des Standardfehlers der geschätzten Werte - empirische Bayes Statistiken an den Daten angewandt (Smyth 2004). 
Material und Methoden

Die p-Werte wurden durch den normalen T-Test gewonnen und für multiple Durchführungen mit der Benjamini-Hochberg-Methode (Benjamini und Hochberg 1995) korrigiert. Die pWert-Anpassung garantiert eine kleine Anzahl an falsch positiven Ergebnissen durch Kontrolle der Falscherkennungsrate (false discovery rate, $f d r$ ).

Für jedes Gen wurde die Nullhypothese, nämlich dass es keine differentielle Expression zwischen den Degradationshöhen gibt, abgelehnt wenn die Falscherkennungsrate kleiner als 0,05 war. Um überrepräsentierte Funktionen $\mathrm{zu}$ finden wurde DAVID verwendet (http://david.abcc.ncifcrf.gov, Stand: 13.04.2010).

\subsubsection{Connectivity Map}

Die Connectivity Map (cmap) ist eine online Datenbank, die es möglich macht, Gemeinsamkeiten von Gensignaturen - induziert durch diverse Substanzen, die in Zellstimulations- und Mikroarray-Versuchen erstellt wurden - festzustellen.

Zur Erstellung dieser Datenbank wurden mithilfe der Mikroarray-Technik zahlreiche Genexpressionsanalysen durchgeführt, nachdem verschiedene etablierte Zelllinie mit einer Vielzahl von Stimulanzien, Medikamente und andere Substanzen in unterschiedlichen Konzentrationen behandelt worden waren. Diese Versuche lieferten Gensignaturen, bestehend aus überexprimierten und inhibierten Genen, welche die Referenzdatenbank bilden.

Erhält man nun aus Zellstimulationsversuchen eine Reihe von induzierten und reprimierten Genen (sogenannte Gensignaturen), so kann man diese in die cmap eingeben und die Datenbank nach Übereinstimmungen mit Substanzen aus der Referenzdatenbank befragen. Die Ergebnisse können Substanzen umfassen, die gleichsinnige (eine Substanz induziert und inhibiert die gleichen Gene) und gegensinnige (eine Substanz regulierte die gleichen Gene genau umgekehrt) Veränderungen bewirken sowie solche, die komplett andere Gene regulieren und daher keine Korrelationen aufweisen. Es wird ein „connectivity score“ erstellt, der die Übereinstimmungen der Substanzen unterschiedlichen Rängen zuweist (Abb. 2) (Lamb et al. 2006).

Für die Erstellung der Gensignaturen zur Eingabe in die Connectivity Map müssen die UniGene IDs in Affymetrix IDs umgewandelt werden, was nach einem Protokoll der cmapBetreiber unter folgender Domain möglich ist (Stand 13.08.2011):

https://www.affymetrix.com/user/login.jsp?toURL=/analysis/netaffx/index.affx

Die Eingabe der Liste von über- und unterexprimierten Genen erfolgte anschließend unter http://www.broadinstitute.org/cmap/ unter Verwendung der Version build 02, welche 7000 Expressionsprofile, die 1309 Verbindungen repräsentieren enthält (Stand: 13.08.2011). 
Material und Methoden

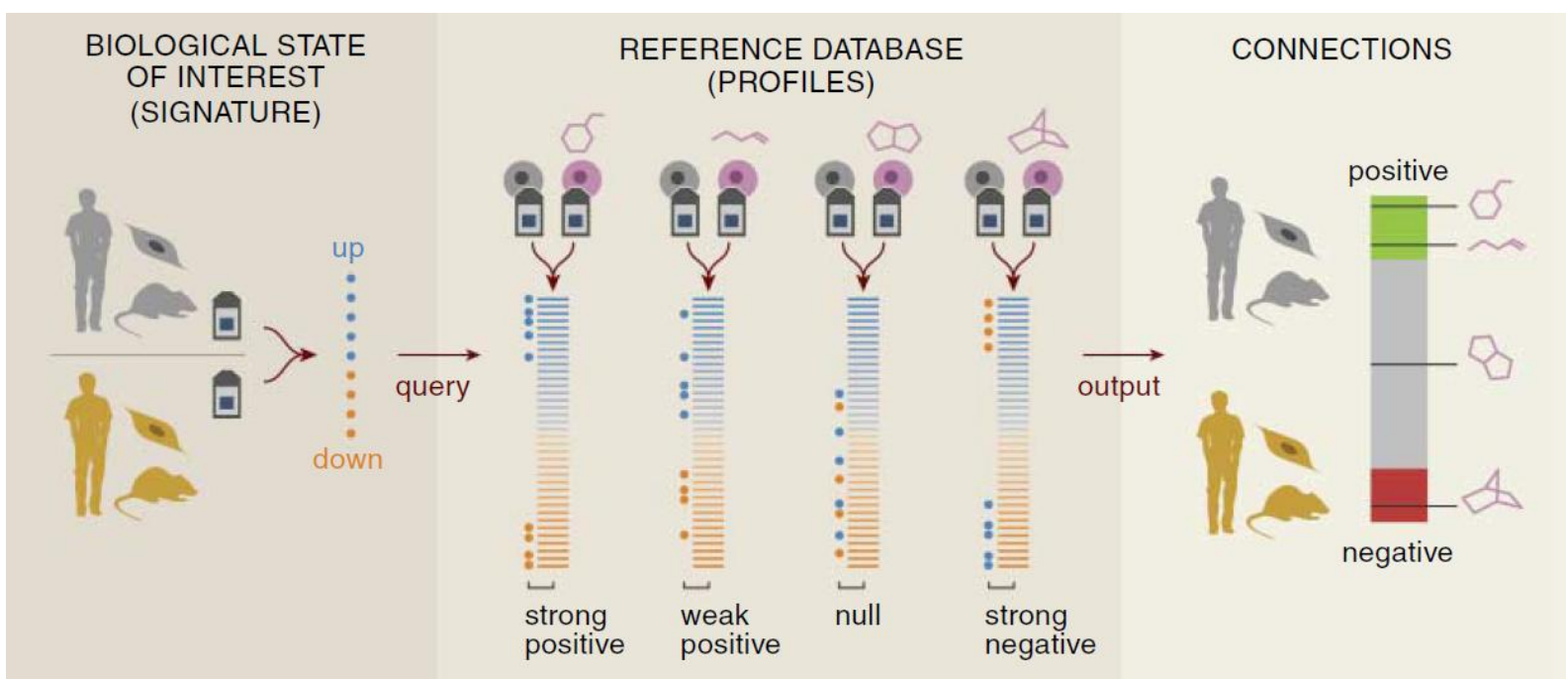

Abb. 2: Prinzip der Connectivity Map

Genexpressionsanalysen liefern Gensignaturen, bestehend aus überexprimierten und inhibierten Genen, welche die Referenzdatenbank (,reference database“) bilden. Diese können mit Ergebnissen aus weiteren Mikroarrays verglichen werden (,,biological state of interest ${ }^{“)}$. Es zeigen sich gleichsinnige (eine Substanz induziert und inhibiert die gleichen Gene - ,strong positive“ bzw. „weak positive") und gegensinnige (eine Substanz reguliert die gleichen Gene genau umgekehrt "strong negative") Veränderungen hervorrufende Substanzen sowie solche, die komplett andere Gene regulieren und daher keine Korrelationen aufweisen (,null“). Es wird ein ,connectivity

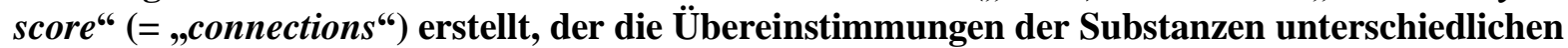
Rängen zuweist. Abbildung aus Lamb et al. (2006, S. 1930)

Zur Auswertung und Darstellung der erzielten Ergebnisse (Konnektivitäten) stehen verschiedene Möglichkeiten zur Verfügung. Zum einen kann man auf eine Einzeldarstellung mit den Konnektivitäten für alle Instanzen zugreifen (,detailed results"). Einen besseren Überblick geben jedoch die ,permuted results“, welche auch zur Ergebnisdarstellungen in dieser Arbeit gewählt wurden. Diese Kategorie liefert eine wesentliche Zusammenfassung der Ergebnisse, gibt einen Stimulanzien-zentrierten Blick auf die Resultate (statt auf die einzelnen Instanzen/Versuche) und rangiert sie nach Schätzung der Wahrscheinlichkeit, dass die Übereinstimmung mit einem Set von Instanzen in der Gesamtliste aller Instanzen per Zufall beobachtet wurde (p-Wert). Die Tabelle zeigt die Namen der Stimulanzien und die Zelllinien, an denen die Versuche durchgeführt wurden. Als statistische Größen stehen das arithmetische Mittel des „connectivity scores“ für die jeweilige Substanz, die Anzahl der Versuchsdurchführungen (n) und ein vermuteter p-Wert für den Übereinstimmungsscore zur Verfügung. Jede Zeile beinhaltet des Weiteren ein Balkensymbol, welches Zugang zu einem Fenster mit den detaillierten Ergebnissen für das jeweilige Stimulans ermöglicht. 
Material und Methoden

\subsection{Proteine}

Zur Proteinanalyse erfolgte eine nukleäre Proteinextraktion, da die untersuchten Transkriptionsfaktoren im Wesentlichen im Zellkern exprimiert werden. Dabei kann ein zytoplasmatischer Anteil nicht komplett ausgeschlossen werden, allerdings liegt die nukleäre Fraktion in einer höheren Konzentration als bei herkömmlichen Methoden vor. Um eine ausreichende Proteinausbeute für die anschließenden Western-Blot-Analysen zu erzielen, wurden pro Zelllinie, Stimulationskonzentration und Zeitpunkt drei $75-\mathrm{cm}^{2}-$ Zellkulturflaschen mit jeweils 4,5 Millionen Zellen angesetzt und stimuliert.

\subsubsection{Isolierung nukleärer Proteine}

Nach dem Ernten der Zellen mit einem Zellschaber wurden die Proben zweimal mit PBS gewaschen. Die anschließende Isolierung der nukleären Proteine erfolgte mit dem Nuc Buster ${ }^{\mathrm{TM}}$ Protein Extraction Kit (Merck, Darmstadt) nach dem Protokoll des Herstellers. Dieses basiert auf den zwei enthaltenen spezifischen Reinigungslösungen wovon die Erste, NucBuster Extraction Reagent 1 (150 $\mu$ l pro Probe) zur Zelllyse führt und der Entfernung der zytoplasmatischen Komponenten dient. Mit dem Nuc Buster Extraction Reagent 2 (150 $\mu 1$ pro Probe), versetzt mit Protease Inhibitor Cocktail Set I ( $2 \mu 1$ pro Probe) und 100 mM DTT ( $2 \mu 1$ pro Probe) wurden anschließend die nukleäre Fraktion extrahiert und konnte weiterverarbeitet oder bei $-80^{\circ} \mathrm{C}$ aufbewahrt werden.

\subsubsection{Quantifizierung der Proteine nach Bradford}

Die quantitative Proteinbestimmung erfolgte mit Hilfe des Bio-Rad Protein-Assays (Bio-Rad, München) nach der Bradford-Methode. Dabei kommt es durch die Bindung von Coomassie brillant blue G-250 an Proteine zu einer Verschiebung des Absorptionsmaximums der Farben: $465 \mathrm{~nm}$ ohne Proteine und $595 \mathrm{~nm}$ mit Proteinen. Die Zunahme der Absorption bei $595 \mathrm{~nm}$ ist also ein Maß für die Proteinkonzentration der Lösung.

Mit Rinderserumalbumin (BSA) in den absteigenden Konzentrationen 2, 1, 0,5, 0,25, 0,125, 0,0625 und $0 \mathrm{mg} / \mathrm{ml}$ wurde eine Eichkurve erstellt. Im Bereich dieser Kurve verhält sich die Extinktion proportional zum Proteingehalt der Probe.

Auf einer 96-well-Platte wurden die Proben in einer Verdünnung von 1:10 mit Wasser aufgetragen. Zu $4 \mu$ l verdünnter Probe wurden $196 \mu$ l verdünnter Protein-Assay hinzugefügt und anschließend für fünf Minuten bei Raumtemperatur inkubiert. Jede Probe, sowie der Standard für die Eichkurve, wurde in dreifachem Ansatz photometrisch im Microplate Reader nach einer Mixzeit von fünf Minuten bei $595 \mathrm{~nm}$ gemessen. In einer eigens dafür konstruierten 
Material und Methoden

Excel-Eichkurve konnten anschließend die Proteinkonzentrationen aus den Extinktionswerten errechnet werden.

\subsubsection{Gel-Elektrophorese}

Die Gel-Elektrophorese erfolgte mit Hilfe eines SDS-Gels. Die Seife SDS (Sodiumdodecylsulfat) verbindet sich mit den Proteinen $\mathrm{zu}$ negativ geladenen SDS-ProteinKomplexen, sodass sich die verschiedenen Proteine nur noch in ihrer Größe unterscheiden und vergleichbare hydrodynamische Eigenschaften haben. Bei der Elektrophorese wandern die SDS-Protein-Komplexe dann im elektrischen Feld zum Plus-Pol und werden durch den Molekularsiebeffekt einer porösen Polyacrylamidmatrix nach ihrem Molekulargewicht aufgetrennt.

Je Probe wurden $50 \mu \mathrm{g}$ Proteine 1:1 mit Tris-HCl SDS loading buffer (AnamedElektrophorese, Groß-Bieberau) versetzt, für 5-10 min bei $95^{\circ} \mathrm{C}$ inkubiert und anschließend auf Eis gestellt. Der Laufpuffer wurde durch Verdünnen des NuPAGE® MES SDS Running Buffer (Invitrogen, Karlsruhe) 1:20 mit destilliertem Wasser angesetzt. Für die Elektrophorese kam ein Gradientengel (NuPAGE® 4-12 \% Bis-Tris Gel, Invitrogen, Karlsruhe) zum Einsatz, welches die beste Auftrennung für kleine bis mittelgroße Proteine ermöglicht. Nach Positionieren des Gels in der XCell SureLock ${ }^{\mathrm{TM}}$ Mini-Cell (Invitrogen, Karlsruhe), wurden $600 \mathrm{ml}$ des Laufpuffers in die äußere Kammer gefüllt. Die restlichen $400 \mathrm{ml}$ Laufpuffer wurden mit $400 \mu \mathrm{l}$ Antioxidans versehen, von denen $200 \mathrm{ml}$ zum Anfüllen der inneren Kammer dienten. Die Geltaschen wurden mit einer $100 \mu 1$ Pipette durchgespült, um eventuell vorhandenes auskristallisiertes SDS herauszuspülen und aufzulösen, welches einen geraden Lauf der Proben stören könnte. Das Gel wurde mit den Proben beladen, wobei die erste Tasche mit $4 \mu \mathrm{l} \mathrm{Full-}$ Range Rainbow ${ }^{\text {TM }}$ Molecular Weight Marker (GE Healthcare, München) versehen wurde. Der Lauf erfolgte für 45 Minuten bei 200 Volt.

\subsubsection{Western Blot}

Beim Blotten werden die Proteine des SDS-Gels elektrophoretisch auf eine (Nitrozellulose-) Membran übertragen, an die sie nichtkovalent binden.

Als Blotkammer diente eine Halbtrockenzelle (Bio-Rad, München). Für den Transfer wurden 3 Filterpapiere, eine Nitrozellulose-Membran, das Gel und zuletzt nochmals 3 Filterpapiere in Transferpuffer eingeweicht und in der Blotkammer luftblasenfrei positioniert. Der Blot erfolgte bei 0,04 Ampere für eine Stunde.

Nach dem Transfer wurde die Membran für eine Stunde bei Raumtemperatur mit $5 \%$ Milchpulver - gelöst in TBST - abgesättigt, um die restlichen Proteinbindungsstellen der Blot- 
Material und Methoden

membran zu blocken. Anschließend konnte der Primärantikörper, verdünnt in TBST / $5 \%$ BSA, bei $4^{\circ} \mathrm{C}$ über Nacht inkubieren (Tabelle 4).

Am zweiten Tag wurde die Membran, nach einmaligen Schwänken in TBST, zweimal zehn Minuten in TBST gewaschen. Anschließend wurde der HRP-konjugierte Sekundärantikörper in einer Konzentration von 1:2000, verdünnt in TBST / 5 \% Milchpulver aufgetragen, um bei Raumtemperatur für eine Stunde zu inkubieren. Nach erneutem Schwenken und zweimal zehn minütigem Waschen in TBST wurde die Chemilumineszenz (Western Lightning ${ }^{\mathrm{TM}}$, Perkin Elmer, Waltham, USA) angesetzt. Diese bestand aus den beiden Agenzien Enhanced Luminol Reagent Plus und Oxidizing Reagent Plus, die eins zu eins vermengt und anschließend für eine Minute auf die Membran aufgetragen wurden.

Alle Inkubations- und Waschvorgänge erfolgten auf einem Schüttler, um eine vollständige Benetzung der Membran zu garantieren. Nach Inkubation in der Chemilumineszenz, wurde die Membran unmittelbar in einer Röntgenkassette positioniert. In einer Dunkelkammer wurde Fotopapier eine Sekunde bis fünf Minuten belichtet, um das Ergebnis anschließend durch Prozessierung in der Röntgenfilm-Entwicklungsmaschine (Röntgenfilm-Prozessor SRX101A, Konica Minolta, Langenhagen) sichtbar zu machen.

Zur Kontrolle wurde jeweils ein Housekeeping-Gen nachgewiesen, das in allen Körperzellen konstant exprimiert wird und somit als Referenz diente. Nachdem die Antikörper nicht für alle Versuche in der nötigen Qualität verfügbar waren, wurde neben Histon H3 auch $\alpha$ Tubulin und $\beta$-Actin eingesetzt.

Um einen Blot mehrmals mit verschiedenen Antikörpern färben zu können, wurde die Membran nach jeder Filmentwicklung einem Waschvorgang mit TBST unterzogen. Für den Nachweis eines neuen Proteins wurde der beschriebene Vorgang ab der Primärantikörperinkubation wiederholt. Alle weiteren Schritte für den erneuten Färbevorgang entsprechen den oben beschriebenen. Dieses Vorgehen ist allerdings nur für Proteine mit unterschiedlichen Molekulargewichten möglich, da die Banden, insbesondere bei gleicher Antikörperspezies, nicht eindeutig zu differenzieren wären. 
Material und Methoden

Tabelle 4: Western Blot - Primärantikörper Verwendete Verdünnungen, Spezies und Hersteller

\begin{tabular}{llll}
\hline Antikörper & Spezies & Verdünnung & Hersteller \\
\hline Anti- $\alpha$-Tubulin & mouse & $1: 10000$ & Sigma-Aldrich, Steinheim \\
Anti- $\beta$-Actin & mouse & $1: 5000$ & Sigma-Aldrich, Steinheim \\
Anti-Acetyl-Histon H4 & rabbit & $1: 1000$ & Millipore, Schwalbach \\
Anti-Histon H3 & rabbit & $1: 200$ & $\begin{array}{l}\text { Santa Cruz Biotechnology, } \\
\text { Heidelberg } \\
\text { Anti-NANOG }\end{array}$ \\
& rabbit & $1: 500$ & $\begin{array}{l}\text { Santa Cruz Biotechnology, } \\
\text { Heidelberg }\end{array}$ \\
Anti-POU5F1 & goat & $1: 200$ & $\begin{array}{l}\text { Santa Cruz Biotechnology, } \\
\text { Heidelberg }\end{array}$ \\
Anti-SOX2 & rabbit & $1: 1000$ & Abcam, Cambridge, UK \\
\hline
\end{tabular}

\subsection{Zytospin und Immunzytochemie}

Zwecks Zytospinpräparation wurden jeweils 3 x 105 Zellen in einem Milliliter Medium auf 6well-Platten kultiviert und stimuliert. Die Isolierung der Zellen erfolgte durch Abkratzen mit Hilfe von Zellschabern, gefolgt von zweimaligem Waschen mit PBS. Anschließend wurden die Zellen in einer Neubauer-Zählkammer gezählt und die Zellzahl nach folgender Formel berechnet: Mittelwert der vier gezählten Kästchen x 10000 (= Kammervolumen) x Volumen aus dem die Zellen entnommen wurden. Pro Objektträger wurden 15000 Zellen in $300 \mu 1$ PBS für die Zentrifugation in der Zytozentrifuge (Shandon Zytospin® 4 Zytozentrifuge, Thermo Fisher, Schwerte) vorbereitet. Die Erstellung der Präparate erfolgte bei 1300 Umdrehungen pro Minute, sieben Minuten lang. Die Zytospins wurden über Nacht bei Raumtemperatur getrocknet und am nächsten Tag immunzytochemisch gefärbt beziehungsweise in Alufolie eingewickelt und bei $-20^{\circ} \mathrm{C}$ aufbewahrt.

\subsubsection{Immunzytochemie}

Die immunzytochemische Färbung von histo- bzw. zytologischen Präparaten dient der Darstellung antigener Strukturen auf oder in Zellen und Geweben mit daran bindenden Antikörper-Farbkomplexen.

Zur Fixierung wurden die trockenen Zytospins zehn Minuten in eiskaltes 100 prozentiges Aceton gestellt und anschließend 20 Minuten bei Raumtemperatur getrocknet. Um die nukleären Proteine NANOG und POU5F1 besser für die Färbung zugänglich zu machen, wurden die beschriebenen Präparate 15 Minuten im Dampfgarer (Braun, Kronberg/Taunus) in Citratpuffer inkubiert und zehn Minuten auf einem Schüttler abgekühlt. Anschließend wurden die Zytospins zwei mal zwei Minuten mit TBST gewaschen, um danach für 20 Minuten mit einem BSA / FCS-Block versehen zu werden. Dies, sowie alle weiteren Inkubationen, erfolg- 
Material und Methoden

ten mit $30 \mu \mathrm{l}$ pro Zytospin in einer geschlossenen luft- und lichtdichten Box, nach Umrandung der Zellansammlungen auf dem Objektträger mit einem Liquid Blocker. Danach wurden die Präparate kurz in TBST getaucht, um anschließend eine Stunde mit dem Primärantikörper (verdünnt in TBST) zu inkubieren (Tabelle 5). Es folgten wieder zwei zweiminütige Waschvorgänge mit TBST. Für die weiteren Schritte wurde mit dem Dako REAL TM Detection System (Dako, Glostrup, Dänemark) gearbeitet und nach Anleitung des Herstellers verfahren. Dementsprechend folgte eine 20-minütige Inkubationen mit je $30 \mu 1$ Link (speziesunabhängiger biotinylierter Sekundärantikörper) und $30 \mu \mathrm{l}$ Label (an alkalische Phosphatase konjugiertes Streptavidin), welche ebenso durch die oben genannte TBST-Spülung getrennt und abgeschlossen wurden. Die endgültige Färbung mit Chromogen erfolgte nach eigenhändiger Zusammensetzung des Farbstoffes mit einem Milliliter AP Substrate Buffer, $40 \mu$ l Chromogen Red 1, $40 \mu \mathrm{l}$ Chromogen Red 2, $40 \mu 1$ Chromogen Red 3 und 5 l Levamisole. Die Präparate wurden 10 min mit dem Chromogen-Ansatz inkubiert. Zuletzt wurden die Zytospins kurz in TBST getaucht, mit destilliertem Wasser gespült und sieben Minuten mit Hämalaun gegengefärbt. Um den Farbumschlag im alkalischen Milieu zu ermöglichen, wurden die Präparate für sieben Minuten in fließendes Leitungswasser gestellt (Bläuen). Nach dem Bläuen wurden die Präparate durch eine aufsteigende Alkoholreihe gezogen und abschließend eingedeckt.

Die Fotos wurden mit einer Olympus DP-50 Kamera (Olympus, Hamburg) erstellt, unter Verwendung der Viewfinder Lite version 1.0.134 Software (Pixera, San Jose, USA).

Tabelle 5: Immunzytochemie - Primärantikörper Verwendete Verdünnungen und Hersteller

\begin{tabular}{lcl}
\hline Antikörper & Verdünnung & Hersteller \\
\hline Anti-NANOG & $1: 50$ & Santa Cruz Biotechnology, Heidelberg \\
Anti-POU5F1 & $1: 50$ & Santa Cruz Biotechnology, Heidelberg \\
\hline
\end{tabular}

\subsection{Verwendete Materialien}

\subsubsection{Chemikalien, Enzyme, Puffer, Kits}

Im Folgenden sind die verschiedenen Materialien aufgelistet und nach der Produktbezeichnung alphabetisch sortiert (Tabelle 6).

Tabelle 6: Verwendete Chemikalien, Enzyme, Puffer, Kits

\begin{tabular}{|l|l|}
\hline \multicolumn{1}{|c|}{ Substanz } & \multicolumn{1}{c|}{ Hersteller } \\
\hline 2-Mercaptoethanol, min. 98 \% & Sigma-Aldrich, Steinheim \\
\hline Aceton & Merck, Darmstadt \\
\hline Albumin Fraktion V & Carl Roth, Karlsruhe \\
\hline Aluminiumkaliumsulfat-Dodecahydrat & Merck, Darmstadt \\
\hline
\end{tabular}


Material und Methoden

\begin{tabular}{|c|c|}
\hline Belamcanda-chinensis-Extrakt & Bionorica SE, Neumarkt \\
\hline BIO-RAD PROTEIN ASSAY & Bio-Rad Laboratories, München \\
\hline Buffer RLT Lysis buffer & QIAGEN, Hilden \\
\hline Cell Proliferation Kit I (MTT) & Roche Diagnostics, Mannheim \\
\hline Chloralhydrat & Merck, Darmstadt \\
\hline Citronensäure-Monohydrat & Merck, Darmstadt \\
\hline Dako REAL ${ }^{\mathrm{TM}}$ Detection System & Dako, Glostrup, Dänemark \\
\hline Dimethyl sulphoxid & Sigma-Aldrich, Steinheim \\
\hline Dithiothreitol & Sigma-Aldrich, Steinheim \\
\hline Ethanol & Merck, Darmstadt \\
\hline Ethanol (99\% und 96\%) & CVH, Hannover \\
\hline Fetal Bovine Serum & PAA, Pasching, Österreich \\
\hline $\begin{array}{l}\text { Full-Range Rainbow }{ }^{\mathrm{TM}} \text { Molecular Weight } \\
\text { Markers }\end{array}$ & GE Healthcare, München \\
\hline Glycerol & Sigma-Aldrich, Steinheim \\
\hline Glycin & Carl Roth, Karlsruhe \\
\hline Hämatoxylin & Merck, Darmstadt \\
\hline HEPES Buffer Solution (1 M) & PAA, Pasching, Österreich \\
\hline Histone H3 Antikörper (FL-136) & Santa Cruz Biotechnology, Heidelberg \\
\hline L-Glutamine & PAA, Pasching, Österreich \\
\hline LNCaP & DSMZ, Braunschweig \\
\hline $\begin{array}{l}\text { Low RNA Input Linear Amplification Kit } \\
\text { Plus, one-color }\end{array}$ & Agilent Technologies, Waldbronn \\
\hline Magermilchpulver & Merck, Darmstadt \\
\hline Methanol & Merck, Darmstadt \\
\hline Natriumchlorid & Merck, Darmstadt \\
\hline Natriumiodat & Merck, Darmstadt \\
\hline Nitrocellulose Transfer Membran & Whatman, Dassel \\
\hline NTERA-2 & DSMZ, Braunschweig \\
\hline $\begin{array}{l}\text { NucBuster }{ }^{\mathrm{TM}} \text { Protein Extraction Kit } \\
\left.\text { (Novagen }{ }^{\circledR}\right)\end{array}$ & Merck, Darmstadt \\
\hline NuPAGE® 4-12 \% Bis-Tris Gel & Invitrogen, Karlsruhe \\
\hline NuPAGE® Antioxidant & Invitrogen, Karlsruhe \\
\hline NuPAGE® MES SDS Running Buffer & Invitrogen, Karlsruhe \\
\hline Omniscript RT Kit & QIAGEN, Hilden \\
\hline PBS DULBECCO INSTAMED $9.55 \mathrm{~g} / 1$ & BIOCHROM, Berlin \\
\hline Penicillin-Streptomycin, liquid & Invitrogen, Karlsruhe \\
\hline $\begin{array}{l}\text { Polyclonal Goat Anti-Rabbit } \\
\text { Immunoglobulins / HRP }\end{array}$ & Dako, Glostrup, Dänemark \\
\hline $\begin{array}{l}\text { Polyclonal Rabbit Anti-Goat } \\
\text { Immunoglobulins / HRP }\end{array}$ & Dako, Glostrup, Dänemark \\
\hline $\begin{array}{l}\text { Polyclonal Rabbit Anti-Mouse } \\
\text { Immunoglobulins / HRP }\end{array}$ & Dako, Glostrup, Dänemark \\
\hline $\begin{array}{l}\text { qPCR MasterMix Plus for SYBR® Green I } \\
\text { w/ fluorescein }\end{array}$ & Eurogentec Deutschland, Köln \\
\hline Random Primers & Invitrogen, Karlsruhe \\
\hline RiboLock $^{\text {TM }}$ RNase Inhibitor & Fermentas, St. Leon-Rot \\
\hline RNA 6000 Nanochip Kit & Agilent Technologies, Waldbronn \\
\hline RNeasy® Mini-Kit (250) & QIAGEN, Hilden \\
\hline RPMI1640 ${ }^{\mathrm{TS}}$ & PAA, Pasching, Österreich \\
\hline
\end{tabular}


Material und Methoden

\begin{tabular}{|l|l|}
\hline Salzsäure rauchend $37 \%$ & Merck, Darmstadt \\
\hline Sodium dodecyl sulfate solution, 10\% & Sigma-Aldrich, Steinheim \\
\hline TCam-2 & $\begin{array}{l}\text { Sohei Kitazawa, Division of Molecular Pa- } \\
\text { thology, Kobe University, Japan }\end{array}$ \\
\hline Tectorigenin & Bionorica SE, Neumarkt \\
\hline Trichostation A & Sigma-Aldrich, Steinheim \\
\hline tri-Natriumcitrat-Dihydrat & Merck, Darmstadt \\
\hline TRIS & Carl Roth, Karlsruhe \\
\hline Tris-HCl SDS loading buffer & Anamed-Elektrophorese, Groß-Bieberau \\
\hline TRIzol® Reagent & Invitrogen, Karlsruhe \\
\hline Trypsin-EDTA (GIBCO®) & Invitrogen, Karlsruhe \\
\hline TWEEN® 20 Detergent (CALBIOCHEM®) & EMD Biosciences, La Jolla, USA \\
\hline Valproat & Sigma-Aldrich, Steinheim \\
\hline Wasser doppelt destilliert & Carl Roth, Karlsruhe \\
\hline Western LightningTM Plus-ECL & Perkin Elmer, Waltham, USA \\
\hline Xylol & $\begin{array}{l}\text { Mallinckrodt Baker B.V., Deventer, } \\
\text { Niederlande }\end{array}$ \\
\hline
\end{tabular}

\subsubsection{Einwegartikel und Geräte}

Im Folgenden sind Einwegartikel und Geräte aufgelistet und nach der Artikelbezeichnung alphabetisch sortiert (Tabelle 7).

Tabelle 7: Verwendete Einwegartikel und Geräte

\begin{tabular}{|l|l|}
\hline \multicolumn{1}{|c|}{ Artikel } & \multicolumn{1}{c|}{ Hersteller } \\
\hline 595 1/2 Faltenfilter, $\varnothing 150 \mathrm{~mm}$ & Whatman, Dassel \\
\hline 96-Well Multiply®-PCR Plate & Sarstedt, Nümbrecht \\
\hline Agilent Bioanalyzer 2100 & Agilent Technologies, Waldbronn \\
\hline Agilent DNA microarray scanner & Agilent Technologies, Waldbronn \\
\hline $\begin{array}{l}\text { Agilent Feature Extraction (FE) Software, } \\
\text { Version 9.5 }\end{array}$ & Agilent Technologies, Waldbronn \\
\hline BIOCLAV & Schütt Labortechnik, Göttingen \\
\hline C.elegans 4x44K Design Array & Agilent Technologies, Waldbronn \\
\hline Centrifuge 5417R & Eppendorf, Hamburg \\
\hline Chromatography Paper 3 mm & Whatman, Dassel \\
\hline CO 2 Inkubator (MCO-1 7A I) & SANYO, München \\
\hline Deckgläser Thermo SCIENTIFIC & Menzel, Braunschweig \\
\hline DUO Therm Hybridisation Oven OV5 & Biometra, Göttingen \\
\hline $\begin{array}{l}\text { Eichfähige elektronische Semi-Mikrowaage } \\
\text { R 160 P }\end{array}$ & Sartorius, Göttingen \\
\hline F96 MicroWellTM Plates & Nunc A/S, Roskilde, Dänemark \\
\hline $\begin{array}{l}\text { FUJI MEDICAL X-RAY FILM 100 NIF } \\
\text { 13x18 }\end{array}$ & FUJIFILM Corporation, Tokyo, Japan \\
\hline $\begin{array}{l}\text { HERAsafe KS Mikrobiologische } \\
\text { Sicherheitswerkbank }\end{array}$ & Thermo Fisher Scientific, Schwerte \\
\hline $\begin{array}{l}\text { iCycler Thermal Cycler 96-Well Thermal } \\
\text { Sealing Ring }\end{array}$ & Bio-Rad Laboratories, München \\
\hline IVO Zählgerät & W. Krannich, Göttingen \\
\hline
\end{tabular}


Material und Methoden

\begin{tabular}{|c|c|}
\hline Limma Package & $\begin{array}{l}\text { Bioconductor, http://www.bioconductor.org/ } \\
\text { (Stand: } 13.04 .2010 \text { ) }\end{array}$ \\
\hline LIQUID BLOCKER (super pap pen) & Daido Sangyo, Tokyo, Japan \\
\hline Magnetrührer & IKA, Staufen \\
\hline Megafuge $1.0 \mathrm{R}$ & Heraeus Sepatech, Osterode \\
\hline Mikroskop ID 03 & Carl Zeiss, Oberkochen \\
\hline Model 680 Series Microplate Readers & Biometra, Göttingen \\
\hline MultiGourmet Dampfgarer & Braun, Kronberg/Taunus \\
\hline NanoDrop ND-1000 & NanoDrop products, Wilmington, USA \\
\hline NEUBAUER Zählkammer & BRAND, Wertheim \\
\hline Objektträger & Waldemar Knittel, Braunschweig \\
\hline Olympus DP-50 Kamera & Olympus, Hamburg \\
\hline Optical Sealing Tape & Bio-Rad Laboratories, München \\
\hline Parafilm & Pechiney Plastic Packaging, Menasha, USA \\
\hline Pasteur Kapillar-Pipetten (150 und $230 \mathrm{~mm}$ ) & Wilhelm Ulbrich, Bamberg \\
\hline pH-Meter CG 811 & SI Analytics, Mainz \\
\hline $\begin{array}{l}\text { Pipetten } \\
\qquad \begin{array}{l}0,1-2,5 \mu 1 \\
10-100 \mu 1 \\
100-1000 \mu 1 \\
200-1000 \mu 1\end{array}\end{array}$ & Eppendorf, Hamburg \\
\hline $\begin{array}{c}\text { Pipettenspitzen } \\
0,5-10 \mu 1 \\
10-100 \mu 1 \\
100-1000 \mu 1\end{array}$ & Sarstedt, Nümbrecht \\
\hline $\begin{array}{c}\text { Pipettenspitzen mit Filter } \\
0,5-10 \mu l \\
10-100 \mu 1 \\
100-1000 \mu 1\end{array}$ & Sarstedt, Nümbrecht \\
\hline Pipettierball & Deutsch \& Neumann, Berlin \\
\hline pipetus $®$-classic & Hirschmann Laborgeräte, Eberstadt \\
\hline Polymax 1040 & Heidolph Instruments, Schwabach \\
\hline $\begin{array}{l}\text { Polypropylen Röhrchen } \\
15 \mathrm{ml} \\
50 \mathrm{ml}\end{array}$ & Greiner Bio-One, Frickenhausen \\
\hline PowerPac 200 Spannungsgerät & Bio-Rad Laboratories, München \\
\hline QIAshredder (250) & QIAGEN, Hilden \\
\hline Reagiergefäß für Mikrolitersysteme $1,5 \mathrm{ml}$ & Sarstedt, Nümbrecht \\
\hline Röntgenfilm-Prozessor SRX-101A & Konica Minolta, Langenhagen \\
\hline Röntgenkassette & rego X-Ray, Augsburg \\
\hline Rotilabo $^{(B)}$-centrifuge with butterfly-rotor & Carl Roth, Karlsruhe \\
\hline Sartorius 1204 A MP & Sartorius, Göttingen \\
\hline Schuett phoenix (Fireboy) & Schütt Labortechnik, Göttingen \\
\hline $\begin{array}{l}\text { Serologische Pipette } \\
5 \mathrm{ml} \\
10 \mathrm{ml} \\
25 \mathrm{ml}\end{array}$ & Sarstedt, Nümbrecht \\
\hline Shandon TPX Filter Cards & Thermo Fisher Scientific, Schwerte \\
\hline Shandon Zytospin ${ }^{\circledR} 4$ Zytozentrifuge & Thermo Fisher Scientific, Schwerte \\
\hline Thermomixer 5436 & Eppendorf, Hamburg \\
\hline
\end{tabular}


Material und Methoden

\begin{tabular}{|l|l|}
\hline \begin{tabular}{l} 
Tissue Culture Flask \\
\multicolumn{1}{|c|}{$25 \mathrm{~cm}^{2}$}
\end{tabular} & Sarstedt, Nümbrecht \\
\hline Tissue Culture Plate 6-Well & Sarstedt, Nümbrecht \\
\hline Tissue-Tek® Prisma® & Sakura Finetek, Staufen \\
\hline Tissue-Tek ${ }^{\circledR}$ SCA ${ }^{\mathrm{TM}}$ Eindeckfolie & Sakura Finetek, Staufen \\
\hline Tissue-Tek SCA ${ }^{\mathrm{TM}}$ Film Coverslipper & Sakura Finetek, Staufen \\
\hline TPersonal 48 & Biometra, Göttingen \\
\hline $\begin{array}{l}\text { Trans-Blot SD Semi-Dry Electrophoretic } \\
\text { Transfer Cell }\end{array}$ & Bio-Rad Laboratories, München \\
\hline Viewfinder Lite version 1.0.134 & Pixera, San Jose, USA \\
\hline $\begin{array}{l}\text { VXR basic IKA-Vibrax } \circledR \\
\text { VX7 Schalenaufsatz }\end{array}$ & IKA, Staufen \\
\hline Wägepapier MN 226 & Macherey-Nagel, Düren \\
\hline XCell SureLock ${ }^{\mathrm{TM}}$ Mini-Cell CE mark & Invitrogen, Karlsruhe \\
\hline Zellschaber 25 cm & Sarstedt, Nümbrecht \\
\hline
\end{tabular}

\subsubsection{Selbst angesetzte Puffer und Lösungen}

Aufsteigende Alkoholreihe: Die Alkoholreihe setzte sich zusammen aus: einmal 70 \% Ethanol (99 \% Ethanol, verdünnt mit $\mathrm{H}_{2} 0$ dest.), zweimal $96 \%$ Ethanol, dreimal $100 \%$ Ethanol und zuletzt dreimal Xylol.

BSA / FCS: Selbst angesetztes TBST wurde mit $10 \%$ BSA und $5 \%$ FCS versehen.

Citratpuffer: $21,01 \mathrm{~g}$ Zitronensäure $(0,1 \mathrm{M})$ und 29,4 g Natriumcitrat $(0,1 \mathrm{M})$ wurden in je $1000 \mathrm{ml} \mathrm{H} \mathrm{H}_{2} \mathrm{O}$ dest. gelöst. Anschließend wurden $18 \mathrm{ml}$ des Zitronensäureansatzes und $82 \mathrm{ml}$ des Natriumcitratansatzes miteinander vermengt.

Hämalaun (nach Mayer): Der Hämalaun-Ansatz erfolgte aus 1 g Hämatoxylin, 50 g Aluminiumkaliumsulfat, 0,15 g Natriumjodat, $50 \mathrm{~g}$ Chloralhydrat und einem Gramm Citronensäure, alles zusammen gelöst in einem Liter doppelt destilliertem $\mathrm{H}_{2} 0$. Natriumjodat diente hier als Oxidationsmittel, da der natürliche Prozess etwa sechs Wochen dauert. Nach Zugabe jedes Reagenzes wurde der Ansatz für eine Stunde auf dem Magnetrührer belassen, um den Lösevorgang zu optimieren und Reaktionen der einzelnen Substanzen im Voraus zu vermeiden.

PBS: 9,55 g PBS wurden in einem Liter $\mathrm{H}_{2} 0$ dest. gelöst und anschließend autoklaviert, um in der Zellkultur Anwendung zu finden.

TBST: $12,1 \mathrm{~g}$ Tris und 17,5 $\mathrm{g} \mathrm{NaCl}$ wurden in $1800 \mathrm{ml} \mathrm{H}_{2} 0$ bi. dest. für 20 Minuten auf dem Magnetrührer gelöst. Anschließend wurde der pH-Wert mit rauchender Salzsäure auf 7,4 eingestellt. Das Volumen wurde auf $2000 \mathrm{ml}$ aufgefüllt, mit 0,1 \% TWEEN versetzt und nochmals gerührt bis der Puffer homogen war.

Transferpuffer: $800 \mathrm{ml} \mathrm{H} \mathrm{H}_{2} 0$ bi. dest. wurden mit $3 \mathrm{~g}$ Tris, $14,4 \mathrm{~g}$ Glycin und $200 \mathrm{ml}$ Methanol versetzt und auf dem Magnetrührer gelöst. 
Material und Methoden

\subsection{Statistische Methoden}

Für die statistische Auswertung der Ergebnisse aus MTT-Test und RTD-PCR wurden Mittelwert und Standardabweichung ermittelt. Bei den PCR-Ergebnissen wurde jeweils der Mittelwert der Kontrollgruppe gleich 100 Prozent gesetzt, d.h. die Ergebnisse wurden prozentrelativiert. Die auf diese Weise entstandenen Verhältnisse, sowie die Extinktionswerte aus den Proliferationsassays, wurden plus der Standardabweichung in Balkendiagrammen dargestellt. Eine Varianzanalyse der Ergebnisse erfolgte anhand der Extinktionswerte aus dem MTT-Test, sowie der relativen mRNA-Expression mit GraphPad Prism® (GraphPad Software), Version 4.0 für Windows ${ }^{\circledR}$ (Microsoft). Für die Prüfung der Signifikanzen wurde zunächst ein ANOVA, gefolgt von einem Tukey Test, verwendet. Statistisch signifikante Abweichungen der Absorption beziehungsweise der relativen mRNA-Expression sind in den Abbildungen gekennzeichnet, wobei $\mathrm{p}<0,05 / 0,01 / 0,001$ durch $* / * * / * * *$ symbolisiert ist. Als Referenzgruppe diente jeweils die Kontrolle, für die Konzentrationsabhängigkeit jeweils kleinere Konzentrationen.

In den Stimulationsversuchen unter Einsatz von NTERA-2- und TCam-2-Zellen wurden, ausgehend von der Hypothese, dass es unter Phytoöstrogen-Stimulation zu einer Proliferationsinhibition und Expressionsinhibition der Stammzellfaktoren kommt, nur in diese Richtung weisende statistisch signifikante Veränderungen als solche kenntlich gemacht. Auf einzelne Ausnahmen mit Angaben zu einer signifikanten Induktion von Genen (insbesondere Stammzellfaktoren) wird gesondert verwiesen. 
Ergebnisse

\section{Ergebnisse}

\subsection{TGCT-Zelllinien unter Phytoöstrogen-Stimulation}

Die TGCT-Zelllinien TCam-2 und NTERA-2 (Seminom- und Nicht-Seminom-Zellen) wurden im Rahmen der genannten Stimulationsversuche unter Verwendung von Tectorigenin und Belamcanda-chinensis-Extrakt auf zeit- und konzentrationsabhängige Veränderungen in ihrem Proliferationsverhalten sowie ihrer Stammzellsignatur untersucht. Dies erfolgte, wie in Kapitel 2 beschrieben, auf mRNA- und Proteinebene.

\subsubsection{Proliferation}

Unter Verwendung des MTT-Tests wurde die Wirkung von Phytoöstrogenen auf die Proliferation der TCam-2- und NTERA-2-Zellen untersucht. Dabei wurden verschiedene Konzentrationen der Stimulanzien eingesetzt und die Proliferationsmessung erfolgte nach unterschiedlichen Inkubationszeiten. Ein unstimulierter Zellansatz diente jeweils als Kontrolle, der den Referenzwert darstellt.

Nach Stimulation mit Tectorigenin zeigte sich bereits nach 24 Stunden in den NTERA-2Zellen unter Einsatz von Konzentrationen $250 \mu \mathrm{M}$ beziehungsweise $500 \mu \mathrm{M}$ ein inhibitorischer Effekt auf die Proliferation der Tumorzellen. Im Gegensatz hierzu konnte bei TCam-2-Zellen nach 24 Stunden keine Proliferationsinhibition beobachtet werden (Abb. 3A). Nach einer Inkubationszeit von 48 Stunden konnte in sämtlichen stimulierten Ansätzen beider Zelllinien eine statistisch signifikante Proliferationshemmung detektiert werden. Zusätzlich zeigte sich in fast allen Proben eine Konzentrationsabhängigkeit der Proliferationshemmung (Abb. 3B). Die Stichprobengröße betrug $\mathrm{n}=5$.

In weiteren Untersuchungen auf das Proliferationsverhalten der Zellen in Stimulationsversuchen unter Verwendung des Belamcanda-chinensis-Extraktes war nach 24 Stunden kein Effekt im Vergleich zur Kontrolle in beiden TGCT-Zelllinien nachweisbar. Als einzige Ausnahme ist die Stimulation von NTERA-2 mit $1000 \mu \mathrm{g} / \mathrm{ml}$ BCE zu nennen, welche eine statistisch signifikant verminderte Proliferation gegenüber der Kontrolle zeigte (Abb. 4A).

Nach Stimulation mit BCE über 72 Stunden konnte in beiden Zelllinien im Vergleich mit den unstimulierten Kontrollen eine Proliferationshemmung erzielt werden. Zudem zeigte sich in den BCE-stimulierten TGCT-Zelllinien eine Konzentrationsabhängigkeit der verminderten Proliferation (Abb. 4B). Die Stichprobengröße betrug n $=10$. 
Ergebnisse

A
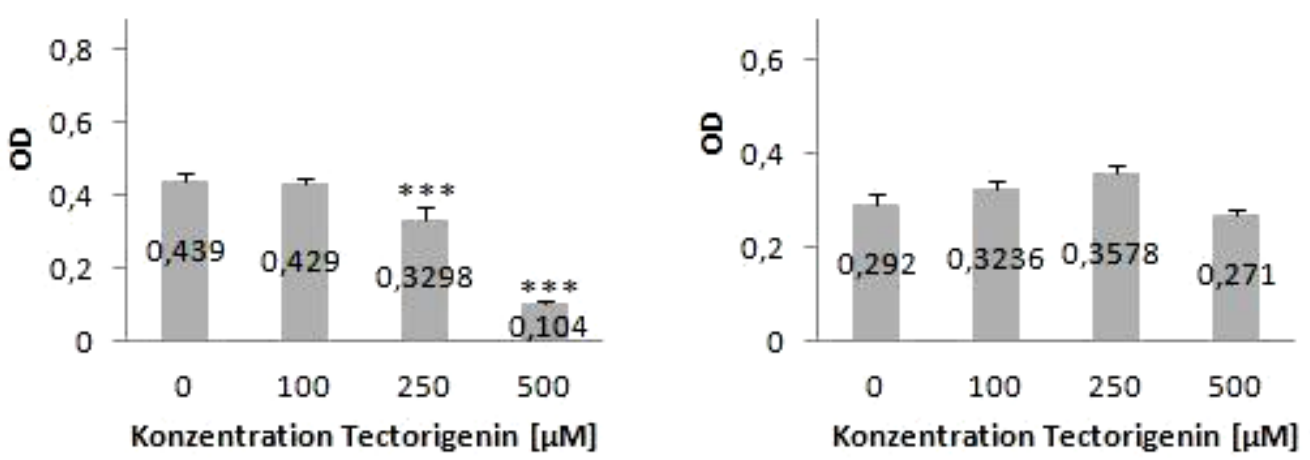

B

NTERA-2 $48 \mathrm{~h}$

TCam-2 $48 \mathrm{~h}$
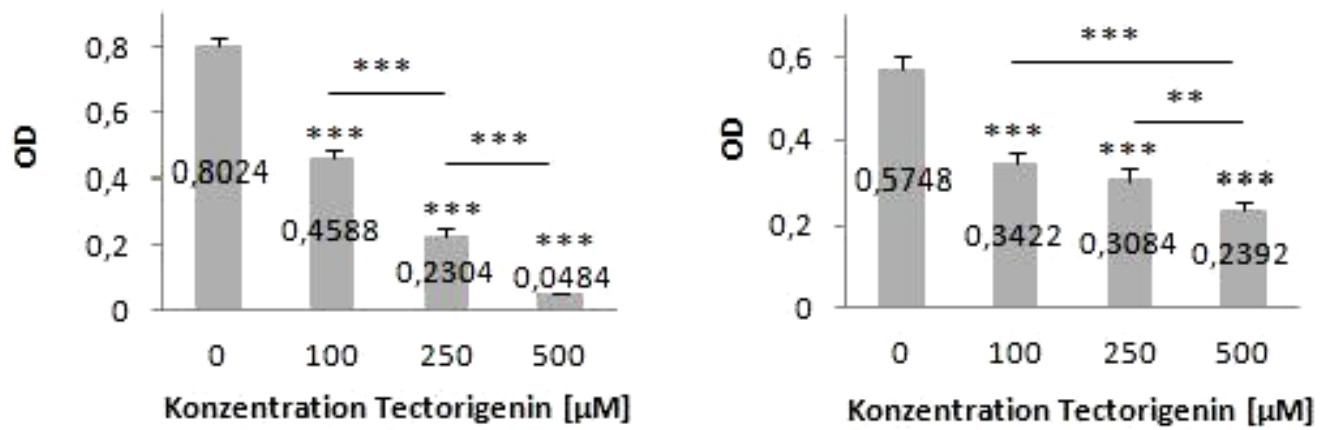

Abb. 3: Proliferation der TGCT-Zelllinien NTERA-2 und TCam-2 nach Stimulation mit Tectorigenin für 24 und $48 \mathrm{~h}$.

Zeit- und konzentrationsabhängige Proliferationsinhibition: (A) Die NTERA-2-Zellen zeigen nach $24 \mathrm{~h}$ Tectorigenin-Stimulation eine Proliferationsinhibition. (B) Nach $48 \mathrm{~h}$ ist in beiden Zelllinien die Proliferation gegenüber der Kontrolle $(0 \mu \mathrm{M})$ sowie gegenüber jeweils kleineren Konzentrationen statistisch signifikant gehemmt. OD = optische Dichte. 
Ergebnisse

A

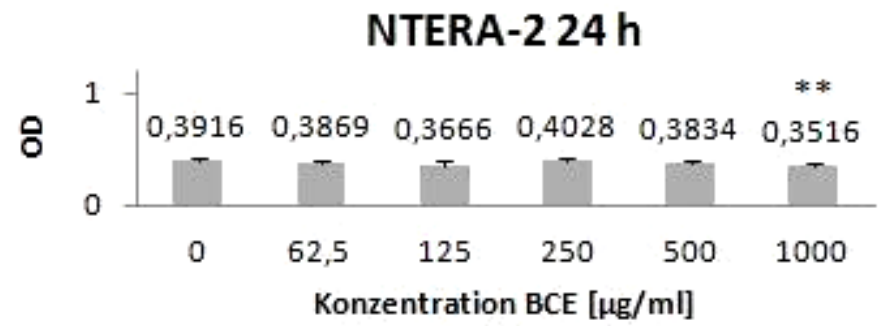

TCam-2 $24 \mathrm{~h}$

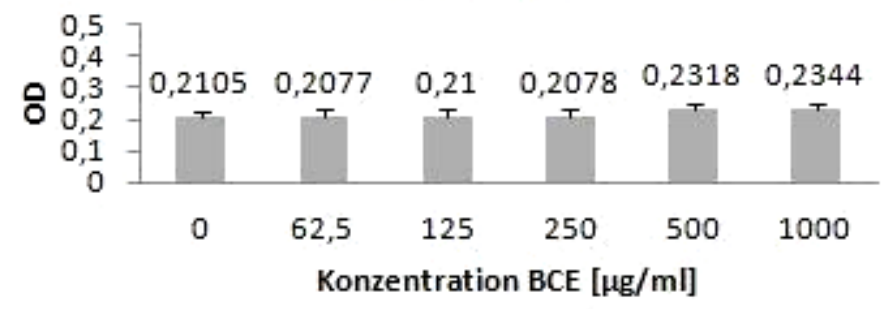

B

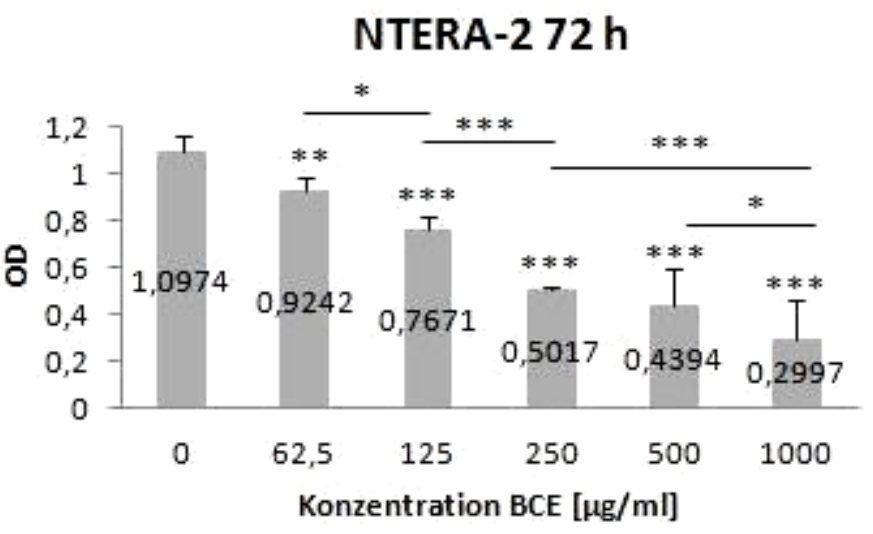

TCam-2 $72 \mathrm{~h}$

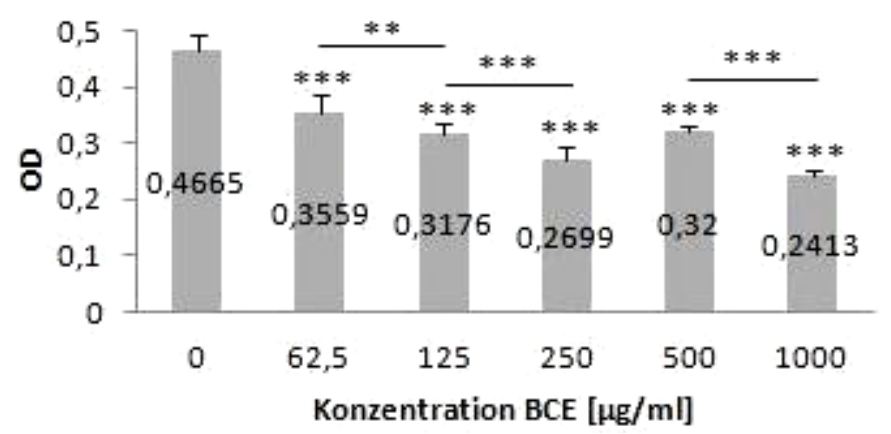

Abb. 4: Proliferation der TGCT-Zelllinien NTERA-2 und TCam-2 nach Stimulation mit BCE für 24 und $72 \mathrm{~h}$.

Zeit- und konzentrationsabhängige Proliferationsinhibition: (A) Die NTERA-2-Zellen zeigen nach 24 h BCE-Stimulation eine Proliferationsinhibition. (B) Nach 48 h ist in beiden Zelllinien die Proliferation gegenüber der Kontrolle $(0 \mu \mathrm{g} / \mathrm{ml})$ sowie gegenüber jeweils kleineren Konzentrationen statistisch signifikant gehemmt. $O D=$ optische Dichte. 
Ergebnisse

\subsection{2 mRNA-Expression der Stammzellgene}

Im Folgenden sind die Ergebnisse der Wirkung von Phytoöstrogenen auf die Expression der Stammzellgene NANOG, POU5F1 und SOX2 in NTERA-2- und TCam-2-Zellen dargestellt. In diesen Versuchen wurde ausschließlich mit dem Belamcanda-chinensis-Extrakt gearbeitet. Die TGCT-Zelllinien wurden über 24 und 72 Stunden stimuliert. Die Stichprobengröße betrug jeweils $n=3$.

\subsubsection{NANOG}

Nach BCE-Stimulation für 24 und 72 Stunden konnte in sämtlichen Proben der TGCTZelllinien NTERA-2 und TCam-2 eine gegenüber den unstimulierten Kontrollen signifikant verminderte mRNA-Expression von NANOG nachgewiesen werden, wobei die verminderte transkriptionelle Expression von NANOG in den TGCT-Zelllinien eine Konzentrationsabhängigkeit zeigte. Insgesamt war der inhibitorische Effekt von BCE auf die Expression von NANOG in beiden Zelllinien nach 24 Stunden größer als nach 72 Stunden (Abb. 5).

\subsubsection{POU5F1}

Nach BCE-Stimulation für 24 Stunden konnte in den TGCT-Zelllinien NTERA-2 und TCam-2 eine gegenüber den unstimulierten Kontrollen signifikant verminderte mRNAExpression von POU5F1 in sämtliche Proben nachgewiesen werden. Verglichen mit dem Transkriptionsfaktor NANOG zeigte die verminderte transkriptionelle Expression von POU5F1 in den TGCT-Zelllinien etwas weniger Tendenz zur Konzentrationsabhängigkeit. Insgesamt war der inhibitorische Effekt von BCE auf die Expression von POU5F1 in beiden Zelllinien nach 24 Stunden größer als nach 72 Stunden. Speziell in den TCam-2-Zellen konnte nach 72 Stunden keine statistisch signifikante Expressionsinhibition des Transkriptionsfaktors, verglichen mit der Kontrolle, festgestellt werden (Abb. 6).

\subsubsection{SOX2}

Nach BCE-Stimulation konnten in den TGCT-Zelllinien NTERA-2 und TCam-2 nach 24 Stunden keine signifikanten Veränderungen der mRNA-Expression von SOX2 nachgewiesen werden. Nach 72 Stunden Inkubationszeit war eine signifikante Induktion des Transkriptionsfaktor SOX2 ab Konzentrationen von $250 \mu \mathrm{g} / \mathrm{ml}$ BCE in der TCam-2-Zelllinie festzustellen. In der Nicht-Seminom-Zelllinie NTERA-2 konnte eine derartige Veränderung statistisch nicht bestätigt werden (Abb. 7). 
Ergebnisse

A

NANOG NTERA-2 $24 \mathrm{~h}$

NANOG TCam-2 $24 \mathrm{~h}$
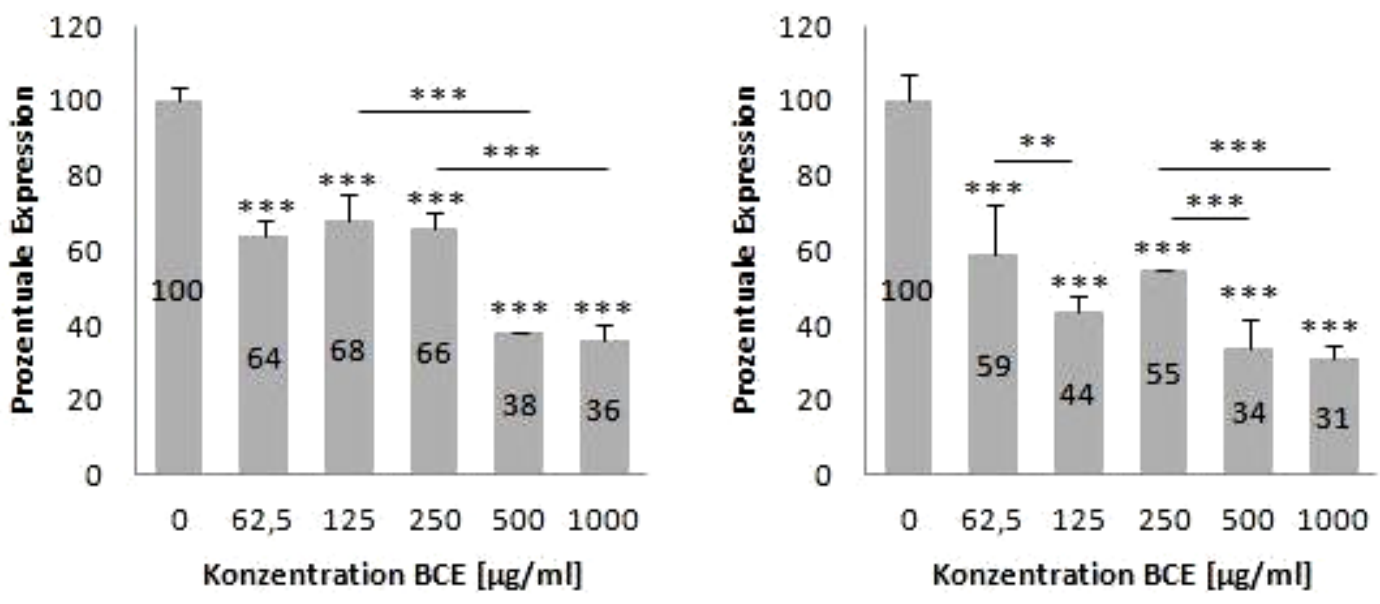

B

NANOG NTERA-2 $72 \mathrm{~h}$

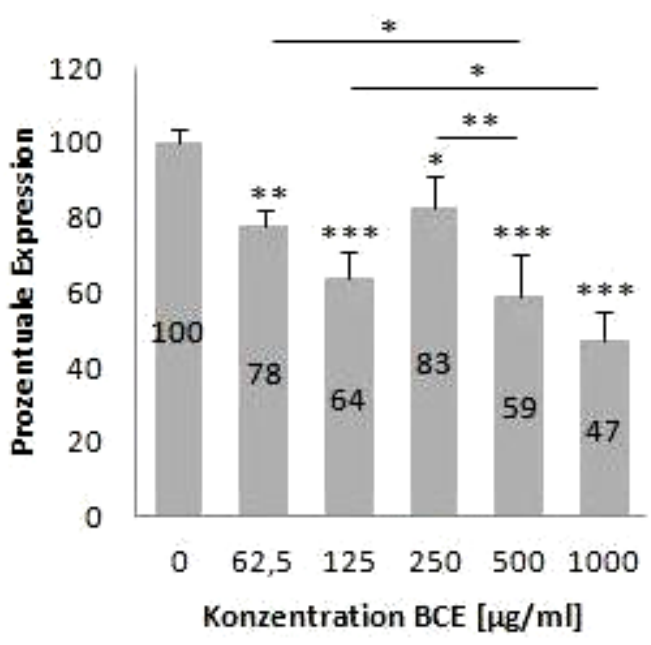

NANOG TCam-2 $72 \mathrm{~h}$

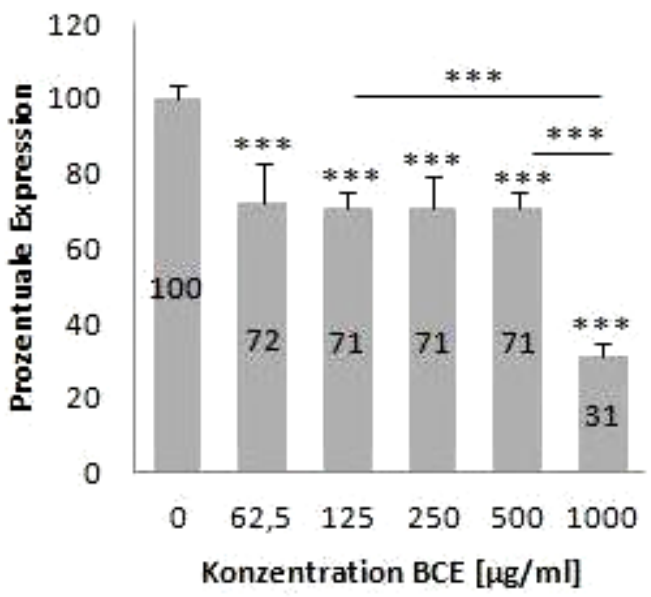

Abb. 5: mRNA-Expression von NANOG in NTERA-2- und TCam-2-Zellen nach Stimulation mit BCE für 24 und $72 \mathrm{~h}$.

Die TGCT-Zelllinien NTERA-2 und TCam-2 zeigen nach BCE-Stimulation eine verminderte mRNA-Expression von NANOG: (A) Nach 24 h ist der Transkriptionsfaktor in beiden Zelllinien konzentrationsabhängig vermindert exprimiert. (B) Der inhibitorische Effekt von BCE auf die Expression von NANOG ist in beiden Zelllinien gegenüber der Kontrolle $(0 \mu \mathrm{g} / \mathrm{ml})$ nach $72 \mathrm{~h}$ insgesamt etwas geringer als nach $24 \mathrm{~h}$, zeigt aber auch eine konzentrationsabhängige Tendenz. 
Ergebnisse

A

POU5F1 NTERA-2 $24 \mathrm{~h}$

POU5F1 TCam-2 $24 \mathrm{~h}$
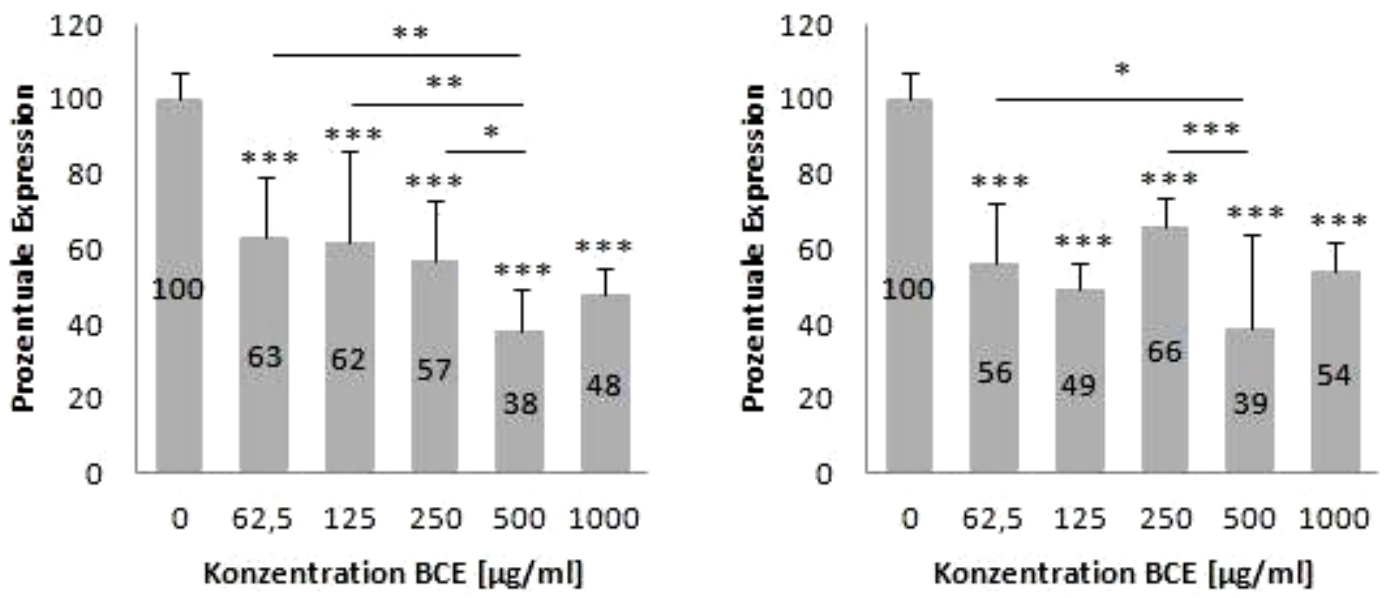

B

POU5F1 NTERA-2 $72 \mathrm{~h}$
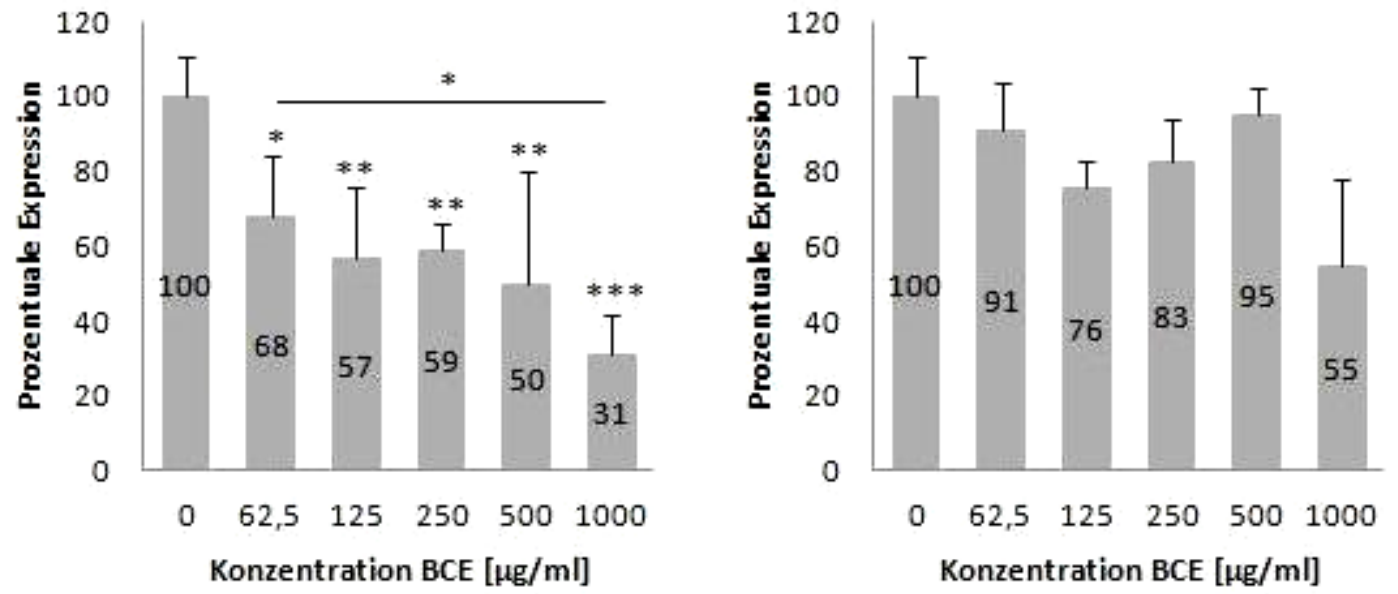

Abb. 6: mRNA-Expression von POU5F1 in NTERA-2- und TCam-2-Zellen nach Stimulation mit BCE für 24 und $72 \mathrm{~h}$.

Die TGCT-Zelllinien NTERA-2 und TCam-2 zeigen nach BCE-Stimulation eine verminderte mRNA-Expression von POU5F1: (A) Nach 24 h ist der Transkriptionsfaktor in beiden Zelllinien vermindert exprimiert. (B) Der inhibitorische Effekt von BCE auf die Expression von POU5F1 ist insgesamt gegenüber der Kontrolle $(0 \mu \mathrm{g} / \mathrm{ml})$ nach $72 \mathrm{~h}$, besonders in den TCam-2-Zellen geringer als nach $24 \mathrm{~h}$. 
Ergebnisse

A

SOX2 NTERA-2 $24 \mathrm{~h}$

SOX2 TCam-2 $24 \mathrm{~h}$
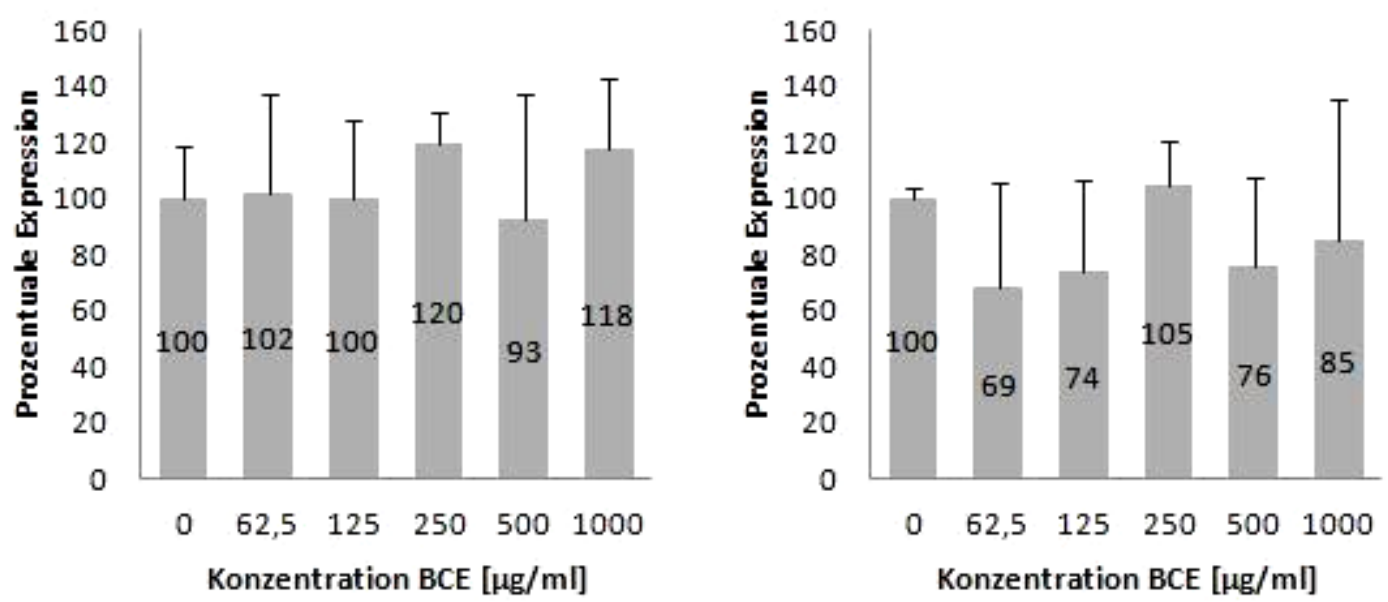

B

SOX2 NTERA-2 $72 \mathrm{~h}$

SOX2 TCam-2 $72 \mathrm{~h}$
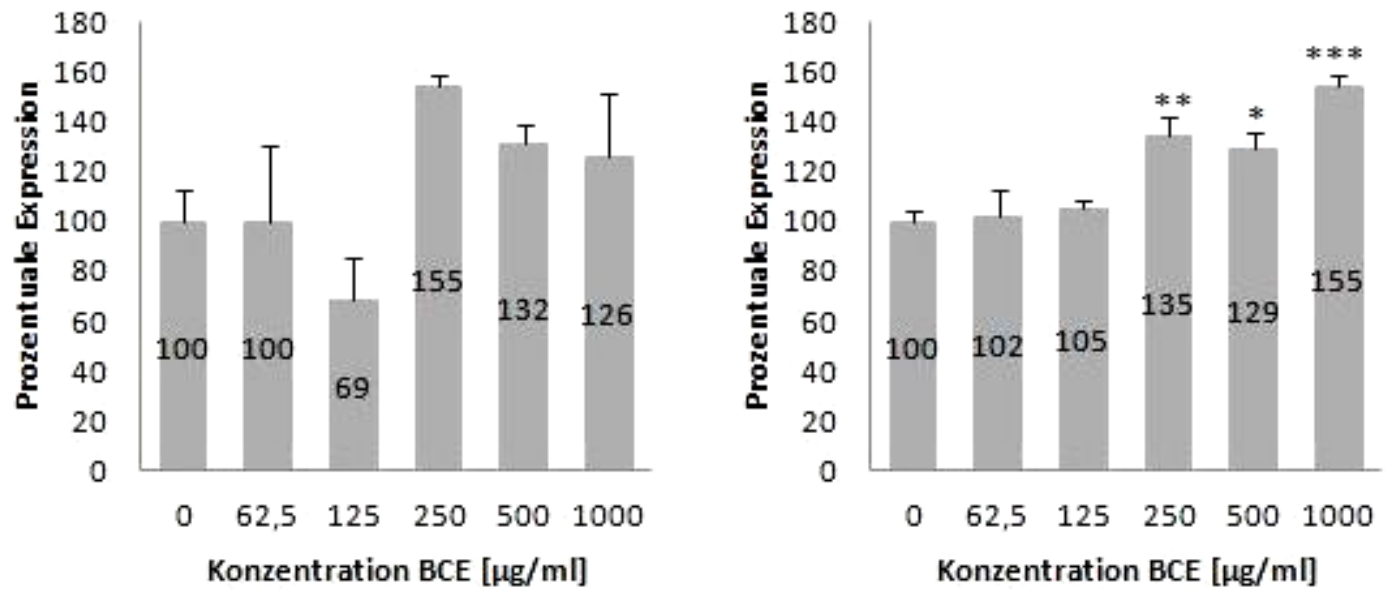

Abb. 7: mRNA-Expression von SOX2 in NTERA-2- und TCam-2-Zellen nach Stimulation mit BCE für 24 und $72 \mathrm{~h}$.

Die TGCT-Zelllinien NTERA-2 und TCam-2 zeigen nach BCE-Stimulation kaum Veränderungen der mRNA-Expression von SOX2: (A) Nach $24 \mathrm{~h}$ ist der Transkriptionsfaktor in beiden Zelllinien unverändert exprimiert. (B) Ein Effekt von BCE auf die Expression von SOX2 ist gegenüber der Kontrolle $(0 \mu \mathrm{g} / \mathrm{ml})$ nach $72 \mathrm{~h}$, besonders in den TCam-2-Zellen, als statistisch signifikante Überexpression feststellbar. 
Ergebnisse

\subsubsection{Proteinexpression der Stammzellgene}

Die transkriptionellen Veränderungen im Expressionsverhalten der Stammzellfaktoren NANOG, POU5F1 und SOX2 nach Stimulation der TGCT-Zelllinien NTERA-2 und TCam-2 mit Belamcanda-chinensis-Extrakt wurden durch Proteinanalysen mittels Western Blot erweitert. In diesen Versuchen wurden BCE-Konzentrationen von 500 und $1000 \mu \mathrm{g} / \mathrm{ml}$ eingesetzt.

In den NTERA-2-Zellen induzierte BCE eine zeit- und konzentrationsabhängige Inhibition des Transkriptionsfaktors POU5F1. Eine konzentrationsabhängige Herabregulation betrifft auch das NANOG-Protein nach 24 Stunden BCE-Stimulation, nach 72 Stunden zeigte sich die Expression relativ konstant. Der Stammzellfaktor SOX2 zeigte keine veränderte Expression nach Behandlung der Nicht-Seminom-Zelllinie mit BCE (Abb. 8A).

In den TCam-2-Zellen zeigten sowohl POU5F1 als auch NANOG eine zeit- und konzentrationsabhängige Expressionsinhibition. SOX2 war wie in der NTERA-2-Zelllinie nach 24 und 72 Stunden BCE-Stimulation unverändert exprimiert (Abb. 8B).

\subsubsection{Immunzytochemie}

Die in den Western-Blot-Analysen nachgewiesene Proteinexpression der Stammzellgene NANOG, POU5F1 und SOX2 wurde durch immunzytochemische Färbungen an Zytospins der TGCT-Zelllinien ergänzt. Hierzu wurden die TGCT-Zelllinien NTERA-2 und TCam-2 mit 100 und $500 \mu \mathrm{M}$ Tectorigenin über 24 Stunden stimuliert. Auf eine immunzytochemische Färbung der Zytospins nach 48 Stunden Stimulation wurde in diesem Zusammenhang verzichtet, da - wie auch im Proliferationsassay detektierbar - bei den genannten Konzentrationen Tectorigenin eine deutlich herabgesetzte Viabilität der Zellen beobachtet wurde.

Ebenso wie in den mRNA- und Western-Blot-Analysen unter Stimulation mit BCE konnte eine konzentrationsabhängig verminderte Expression der Stammzellfaktoren NANOG und POU5F1 in den untersuchten TGCT-Zelllinien gezeigt werden (Abb. 9).

Auf einen immunzytochemischen Nachweis von SOX2 wurde aufgrund eines nicht für diese Methode verfügbaren Antikörpers verzichtet. 
A

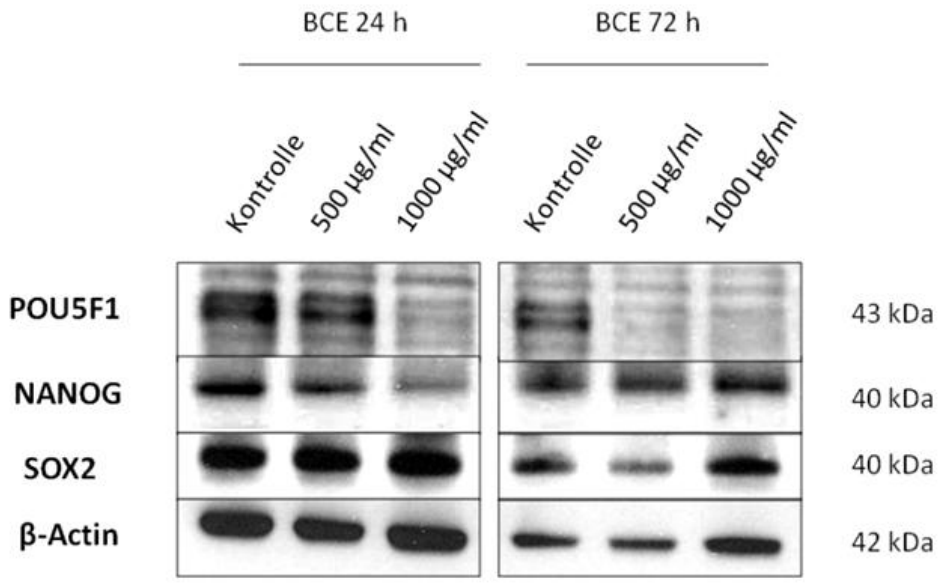

B

\section{TCam-2}

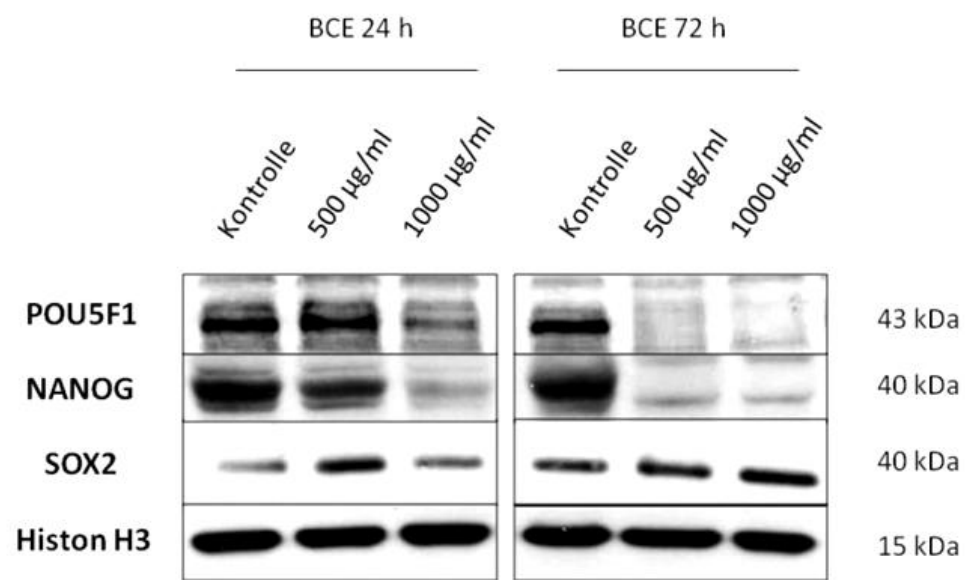

Abb. 8: Proteinexpression der Stammzellfaktoren in den TGCT-Zelllinien NTERA-2 und TCam-2 nach 24 und 72 h BCE-Stimulation.

(A) In den NTERA-2-Zellen wird POU5F1 konzentrations- und zeitabhängig inhibiert, NANOG wird nach 24 h konzentrationsabhängig reduziert exprimiert. Die SOX2-Expression ist unverändert. (B) In den TCam-2-Zellen werden POU5F1 und NANOG konzentrations- und zeitabhängig inhibiert, die SOX2-Expression ist unverändert.

ß-Actin und Histon H3 dienen als Housekeeping-Gen. Die als Kontrolle gekennzeichneten Proben sind unstimulierte Ansätze, die als Referenz dienen. Für die untersuchten Proteine ist das Molekulargewicht [kDa] angegeben. 
A

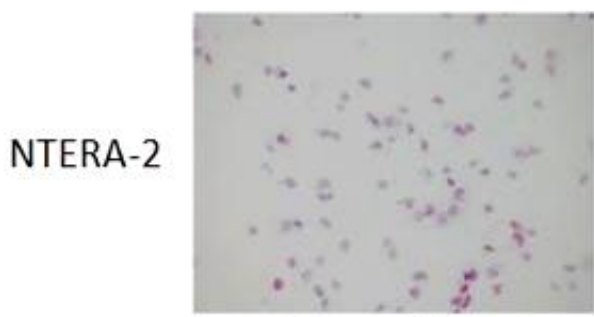

Kontrolle

TCam-2

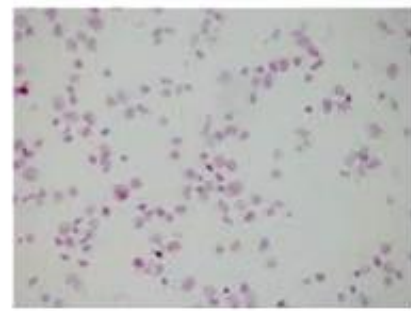

Kontrolle

B

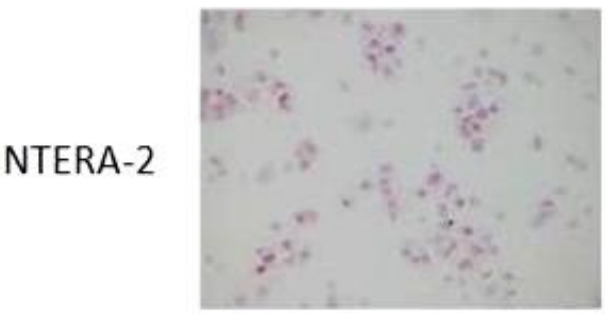

Kontrolle

TCam-2

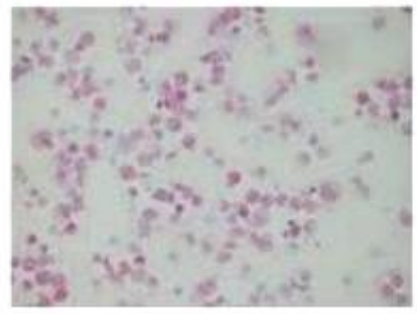

Kontrolle
NANOG

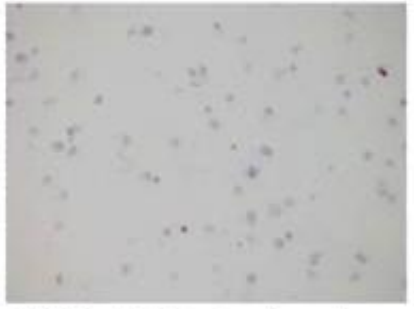

$100 \mu \mathrm{M}$ Tectorigenin

$500 \mu \mathrm{M}$ Tectorigenin

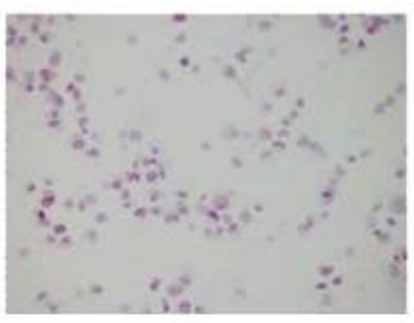

$100 \mu \mathrm{M}$ Tectorigenin

POU5F1

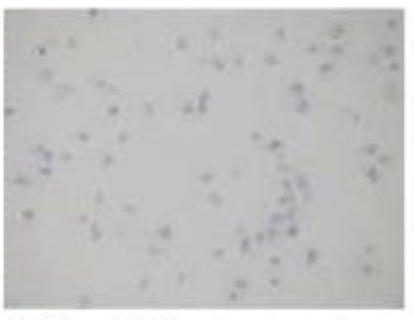

$100 \mu \mathrm{M}$ Tectorigenin

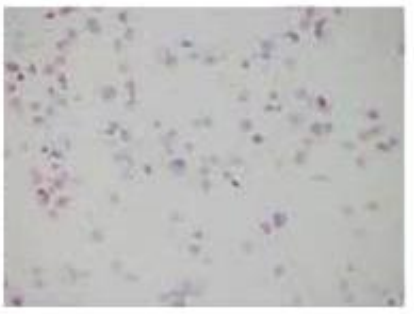

$100 \mu \mathrm{M}$ Tectorigenin
$500 \mu \mathrm{M}$ Tectorigenin
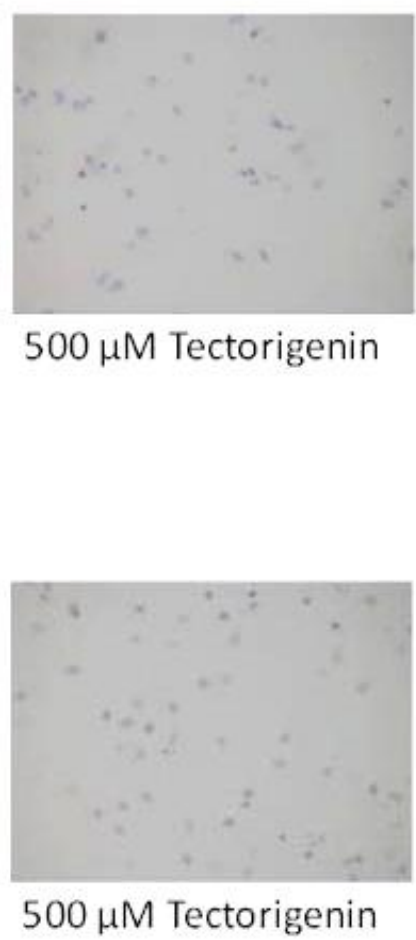

$500 \mu \mathrm{M}$ Tectorigenin

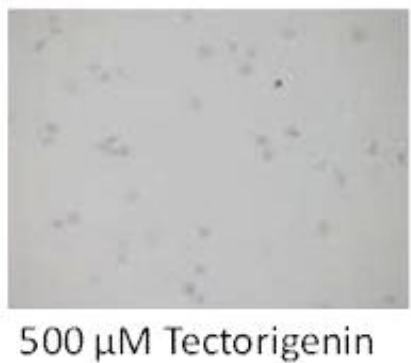

Abb. 9: Immunzytochemische Darstellung von NANOG und POU5F1 in TGCT-Zelllinien nach 24 h Tectorigenin-Stimulation.

(A) Neben einer reduzierten Anzahl viabler Zellen ist der Transkriptionsfaktor NANOG in beiden Zelllinien konzentrationsabhängig reprimiert. (B) Auch der Transkriptionsfaktor POU5F1 zeigt mit zunehmender Konzentration von Tectorigenin eine deutlich verminderte Expression in NTERA-2- und TCam-2-Zellen.

Die Transkriptionsfaktoren sind jeweils pink angefärbt. Die Zellkerne sind durch Hämatoxylin blau sichtbar gemacht. Die Fotografien wurden bei 200-facher Vergrößerung erstellt. 
Ergebnisse

\subsubsection{Genexpressionsanalyse}

Für die Probengewinnung im Rahmen der Genexpressionsanalyse mit Hilfe der MikroarrayTechnik wurden die NTERA-2- und TCam-2-Zellen mit $1000 \mu \mathrm{g} / \mathrm{ml}$ BCE für 72 Stunden stimuliert. Die differentiell regulierten Gene wurden im Vergleich zu DMSO-Kontrollen ermittelt. Die Stichprobengröße betrug $n=3$.

Es zeigte sich eine Vielzahl von induzierten und inhibierten Genen. Als differentiell reguliert wurden jedoch nur die Gene angesehen, welche mindestens einen 2-fachen Expressionsunterschied verglichen mit der Kontrolle aufwiesen. Eine erhöhte Expression von 33 bzw. 230 Genen war in den NTERA-2- bzw. TCam-2-Zellen nachweisbar. Von einer Expressionsinhibition waren in der NTERA-2-Zelllinie 164 Gene und in der TCam-2-Zelllinie 185 betroffen (Abb. 10).

\section{NTERA-2}

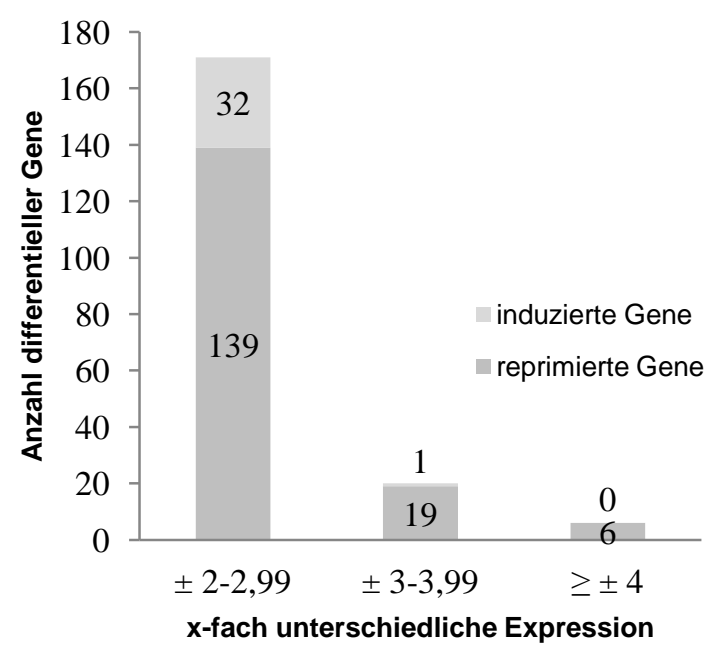

TCam-2

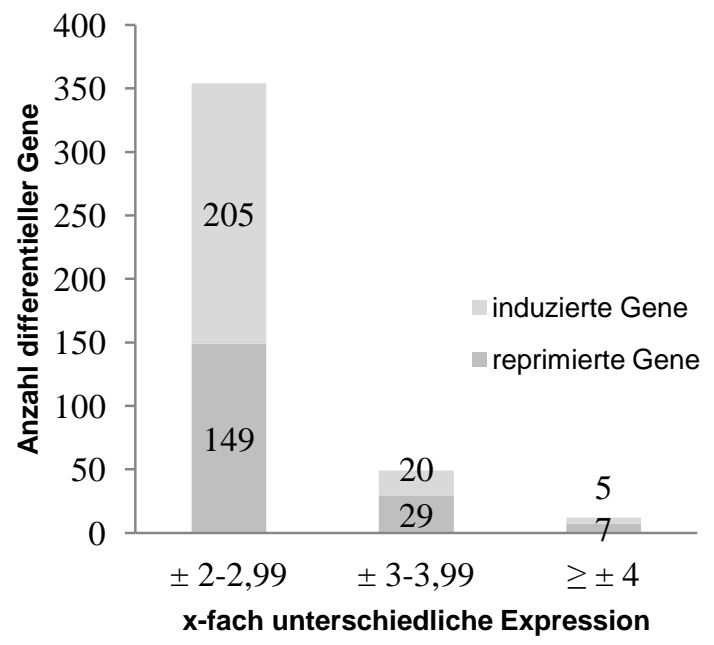

Abb. 10: Mikroarray-Expressionsanalyse in TGCT-Zelllinien nach BCE-Stimulation. Nach Stimulation der TGCT-Zelllinien NTERA-2 und TCam-2 mit $1000 \mu \mathrm{g} / \mathrm{ml}$ BCE für $72 \mathrm{~h}$ wurden in NTERA-2-Zellen 33 und in den TCam-2-Zellen 230 Gene induziert. Im Gegensatz dazu kam es zu einer Expressionsinhibition von 164 bzw. 185 Genen in der NTERA-2- bzw. TCam-2-Zelllinie. Dargestellt sind ausschließlich $\geq 2$-fach differentiell regulierte Gene.

In diesem Versuch konnte außerdem die zuvor beobachtete Wirkung von BCE auf die Stammzellsignatur der NTERA-2- und TCam-2-Zellen bestätigt werden, da NANOG und POU5F1 unter den inhibierten Genen zu finden waren (NANOG: -1,54 bzw. -2,81-fach und POU5F1: -1,92 bzw. -1,09-fach). SOX2 scheint induziert zu sein, allerdings in sehr geringem Ausmaß (0,13 bzw. 0,34) (Abb. 11). 
Ergebnisse

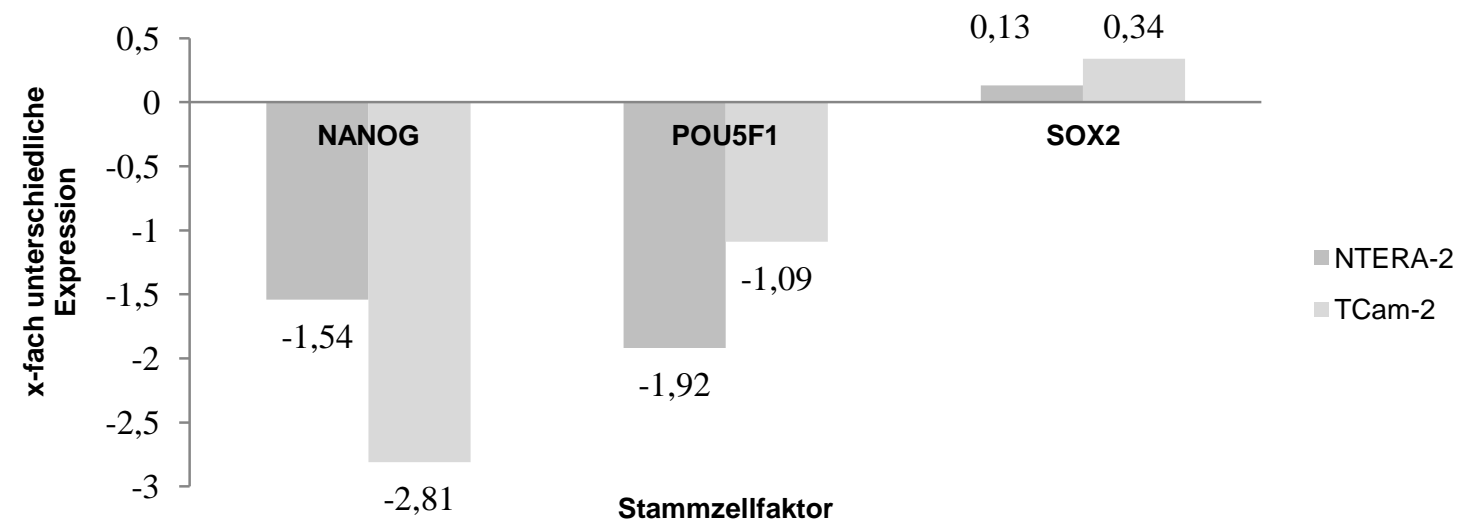

Abb. 11: Mikroarray-Expressionsanalyse der Stammzellsignatur in TGCT-Zelllinien nach BCEStimulation.

Nach Stimulation der TGCT-Zelllinien NTERA-2 und TCam-2 mit $1000 \mu \mathrm{g} / \mathrm{ml}$ BCE für $72 \mathrm{~h}$ zeigte sich in NTERA-2- und TCam-2-Zellen eine verminderte Expression von NANOG und POU5F1 bei weitgehend konstanter Expression von SOX2.

Des Weiteren wurde untersucht, welche Differenzierungsgene in den TGCT-Zelllinien eine differentielle Genexpression nach BCE-Stimulation erfahren. Nach Gruppierung der Gene mit Hilfe des Programms DAVID, wurden wieder ausschließlich mindestens 2-fach über- oder unterexprimierte Gene als differentiell reguliert gewertet.

Für die TCam-2-Zellen zeigte sich in der Analyse, dass 36 Gene von einer mehr als 2-fach veränderten Expression betroffen waren, 21 davon waren reprimiert und 15 induziert (Tabelle 8). Für NTERA-2 waren es 17 Gene, davon 2 induziert und 15 reprimiert (Tabelle 9). 
Ergebnisse

Tabelle 8: Differentielle Expression von Differenzierungsgenen in TCam-2-Zellen nach BCEStimulation.

Die TGCT-Zellen wurden mit $1000 \mu \mathrm{g} / \mathrm{ml} \mathrm{BCE}$ für $72 \mathrm{~h}$ stimuliert. Die Tabelle enthält alle mehr als 2-fach differentiell exprimierten Differenzierungsgene aus dem Mikroarray. Für jedes Gen sind Name (Symbol), Beschreibung und die differentielle Expression (stimuliert vs. unstimuliert) angegeben. Dabei stehen positive Werte für eine Induktion in den stimulierten Proben, während negative Werte eine Repression kennzeichnen.

\begin{tabular}{|c|c|c|}
\hline Symbol & Beschreibung & $\begin{array}{c}\text { stimuliert } \\
\text { vS. } \\
\text { unstimuliert }\end{array}$ \\
\hline TDGF1 & teratocarcinoma-derived growth factor 1 & $-3,64498427$ \\
\hline GDF3 & growth differentiation factor 3 & $-3,30046962$ \\
\hline AICDA & activation-induced cytidine deaminase & $-3,06946142$ \\
\hline MAL2 & mal, T-cell differentiation protein 2 & $-2,94317608$ \\
\hline NANOG & Nanog homeobox & $-2,80801492$ \\
\hline CALCA & calcitonin-related polypeptide alpha & $-2,79270140$ \\
\hline SFRP2 & secreted frizzled-related protein 2 & $-2,74250874$ \\
\hline GDF15 & growth differentiation factor 15 & $-2,71933667$ \\
\hline SLC7A5 & solute carrier family 7, member 5 & $-2,40901474$ \\
\hline AKT1 & $\mathrm{v}$-akt murine thymoma viral oncogene homolog 1 & $-2,40140303$ \\
\hline TNP1 & transition protein 1 & $-2,32945047$ \\
\hline DIAPH2 & diaphanous homolog 2 & $-2,30056293$ \\
\hline ANGPTL4 & angiopoietin-like 4 & $-2,22365909$ \\
\hline PLP1 & proteolipid protein 1 & $-2,19402246$ \\
\hline EGFL6 & EGF-like-domain, multiple 6 & $-2,07811749$ \\
\hline IRX3 & iroquois homeobox 3 & 2,00809989 \\
\hline SOX3 & SRY(sex determining region Y)-box 3 & 2,02243437 \\
\hline EGR2 & early growth response 2 & 2,02544860 \\
\hline TFAP2C & transcription factor AP-2 gamma & 2,06704718 \\
\hline МYH9 & myosin, heavy chain 9 , non-muscle & 2,08986129 \\
\hline MAFB & v-maf musculoaponeurotic fibrosarcoma oncogene homolog B & 2,16265907 \\
\hline DHRS2 & dehydrogenase/reductase (SDR family) member 2 & 2,17320630 \\
\hline NEUROG3 & neurogenin 3 & 2,18466194 \\
\hline HAND1 & heart and neural crest derivatives expressed 1 & 2,22679298 \\
\hline GADD45B & growth arrest and DNA-damage-inducible, beta & 2,23350339 \\
\hline FOXC1 & forkhead box $\mathrm{C} 1$ & 2,23534918 \\
\hline JAG1 & jagged 1 & 2,29704928 \\
\hline ID3 & $\begin{array}{l}\text { inhibitor of DNA binding } 3 \text {, dominant negative helix-loop- } \\
\text { helix protein }\end{array}$ & 2,32132095 \\
\hline AXIN2 & axin 2 & 2,33187150 \\
\hline SEMA4D & sema domain (semaphorin) 4D & 2,44474977 \\
\hline NEUROG2 & neurogenin 2 & 2,50755566 \\
\hline ZIC2 & Zic family member 2 & 2,60007737 \\
\hline HES1 & hairy and enhancer of split 1 & 2,61040586 \\
\hline NEUROG1 & neurogenin 1 & 2,66822134 \\
\hline TOB1 & transducer of ERBB2, 1 & 2,98182169 \\
\hline CTNNB1 & catenin (cadherin-associated protein), beta 1 & 3,17212460 \\
\hline
\end{tabular}


Ergebnisse

Tabelle 9: Differentielle Expression von Differenzierungsgenen in NTERA-2-Zellen nach BCEStimulation.

Die TGCT-Zellen wurden mit $1000 \mu \mathrm{g} / \mathrm{ml}$ BCE für $72 \mathrm{~h}$ stimuliert. Die Tabelle enthält alle mehr als 2-fach differentiell exprimierten Differenzierungsgene aus dem Mikroarray. Für jedes Gen sind Name (Symbol), Beschreibung und die differentielle Expression (stimuliert vs. unstimuliert) angegeben. Dabei stehen positive Werte für eine Induktion in den stimulierten Proben, während negative Werte eine Repression kennzeichnen.

\begin{tabular}{llr}
\hline Symbol & Beschreibung & $\begin{array}{c}\text { stimuliert } \\
\text { vs. } \\
\text { unstimuliert }\end{array}$ \\
\hline PLA2GA & phospholipase A2, group IIA & $-4,50524574$ \\
DAZL & deleted in azoospermia-like & $-4,24188732$ \\
GDF3 & growth differentiation factor 3 & $-4,05681564$ \\
GPNMB & glycoprotein (transmembrane) nmb & $-3,53842977$ \\
DAZ2 & deleted in azoospermia 2 & $-3,09757669$ \\
\hline CALCA & calcitonin-related polypeptide alpha & $-3,08562471$ \\
GDF15 & growth differentiation factor 15 & $-2,94113312$ \\
TDGF1 & teratocarcinoma-derived growth factor 1 & $-2,66779679$ \\
GLI1 & GLI family zinc finger 1 & $-2,64231869$ \\
DMRTB1 & DMRT-like family B with proline-rich C-terminal, 1 & $-2,48681816$ \\
ASCL2 & achaete-scute complex homolog 2 & $-2,36505642$ \\
AICDA & activation-induced cytidine deaminase & $-2,29749784$ \\
LPL & lipoprotein lipase & $-2,17198906$ \\
THRB & thyroid hormone receptor, beta & $-2,07564477$ \\
EGFL6 & EGF-like-domain, multiple 6 & $-2,06340066$ \\
HAND1 & heart and neural crest derivatives expressed 1 & 2,58323485 \\
HMX2 & H6 family homeobox 2 & 2,65700884 \\
\hline
\end{tabular}

\subsection{BCE: Vergleich von TGCT- und Prostatakrebszellen im Stimulati- onsversuch}

In diesen Experimenten wurde untersucht, ob die BCE-Stimulation in den TGCT-Zelllinien NTERA-2 und TCam-2 eine Wirkung auf die Expression von Hormonrezeptoren und nachgeschaltete Signalwege, die für die Prostatakarzinomzelllinie LNCaP beschrieben ist, hat. Ferner sollte die Stammzellsignatur in der Prostatakarzinomzelllinie LNCaP unter Stimulation mit BCE untersucht werden.

\subsection{1 mRNA-Expression}

Die TGCT-Zelllinien NTERA-2 und TCam-2 wurden nach BCE-Stimulation (Stimulation wie in Abschnitt 3.1.2) mit freundlicher Unterstützung von PD Dr. Thelen (Abteilung Urologie, Universitätsmedizin Göttingen) mittels PCR-Analysen auf Hormonrezeptoren und ihren Expressionsstatus untersucht. Die Zielstrukturen AR, IGF1R, IGFBP3 und ER- $\beta$ zeigten jedoch keine schlüssige Regulation beziehungsweise konnten vereinzelt nicht detektiert werden. Aus diesen Gründen erfolgte keine weitere Analyse dieser Gene. 
Ergebnisse

Des Weiteren wurde die Stammzellsignatur mit den Genen NANOG, POU5F1 und SOX2 in der Prostatakarzinomzelllinie LNCaP nach BCE-Stimulation untersucht.

Ab Stimulationskonzentrationen von $250 \mu \mathrm{g} / \mathrm{ml}$ BCE zeigte sich nach 24 Stunden Stimulation eine signifikante Expressionsinduktion der Stammzellfaktoren. Nach 72 Stunden sind für alle drei untersuchten Gene kaum signifikante Veränderungen in der mRNA-Expression festzustellen (Abb. 13). Die Stichprobengröße betrug jeweils $n=3$.

\subsubsection{Proteinexpression der Stammzellgene}

Das Expressionsverhalten der Stammzellfaktoren NANOG, POU5F1 und SOX2 nach Stimulation der Prostatakrebszelllinie LNCaP mit Belamcanda-chinensis-Extrakt wurden durch Proteinanalysen mittels Western Blot erweitert. In diesen Versuchen wurden BCEKonzentrationen von 500 und $1000 \mu \mathrm{g} / \mathrm{ml}$ eingesetzt und die Zellen wurden über 24 und 72 Stunden stimuliert.

Im Gegensatz zur mRNA-Analyse ist im Western-Blot-Versuch für die Stammzellfaktoren NANOG und POU5F1 eine Expressionsabnahme zu beobachten, die zeit- und konzentrationsabhängig war. SOX2 konnte auf Proteinebene mittels Western Blot in den LNCaP-Zellen nicht detektiert werden (Abb. 12).

\section{LNCaP}

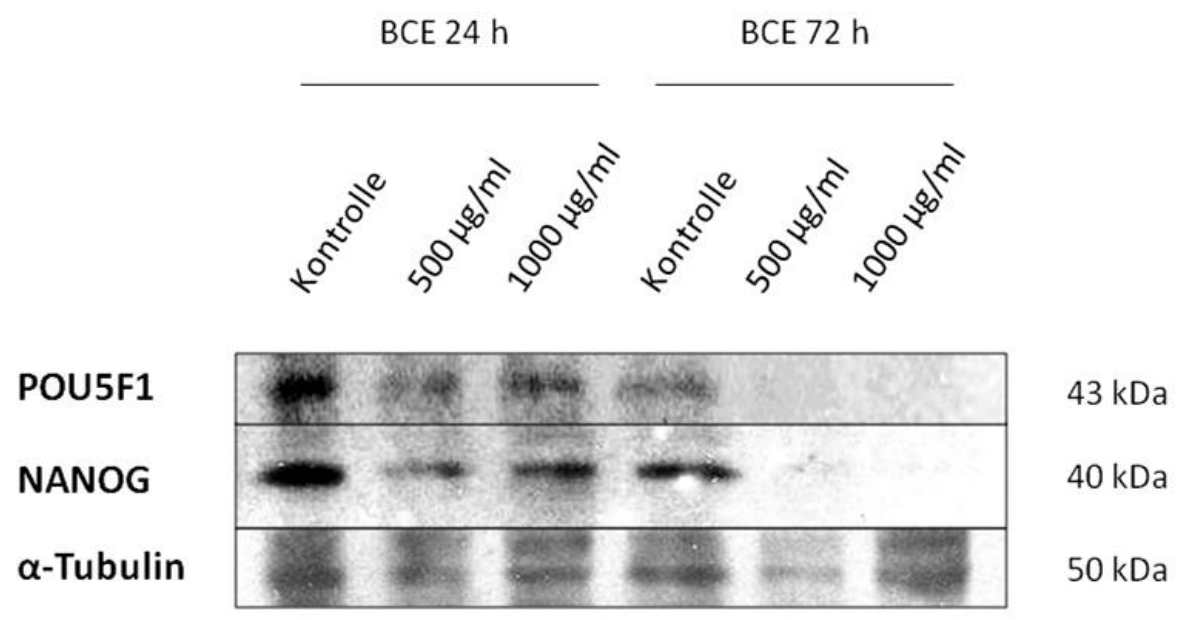

Abb. 12: Proteinexpression der Stammzellfaktoren in der Prostatakrebszellinie LNCaP nach 24 und $72 \mathrm{~h}$ BCE-Stimulation.

Die Stammzellfaktoren POU5F1 und NANOG werden zeit- und konzentrationsabhängig inhibiert.

$\alpha$-Tubulin dient als Housekeeping-Gen. Die als Kontrolle gekennzeichneten Proben sind unstimulierte Ansätze, die als Referenz dienen. Für die untersuchten Proteine ist das Molekulargewicht [kDa] angegeben. 
Ergebnisse

A

NANOG LNCaP $24 \mathrm{~h}$

NANOG LNCaP 72 h
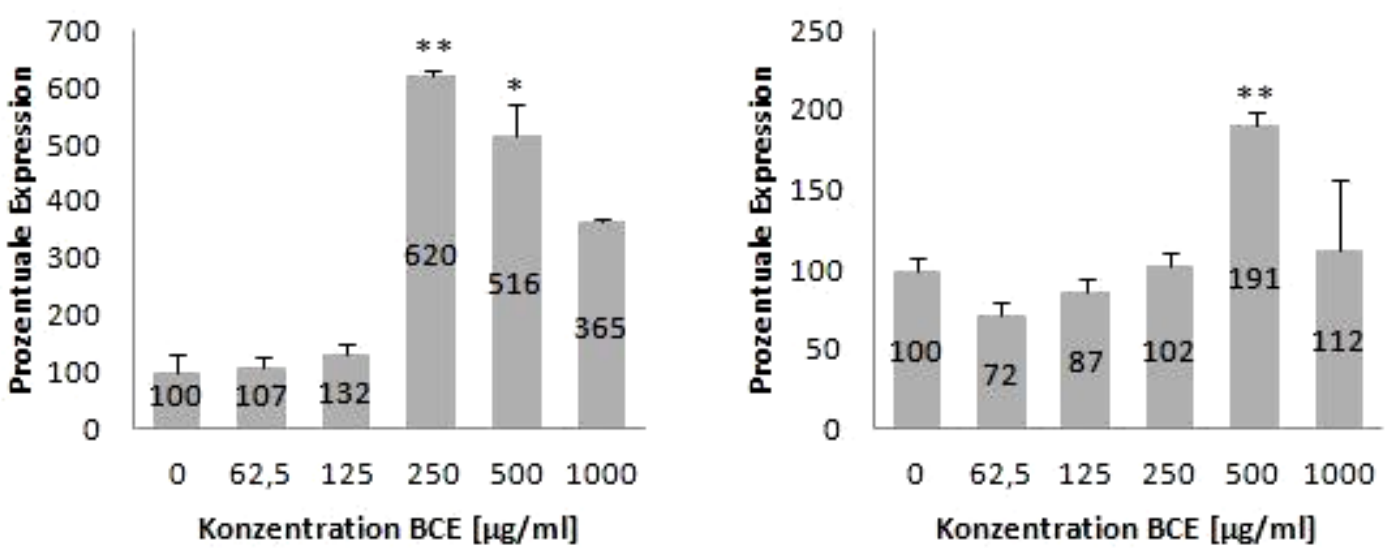

B

POU5F1 LNCaP $24 \mathrm{~h}$

POU5F1 LNCaP $72 \mathrm{~h}$
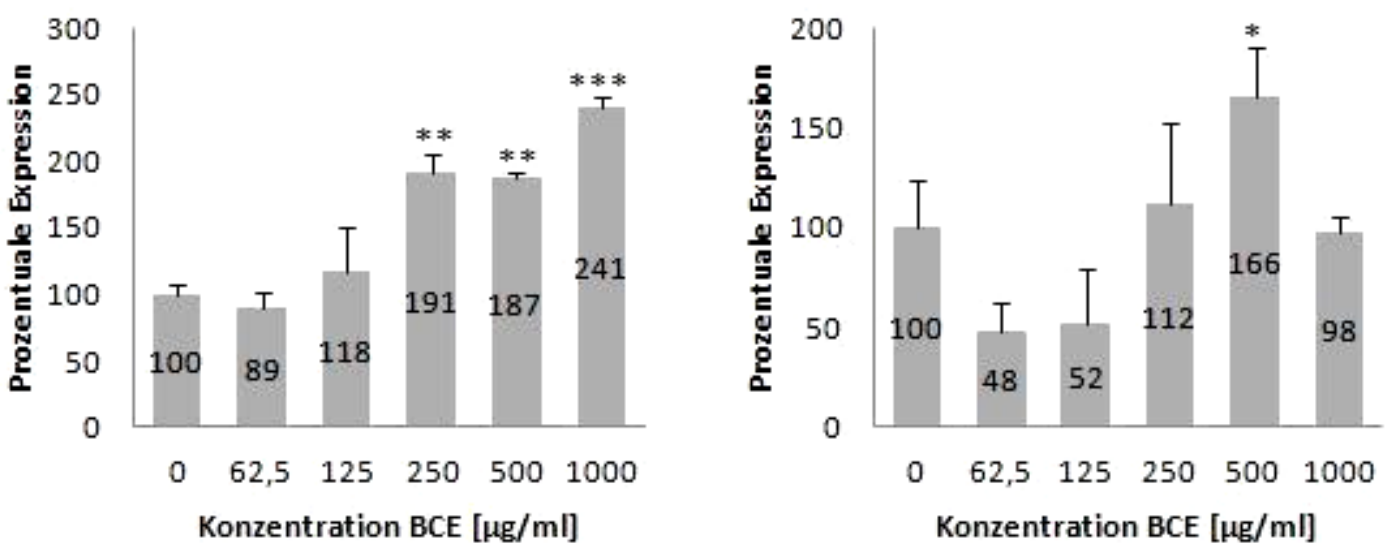

C

SOX2 LNCaP $24 \mathrm{~h}$

SOX2 LNCaP 72 h
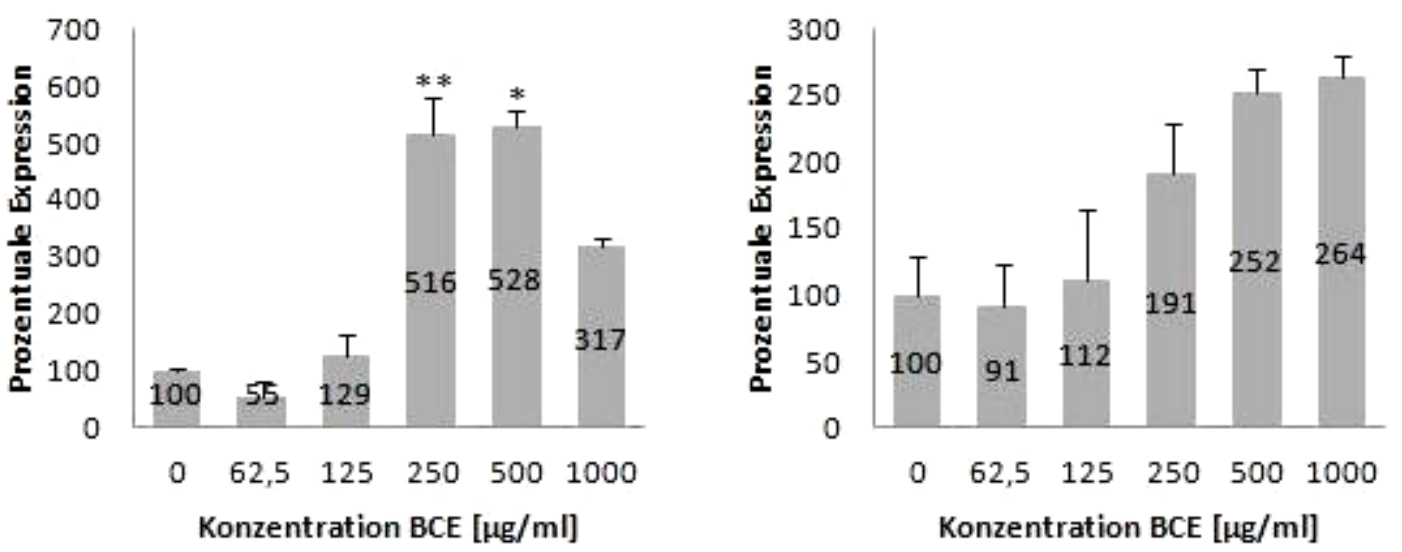

Abb. 13: mRNA-Expression der Stammzellfaktoren in LNCaP-Zellen nach Stimulation mit BCE für 24 und $72 \mathrm{~h}$.

Die Prostatakarzinom-Zelllinie LNCaP zeigt nach BCE-Stimulation einzelne Induktionen der mRNA-Expression der Stammzellfaktoren (A) NANOG, (B) POU5F1 und (C) SOX2 gegenüber der Kontrolle $(0 \mu \mathrm{g} / \mathrm{ml})$, nach $24 \mathrm{~h}>72 \mathrm{~h}$. 
Ergebnisse

\subsection{Effekte von BCE und HDAC-Inhibitoren im Vergleich}

In den folgenden Versuchen wurde der Effekt von BCE auf die Hyperacetylierung von Histonen in NTERA-2- und TCam-2-Zellen untersucht. Dabei kamen die HDAC-Inhibitoren (HDACi) Trichostatin A (TSA) und Valproat (VPA) als Positivkontrollen zum Einsatz. Es wurden Konzentrationen von $500 \mathrm{nM}$ TSA und $50 \mu \mathrm{M}$ VPA verwendet und eine Inkubationszeit von 24 Stunden gewählt.

\subsection{1 mRNA-Expression der Stammzellgene}

Da der Mechanismus der Hyperacetylierung nur auf Proteinebene detektierbar ist, diente die mRNA-Analyse lediglich der Verifizierung bereits bekannter Ergebnisse, der Depletion der Stammzellfaktoren durch HDACi.

Wie erwartet zeigte sich, sowohl unter Valproat- als auch unter Trichostatin-A-Stimulation, eine deutliche Expressionsinhibition von NANOG, POU5F1 und SOX2 (Abb. 14). Die Stichprobengröße betrug jeweils $n=3$.

\subsubsection{Proteinexpression der Stammzellgene}

Mit den nachfolgenden Western-Blot-Analysen sollten zum einen die mRNA-Analysen auf Proteinebene verifiziert werden und zum anderen die Wirkung der HDACi Trichostatin A und Valproat sowie die von BCE auf die Hyperacetylierung von Histonproteinen untersucht und miteinander verglichen werden. Dazu wurde im folgenden Versuch die acetylierte Form des Histonproteins $\mathrm{H} 4$ untersucht.

Die Experimente zeigten, dass NANOG und POU5F1 nach BCE-Stimulation, als auch nach HDAC-Inhibition durch TSA und VPA, eine deutliche Herunterregulation erfahren. SOX2 allerdings, welches unter Phytoöstrogen-Behandlung keine derartige Veränderung erfährt, war dagegen im Vergleich zur unstimulierten Kontrolle unter TSA- und Valproat-Behandlung in deutlich geringerem Ausmaß detektierbar. Bei den Untersuchungen der Proben auf hyperacetyliertes Histon H4 konnte dieses in den mit BCE behandelten Proben nicht nachgewiesen werden. In den mit HDAC-Inhibitoren stimulierten Zellen, die gleichzeitig als Positivkontrolle dienten, konnten die bekannte Wirkung auf eine Hemmung der Histon-Deacetylase jedoch reproduziert werden.

Um die Gemeinsamkeiten und Unterschiede von BCE und HDACi deutlich zu machen, sind die Western-Blot-Resultate hier zusammen mit denen aus den BCE-Stimulationsversuchen nach 24-stündiger Stimulation dargestellt (Abb. 15). 
Ergebnisse

A

NANOG NTERA-2

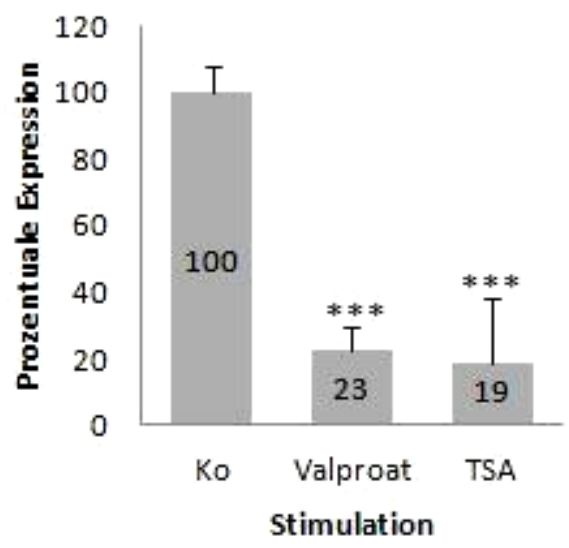

B

POU5F1 NTERA-2

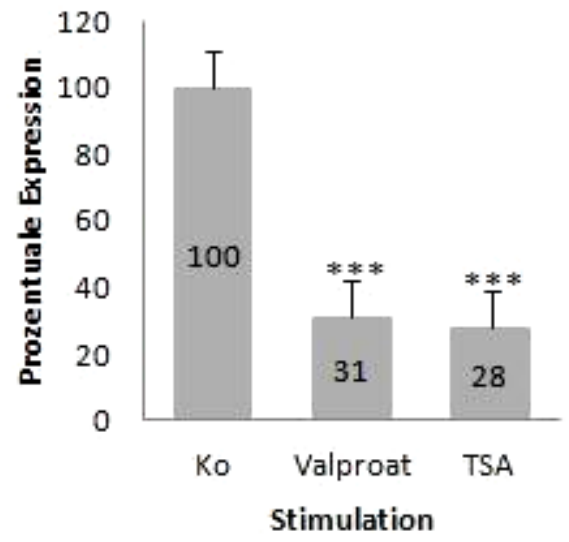

C
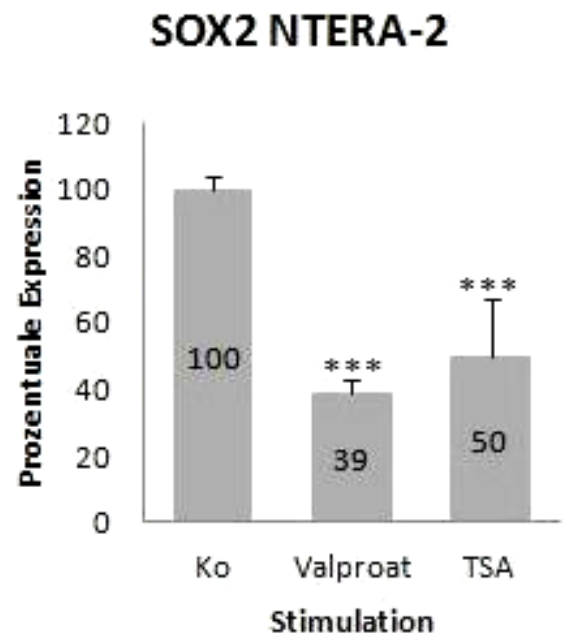

NANOG TCam-2

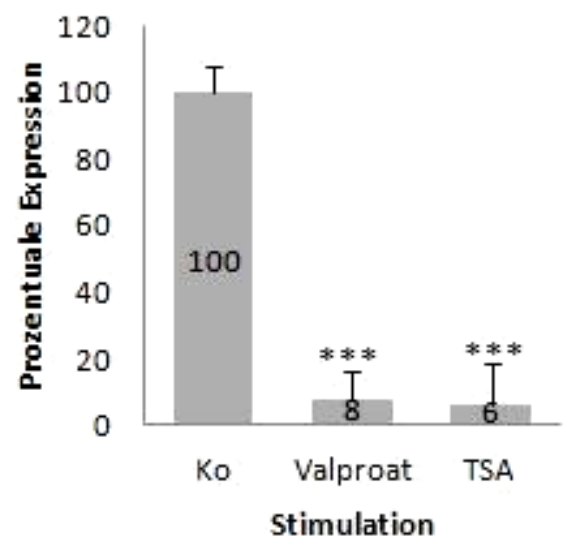

POU5F1 TCam-2

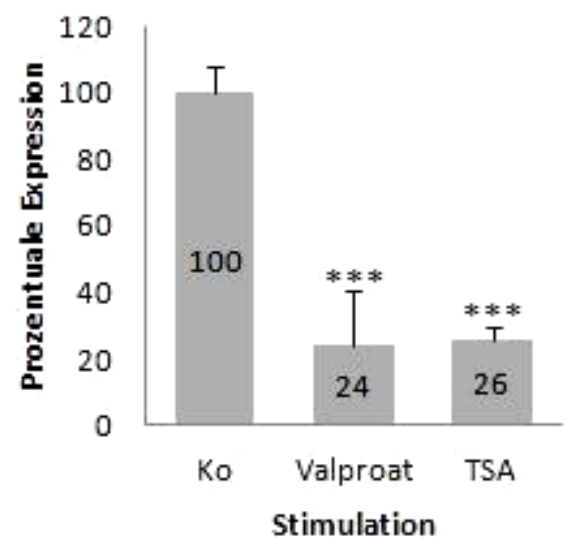

SOX2 TCam-2

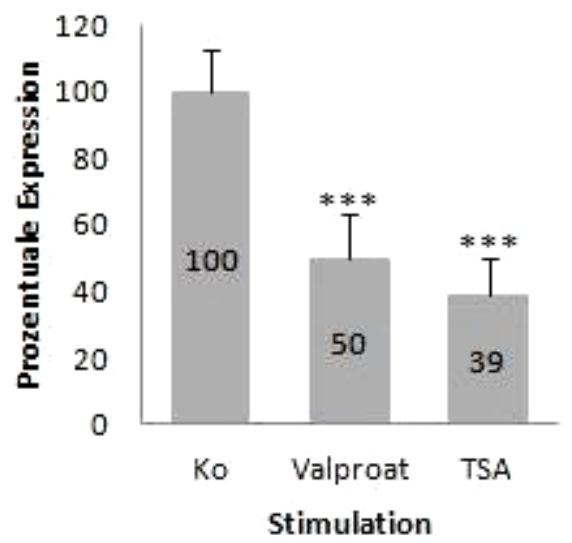

Abb. 14: mRNA-Expression der Stammzellfaktoren in TGCT-Zelllinien nach Stimulation mit HDAC-Inhibitoren für $24 \mathrm{~h}$.

Die TGCT-Zelllinien NTERA-2 und TCam-2 zeigen nach HDACi-Stimulation mit Trichostatin A (TSA) und Valproat eine verminderte mRNA-Expression von allen drei Stammzellfaktoren (A) NANOG, (B) POU5F1 und (C) SOX2. 
A

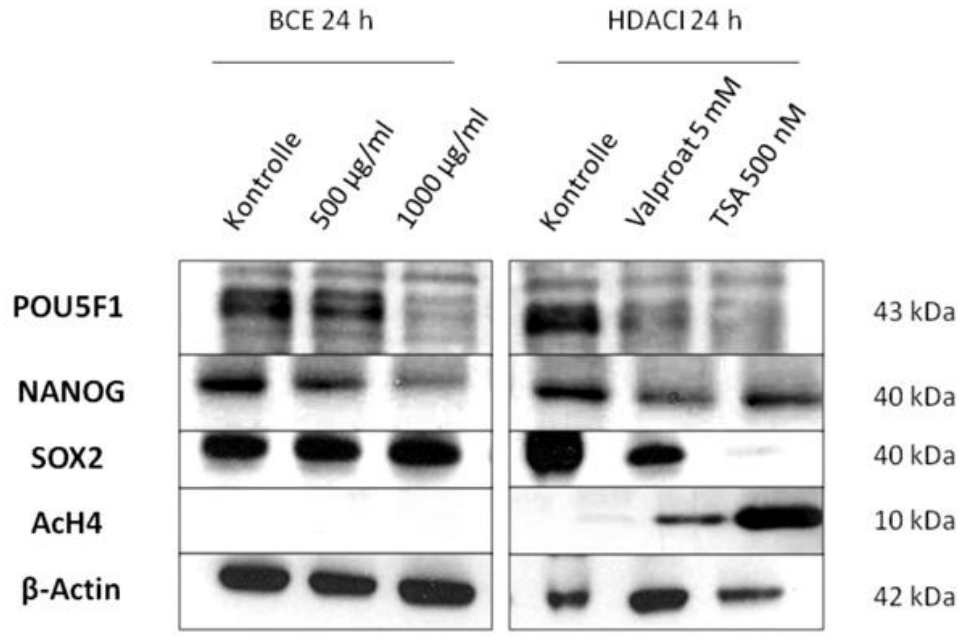

B

\section{TCam-2}

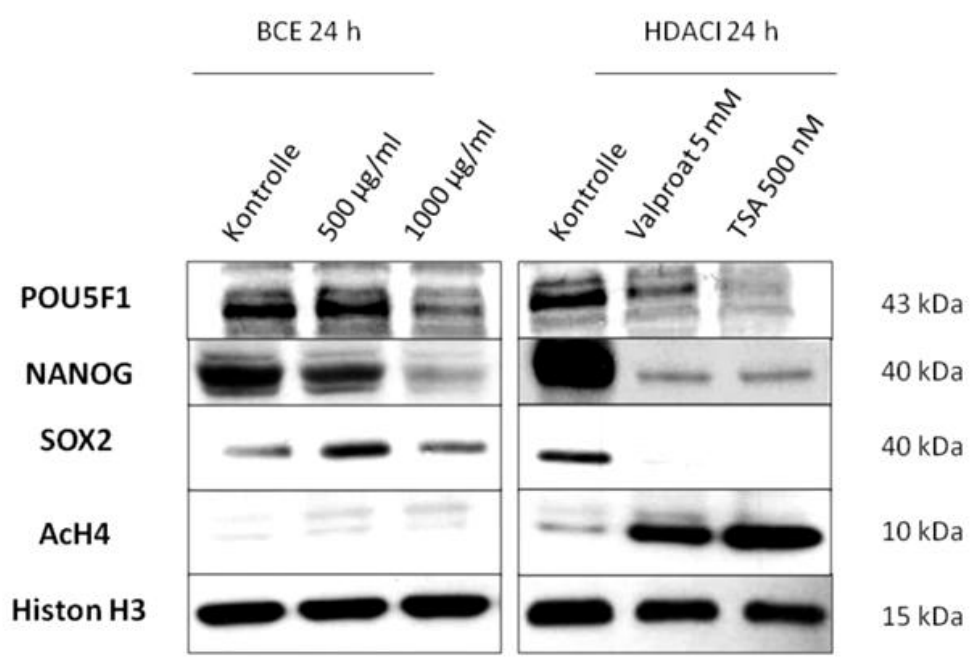

Abb. 15: Proteinexpression der Stammzellfaktoren in den TGCT-Zelllinien NTERA-2 und TCam-2 nach 24 h BCE- bzw. HDACi-Stimulation.

(A) In den NTERA-2-Zellen zeigt sich eine Inhibition von POU5F1 und NANOG, sowohl nach BCE- als auch nach HDACi-Stimulation. SOX2 wird nur in HDACi-stimulierten Zellen inhibiert, Histon $\mathrm{H} 4$ nur in diesen hyperacetyliert. (B) In den TCam-2-Zellen wird ebenfalls NANOG und POU5F1 durch beide Substanzklassen inhibiert. SOX2 wird nur in HDACistimulierten Zellen inhibiert, Histon $\mathrm{H4}$ nur in diesen hyperacetyliert.

$\beta$-Actin und Histon $\mathrm{H3}$ dienen jeweils als Housekeeping-Gen. Die als Kontrolle gekennzeichneten Proben sind unstimulierte Ansätze, die als Referenz dienen. Für die untersuchten Proteine ist das Molekulargewicht [kDa] angegeben. 
Ergebnisse

\subsection{Connectivity Map}

Der Einsatz der Connectivity Map (cmap) diente dem Versuch, eine Annäherung an den Wirkmechanismus der Phytoöstrogene des Belamcanda-chinensis-Extraktes zu erzielen. Mit der cmap ist es möglich, Gemeinsamkeiten zu den von anderen Substanzen hervorgerufenen Gensignaturen aufzudecken. Als induzierte und reprimierte Gene dienten hierbei 250 der jeweils am stärksten regulierten Gene.

Dabei zeigten sich für die NTERA-2-Zellen die drei größten Übereinstimmungen von differentiell regulierten Genen mit denen der HDAC-Inhibitoren Vorinostat (Abb. 16), CP690334-01 und Trichostatin A (Abb. 17). Hier muss allerdings angemerkt werden, dass die Gensignaturen der cmap aus der Mammakarzinomzelllinie MCF7, der Leukämiezelllinie HL60 und der Prostatakarzinomzelllinie PC3 stammen. Positive Konnektivität wurde des Weiteren mit dem Antibiotikum Monensin und dem Phenothiazin Perphenazin gefunden. Eine teilweise inverse Gensignatur scheint der GABA-Antagonisten Securinin zu induzieren (Tabelle 10).

Auf der Suche nach Übereinstimmungen mit dem Phytoöstrogen Genistein konnten auch Gemeinsamkeiten festgestellt werden, die jedoch anhand des Mittelwertes des Übereinstimmungsscore von 0,265 auf Rang 862 gestuft waren (Abb. 18).

Tabelle 10: Übersicht über die ersten sechs Ränge der ,permuted results“ (Stimulanzienzentrierte Übersicht) für die NTERA-2-Zellen in der cmap.

Stimulation der Zelllinie mit $1000 \mu \mathrm{g} / \mathrm{ml}$ BCE für $72 \mathrm{~h}$. Die Tabelle zeigt die Rangeinordnung von Substanzen (nach p-Wert), die ähnliche oder inverse (negatives Vorzeichen) Gensignaturen erzeugt haben. Der Mittelwert stellt das arithmetische Mittel des Übereistimmungsscore für die mit dem jeweiligen Stimulans erzielten Instanzen dar.

\begin{tabular}{clccc}
\hline Rang & Stimulans & n & Mittelwert & p-Wert \\
\hline $\mathbf{1}$ & Vorinostat & 12 & 0,592 & 0,00000 \\
$\mathbf{2}$ & CP-690334-01 & 8 & 0,545 & 0,00000 \\
$\mathbf{3}$ & Trichostatin A & 182 & 0,394 & 0,00000 \\
$\mathbf{4}$ & Securinin & 4 & $-0,588$ & 0,00016 \\
$\mathbf{5}$ & Monensin & 6 & 0,557 & 0,00032 \\
$\mathbf{6}$ & Perphenazin & 5 & 0,444 & 0,00050 \\
\hline
\end{tabular}


Ergebnisse

\section{Vorinostat}

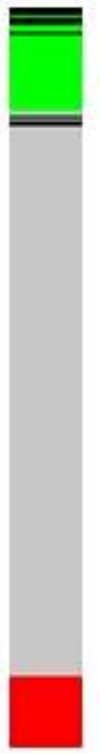

\begin{tabular}{|c|c|c|c|c|}
\hline Rang & Stimulans & Dosis & Zelllinie & Score \\
\hline 13 & Vorinostat & $10 \mu \mathrm{M}$ & MCF7 & 0,873 \\
\hline 20 & Vorinostat & $10 \mu \mathrm{M}$ & HL60 & 0,851 \\
\hline 24 & Vorinostat & $10 \mu \mathrm{M}$ & MCF7 & 0,845 \\
\hline 32 & Vorinostat & $10 \mu \mathrm{M}$ & MCF7 & 0,825 \\
\hline 46 & Vorinostat & $10 \mu \mathrm{M}$ & MCF7 & 0,805 \\
\hline 92 & Vorinostat & $10 \mu \mathrm{M}$ & HL60 & 0,758 \\
\hline 103 & Vorinostat & $10 \mu \mathrm{M}$ & MCF7 & 0,749 \\
\hline 141 & Vorinostat & $10 \mu \mathrm{M}$ & HL60 & 0,722 \\
\hline 220 & Vorinostat & $10 \mu \mathrm{M}$ & $\mathrm{PC} 3$ & 0,675 \\
\hline 914 & Vorinostat & $10 \mu \mathrm{M}$ & MCF7 & 0 \\
\hline 943 & Vorinostat & $10 \mu \mathrm{M}$ & $\mathrm{PC} 3$ & 0 \\
\hline 958 & Vorinostat & $10 \mu \mathrm{M}$ & MCF7 & 0 \\
\hline
\end{tabular}

Abb. 16: Übereinstimmungen von BCE-stimulierten NTERA-2-Zellen mit VorinostatSignaturen in der cmap.

Die Konnektivitäten der BCE-induzierten Signatur mit Vorinostat-Signaturen reichen von überwiegend „hoher positiver Korrelation“ bis „,keine Übereinstimmung“ (Score). Dargestellt sind außerdem der Rang (in der gesamten cmap), die Dosis und die Zelllinie.

\section{Trichostatin A}

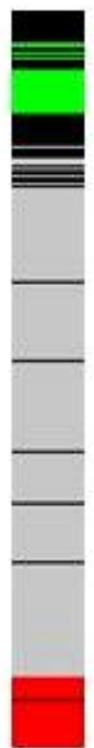

\begin{tabular}{rlrrr} 
Rang & Stimulans & Dosis & Zelllinie & Score \\
\hline 2 & TrichostatinA & $1 \mu \mathrm{M}$ & MCF7 & 0,962 \\
3 & Trichostatin A & $1 \mu \mathrm{M}$ & HL60 & 0,930 \\
4 & TrichostatinA & $100 \mathrm{nM}$ & MCF7 & 0,919 \\
5 & Trichostatin A & $100 \mathrm{nM}$ & MCF7 & 0,917
\end{tabular}

$\begin{array}{lllll}871 & \text { Trichostatin A } & 100 \mathrm{nM} & \text { MCF7 } & 0 \\ 872 & \text { Trichostatin A } & 100 \mathrm{nM} & \text { PC3 } & 0 \\ 873 & \text { TrichostatinA } & 100 \mathrm{nM} & \text { MCF7 } & 0\end{array}$

5705 Trichostatin A $\quad 100 \mathrm{nM}$ MCF7 $-0,610$

Abb. 17: Übereinstimmungen von BCE-stimulierten NTERA-2-Zellen mit Trichostatin-ASignaturen in der cmap.

Die Konnektivitäten der BCE-induzierten Signatur mit Trichostatin-A-Signaturen reichen von überwiegend „hoher positiver Korrelation“, über „keine Übereinstimmung“仿 bu einer „negativen Konnektivität" (Score). Dargestellt sind außerdem der Rang (in der gesamten cmap), die Dosis und die Zelllinie. 
Ergebnisse

\title{
Genistein
}

\begin{tabular}{rrrrrr}
\multicolumn{1}{c}{ Rang } & Stimulans & \multicolumn{1}{c}{ Dosis } & Zelllinie & Score \\
\hline 47 & Genistein & $10 \mu \mathrm{M}$ & MCF7 & 0,802 \\
137 & Genistein & $10 \mu \mathrm{M}$ & MCF7 & 0,724 \\
168 & Genistein & $10 \mu \mathrm{M}$ & HL60 & 0,702 \\
213 & Genistein & $10 \mu \mathrm{M}$ & MCF7 & 0,677 \\
328 & Genistein & $10 \mu \mathrm{M}$ & MCF7 & 0,624 \\
533 & Genistein & $10 \mu \mathrm{M}$ & HL60 & 0,555 \\
681 & Genistein & $10 \mu \mathrm{M}$ & PC3 & 0,502 \\
819 & Genistein & $10 \mu \mathrm{M}$ & MCF7 & 0,429 \\
1039 & Genistein & $10 \mu \mathrm{M}$ & HL60 & 0 \\
1520 & Genistein & $10 \mu \mathrm{M}$ & MCF7 & 0 \\
2894 & Genistein & $10 \mu \mathrm{M}$ & PC3 & 0 \\
4316 & Genistein & $1 \mu \mathrm{M}$ & MCF7 & 0 \\
4402 & Genistein & $10 \mu \mathrm{M}$ & MCF7 & 0 \\
4458 & Genistein & $1 \mu \mathrm{M}$ & MCF7 & 0 \\
4511 & Genistein & $10 \mu \mathrm{M}$ & MCF7 & 0 \\
5260 & Genistein & $10 \mu \mathrm{M}$ & MCF7 & 0 \\
5560 & Genistein & $10 \mu \mathrm{M}$ & PC3 & $-0,513$
\end{tabular}

\begin{abstract}
Abb. 18: Übereinstimmungen von BCE-stimulierten NTERA-2-Zellen mit Genistein-Signaturen in der cmap.

Die Konnektivitäten der BCE-induzierten Signatur mit Genistein-Signaturen reichen von „hoher positiver Korrelation“, über „keine Übereinstimmung“, bis zu einer „,negativen Konnektivität"“ (Score). Dargestellt sind außerdem der Rang (in der gesamten cmap), die Dosis und die Zelllinie.
\end{abstract}

Für die TCam-2-Zellen wurden andere Übereinstimmungen gefunden. Hohe positive Konnektivität fanden sich unter anderem mit Lisurid (Abb. 19), einem vom Mutterkornalkaloid abgeleiteten Dopaminantagonisten, mit Vigabatrin, das den GABA-Abbau hemmt sowie mit dem HDAC-Inhibitor CP-690334-01 (Abb. 20). In dieser Zelllinie waren auch zahlreiche negative Korrelationen, das heißt Substanzen mit gegenteiligem Einfluss auf Gensignaturen unter den ersten acht Rängen vertreten. Beispiele hierfür sind Meticrane, ein in der antihypertensiven Therapie eingesetzter Wirkstoff, Medrysone (Abb. 21), ein Corticosteroid und Doxorubicin, welches zur Gruppe der Interkalantien gehört und in der Krebstherapie eingesetzt wird. Auch für H-7, besser bekannt als Piperazin wurde eine negative Konnektivität erzielt, ebenso wie für 0173570-0000 (einer in der cmap getesteten Substanz der Firma Pfizer) (Tabelle 11). An dieser Stelle gilt ebenso, dass die Konnektivität mit den in der cmap vertretenen Gensignaturen aus der Mammakarzinomzelllinie MCF7, der Leukämiezelllinie HL60 und der Prostatakarzinomzelllinie PC3 erzielt wurden.

Auch für diese Zelllinie wurde gezielt nach einer Übereinstimmung mit Genistein gesucht. Diese wurde jedoch anhand des Mittelwertes des Übereinstimmungsscore von 0,237 insgesamt auf Rang 982 der „permued results“ gestuft, wobei in der Einzelbetrachtung dieses 
Ergebnisse

Phytoöstrogen die beiden höchsten Korrelationen brachte (unter Einsatz von $10 \mu \mathrm{M}$ Genistein in MCF7-Zellen) (Abb. 22).

Tabelle 11: Übersicht über die ersten acht Ränge der ,permuted results“ (Stimulanzienzentrierte Übersicht) für die TCam-2-Zellen in der cmap.

Stimulation der Zelllinie mit $1000 \mu \mathrm{g} / \mathrm{ml} \mathrm{BCE}$ für $72 \mathrm{~h}$. Die Tabelle zeigt die Rangeinordnung von Substanzen (nach p-Wert), die ähnliche oder inverse (negatives Vorzeichen) Gensignaturen erzeugt haben. Der Mittelwert stellt das arithmetische Mittel des Übereistimmungsscore für die mit dem jeweiligen Stimulans erzielten Instanzen dar.

\begin{tabular}{cllrl}
\hline Rang & Stimulans & n & Mittelwert & p-Wert \\
\hline $\mathbf{1}$ & Meticrane & 5 & $-0,719$ & 0,00004 \\
$\mathbf{2}$ & Lisrurid & 5 & 0,624 & 0,00006 \\
$\mathbf{3}$ & Medrysone & 6 & $-0,725$ & 0,00006 \\
$\mathbf{4}$ & Doxorubicin & 3 & $-0,819$ & 0,00026 \\
$\mathbf{5}$ & Vigabatrin & 3 & 0,689 & 0,00036 \\
$\mathbf{6}$ & H-7 & 4 & $-0,670$ & 0,00060 \\
$\mathbf{7}$ & $0173570-0000$ & 6 & $-0,585$ & 0,00068 \\
$\mathbf{8}$ & CP-690334-01 & 8 & 0,437 & 0,00076 \\
\hline
\end{tabular}

\section{Lisurid}

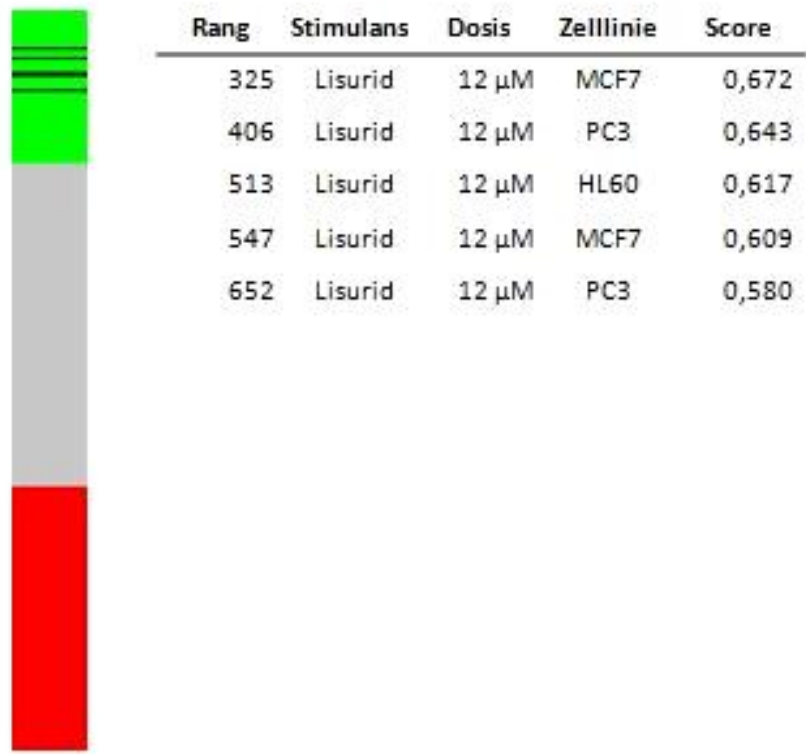

Abb. 19: Übereinstimmungen von BCE-stimulierten TCam-2-Zellen mit Lisurid-Signaturen in der cmap.

Die Konnektivitäten der BCE-induzierten Signatur mit Lisurid-Signaturen umfassen ausschließlich „positive Korrelationen“ (Score). Dargestellt sind außerdem der Rang (in der gesamten cmap), die Dosis und die Zelllinie. 
Ergebnisse

CP-690334-01

\begin{tabular}{rrrcr}
\hline \multicolumn{1}{c}{ Rang } & Stimulans & \multicolumn{1}{c}{ Dosis } & Zellinie & \multicolumn{1}{l}{ Score } \\
\hline \hline 36 CP-690334-01 & $10 \mu \mathrm{M}$ & $\mathrm{MCF} 7$ & 0,843 \\
\hline 89 CP-690334-01 & $1 \mu \mathrm{M}$ & PC3 & 0,792 \\
167 CP-690334-01 & $1 \mu \mathrm{M}$ & PC3 & 0,735 \\
514 CP-690334-01 & $10 \mu \mathrm{M}$ & PC3 & 0,616 \\
955 CP-690334-01 & $10 \mu \mathrm{M}$ & PC3 & 0,503 \\
1202 CP-690334-01 & $1 \mu \mathrm{M}$ & MCF7 & 0,418 \\
1344 CP-690334-01 & $10 \mu \mathrm{M}$ & MCF7 & 0 \\
4073 CP-690334-01 & $1 \mu \mathrm{M}$ & MCF7 & $-0,412$
\end{tabular}

Abb. 20: Übereinstimmungen von BCE-stimulierten TCam-2-Zellen mit CP-690334-01-

Signaturen in der cmap.

Die Konnektivitäten der BCE-induzierten Signatur mit CP-690334-01-Signaturen reichen von überwiegend „hoher positive Korrelation“, über eine „Null-Konnektivität“", bis zu einer „negativen Übereinstimmung“ (Score). Dargestellt sind außerdem der Rang (in der gesamten cmap), die Dosis und die Zelllinie.

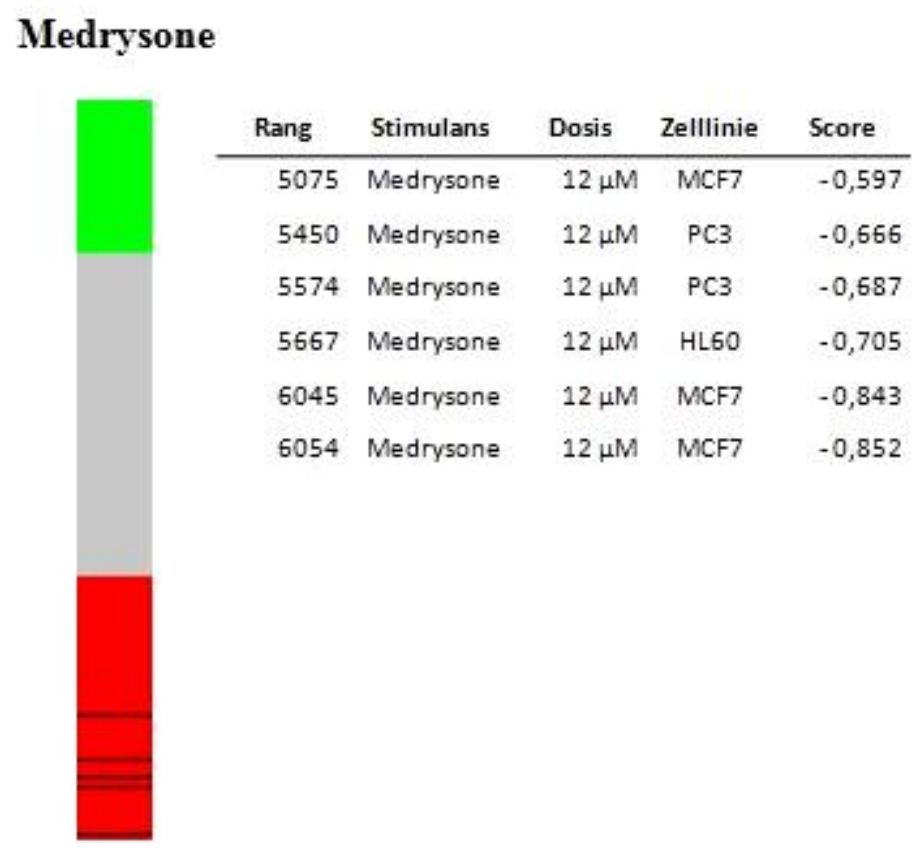

Abb. 21: Übereinstimmungen von BCE-stimulierten TCam-2-Zellen mit Medrysone-Signaturen in der cmap.

Die Konnektivitäten der BCE-induzierten Signatur mit Medrysone-Signaturen umfassen ausschließlich „negative Korrelationen“ (Score). Dargestellt sind außerdem der Rang (in der gesamten cmap), die Dosis und die Zelllinie. 
Ergebnisse

\section{Genistein}

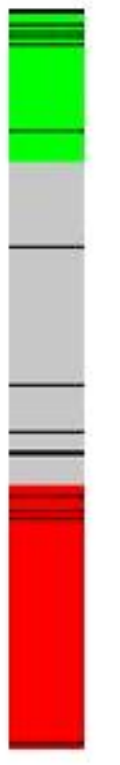

\begin{tabular}{rrrrr} 
Rang & Stimulans & Dosis & Zelllinie & \multicolumn{2}{c}{ Score } \\
\hline 1 & Genistein & $10 \mu \mathrm{M}$ & MCF7 & 1 \\
2 & Genistein & $10 \mu \mathrm{M}$ & MCF7 & 0,950 \\
31 & Genistein & $10 \mu \mathrm{M}$ & MCF7 & 0,850 \\
137 & Genistein & $10 \mu \mathrm{M}$ & MCF7 & 0,747 \\
188 & Genistein & $10 \mu \mathrm{M}$ & HL60 & 0,723 \\
230 & Genistein & $10 \mu \mathrm{M}$ & HL60 & 0,700 \\
293 & Genistein & $10 \mu \mathrm{M}$ & MCF7 & 0,682 \\
1002 & Genistein & $10 \mu \mathrm{M}$ & MCF7 & 0,492 \\
1953 & Genistein & $10 \mu \mathrm{M}$ & HL60 & 0 \\
3103 & Genistein & $10 \mu \mathrm{M}$ & PC3 & 0 \\
3480 & Genistein & $1 \mu \mathrm{M}$ & MCF7 & 0 \\
3652 & Genistein & $10 \mu \mathrm{M}$ & MCF7 & 0 \\
3677 & Genistein & $1 \mu \mathrm{M}$ & MCF7 & 0 \\
4016 & Genistein & $10 \mu \mathrm{M}$ & MCF7 & $-0,389$ \\
4133 & Genistein & $10 \mu \mathrm{M}$ & PC3 & $-0,431$ \\
4206 & Genistein & $10 \mu \mathrm{M}$ & PC3 & $-0,448$ \\
6047 & Genistein & $10 \mu \mathrm{M}$ & MCF7 & $-0,847$
\end{tabular}

Abb. 22: Übereinstimmungen von BCE-stimulierten TCam-2-Zellen mit Genistein-Signaturen in der cmap.

Die Konnektivitäten der BCE-induzierten Signatur mit Genistein-Signaturen reichen von „hoher positiver Korrelation“ (inklusive Rang 1 und 2), über „keine Übereinstimmung“, bis zu ,negativer Konnektivität" (Score). Dargestellt sind außerdem der Rang (in der gesamten cmap), die Dosis und die Zelllinie.

Des Weiteren wurde in der cmap untersucht, ob die Wirkung der Phytoöstrogene des Belamcanda-chinensis-Extraktes eine Beziehung zu der von Östrogenen und Östrogenantagonisten hat. Daher wurde gezielt nach Übereinstimmungen mit Estradiol, Fulvestrant, Tamoxifen und Raloxifen in der cmap gesucht. Diese erzielten in beiden Zelllinien im ,permuted results"-Ranking (Rangliste aller 1309 getesteten Substanzen) insgesamt mittlere bis geringe positive und teilweise auch negative Konnektivität (Score) (Tabelle 12).

Tabelle 12: Konnektivitäten von BCE zu Stimulanzien, die mit Östrogen in Verbindung stehen. In der cmap sind folgende Östrogene und Antagonisten aufgeführt: Estradiol, die Östrogenantagonisten Fulvestrant, Tamoxifen und Raloxifen und das Phytoöstrogen Genistein. Der Mittelwert des Übereinstimmungsscore führte unter Berücksichtigung von Größen wie Fallzahl zu der jeweiligen Rangeinstufung. Diese Ergebnisse wurden in der Kategorie ,permuted results “ (Stimulans-zentrierte Übersicht) erzielt und verweisen auf geringe Konnektivität.

\begin{tabular}{lcc}
\hline Stimulanzien & $\begin{array}{c}\text { NTERA-2 } \\
\text { Rang / Score }\end{array}$ & $\begin{array}{c}\text { TCam-2 } \\
\text { Rang / Score }\end{array}$ \\
\hline Estradiol & $1249 / 0,029$ & $1238 / 0,152$ \\
Fulvestrant & $1255 / 0,112$ & $1309 /-0,068$ \\
Tamoxifen & $767 / 0,108$ & $1184 /-0,132$ \\
Raloxifen & $655 / 0,251$ & $860 / 0,209$ \\
Genistein & $862 / 0,265$ & $982 / 0,237$ \\
\hline
\end{tabular}


Diskussion

\section{Diskussion}

\subsection{Proliferationsinhibition in TGCT-Zelllinien nach Stimulation mit Tectorigenin und BCE}

Wie die Untersuchungen an den TGCT-Zelllinien NTERA-2 und TCam-2 gezeigt haben, lässt sich mit den Phytoöstrogenen des Belamcanda-chinensis-Extraktes und der Reinsubstanz Tectorigenin eine konzentrations- und zeitabhängige Hemmung der Proliferation erzielen. Die NTERA-2-Zellen scheinen allerdings sensibler für die proliferationsinhibitorische Wirkung beider Stimulanzien, da in dieser Zelllinie bereits nach 24 Stunden statistisch signifikante Reduktionen der Zellzahl detektiert werden konnten, nicht jedoch in den TCam-2-Zellen.

Eine konzentrations- und zeitabhängige Proliferationsinhibition konnte bereits in frühen Studien unter Einsatz von Tectorigenin an HL-60-Zellen (humane akute myelozytische Leukämiezellen) gezeigt werden. In diesen Untersuchungen wurde außerdem eine Induktion von Differenzierung in den genannten Zellen durch Tectorigenin festgestellt. Aus diesem Grund wurde die antiproliferative Aktivität des Phytoöstrogens auf eine Induktion von Differenzierung und Apoptose zurückgeführt (Lee et al. 2001). Später wurde dies allerdings widerlegt, da die Abnahme der Zellzahl ausschließlich mit einer Proliferationsinhibition assoziiert war (Veränderungen in der G1-, S- und G2M-Phase), jedoch kein Anstieg der Apoptoserate detektierbar war. Diese Ergebnisse führten zu der Schlussfolgerung, dass die inhibitorische Wirkung auf die Viabilität von Zellen auf einem Zellzyklusarrest beruht (Morrissey et al. 2004).

Im MTT-Test scheint Tectorigenin auf den ersten Blick zudem potenter in der Reduktion der Zellzahl, verglichen mit dem Belamcanda-chinensis-Extrakt. Ein Vergleich der eingesetzten Konzentrationen, nämlich 100-500 $\mu \mathrm{M}$ Tectorigenin und 62,5-1000 $\mu \mathrm{g} / \mathrm{ml} \mathrm{BCE}$, zeigt aber, dass ein derartiger Vergleich nicht möglich und unter Betrachtung verschiedener Aspekte zudem falsch ist. So haben beispielsweise Morrissey et al. (2004) beschrieben, dass $100 \mu \mathrm{g} / \mathrm{ml}$ BCE etwa $17 \mu \mathrm{M}$ Tectorigenin enthalten und auch Thelen et al. (2005) benennen den Anteil von Tectorigenin am BCE auf etwa $5 \%$. In derselben Arbeit wurden im Rahmen eines Proliferationsassays 100 und $400 \mu \mathrm{g} / \mathrm{ml}$ BCE im Vergleich zu $100 \mu \mathrm{M}$ Tectorigenin eingesetzt. Die Ergebnisse spiegelten die unter Abschnitt 3.1.1 erzielten Resultate wider: nämlich, dass in einem derartigen Vergleich Tectorigenin potenter wirkt beziehungsweise ist. In einer weiteren Arbeit von Thelen et al. (2007) wurde dann die Hypothese aufgestellt, dass sich möglicherweise durch synergistische Effekte anderer Komponenten des Extraktes, welche 
Diskussion

sich zu der Wirkung von Tectorigenin addieren, eine stärkere Potenz für das Gesamtextrakt ergibt, da es insgesamt einen vergleichsweise geringen Anteil an der Reinsubstanz Tectorigenin enthält und trotzdem beachtliche Effekte erzielt. Ebenso sollte aber beachtet werden, dass die 5-hydroxyl-Gruppe an der Isoflavonstruktur diverser Phytoöstrogene maßgeblich für den zytotoxischen Effekt verantwortlich ist (Lee et al. 2001). Ebenso wie einige andere Isoflavonoide des Belamcanda-chinensis-Extraktes, enthält Tectorigenin diese Struktur (Yamaki et al. 1990; Ito et al. 2001). Jedoch finden sich auch Bestandteile im BCE, die diese Struktur nicht ausbilden, sowie Substanzen mit Glykosid-Rest (Zhang Y-Y et al. 2011), welcher schlecht permeabel für die Zellmembran ist (Lee et al. 2001).

\subsection{Differentielle Expression von Stammzellfaktoren in TGCT-Zelllinien unter BCE-Stimulation}

Es hat sich gezeigt, dass verschiedene embryonale Stammzellfaktoren, die für die Selbsterneuerung einer Zelle große Bedeutung haben, auch mit schlecht differenzierten Tumoren assoziiert sind. Nach der Identifikation der Schlüsselgene NANOG, POU5F1 und SOX2, welche normalerweise in embryonalen Stammzellen angereichert sind, wurden sie zur Differentialdiagnose für Malignität und zielgerichtete Therapie vorgeschlagen (Ben-Porath et al. 2008). Als potentielle pharmakotherapeutische Zielstrukturen wurde untersucht, ob die Phytoöstrogene des Belamcanda-chinensis-Extraktes eine Veränderung in der genannten Stammzellsignatur hervorrufen. Dabei konnte gezeigt werden, dass bereits nach 24 Stunden in beiden Zelllinien eine signifikante Reduktion der mRNA-Expression der Stammzellfaktoren NANOG und POU5F1 gegenüber den unstimulierten Kontrollen besteht. Während die Abnahme der mRNA lediglich eine konzentrationsabhängige Tendenz zeigte, für NANOG etwas deutlicher als für POU5F1, konnte in der Western-Blot-Analyse zusätzlich zu einer Konzentrationsabhängigkeit ein zeitabhängiger Effekt festgestellt werden, da nach 72 Stunden deutlich geringere Proteinmengen von NANOG und POU5F1 detektiert werden konnten. Die konzentrationsabhängige Herabregulation dieser beiden Transkriptionsfaktoren konnte des Weiteren mit Hilfe immunzytochemischer Färbungen bestätigt werden (diese Methode wurde nur für einen Zeitraum, nämlich 24 Stunden angewandt), und auch im Mikroarray zeigte sich eine gleichsinnige differentielle Regulation der drei Transkriptionsfaktoren.

In Versuchen von You et al. (2009) wurde eine Inhibition von NANOG durch HDACInhibitoren zusammen mit einem Zellzyklusarrest und einer Differenzierung von Zellen beschrieben, ohne dass eine erhöhte Apoptosezahl detektierbare gewesen wäre. Zudem wurde 
Diskussion

gezeigt, dass die NANOG-Inhibition keine Folge des G2M-Arrestes war, da umgekehrt nach gezieltem G2M-Arrest von NCCIT-Zellen mittels Nocodazole die NANOG-Expression unverändert blieb (You et al. 2009), was allerdings später zumindest für hESC-Zellen (humane embryonale Stammzellen) widerlegt wurde (Kallas et al. 2011). Eine direkte Vergleichbarkeit der beiden Zelllinien ist trotz der Gemeinsamkeit der Stammzellsignatur allerdings fraglich, da ein deutlich höheres Level an NANOG in der (malignen) humanen EmbryonalenKarzinom-Zelllinie NCCIT, verglichen mit der humanen Embryonalen-Stammzelllinie H9, vorliegt und eine NANOG-Suppression nach Apicidin-Stimulation beispielsweise nur in der humanen Embryonalen-Karzinom-Zelllinie, nicht jedoch in den Stammzellen, auslösbar war (You et al. 2009).

Die Gemeinsamkeiten, dass das reduzierte Proliferationsverhalten von Zellen nach Phytoöstrogenstimulation auf einen Zellzyklusarrest zurückgeführt wird und in dieser Arbeit, ebenso wie nach HDACi-Behandlung (You et al. 2009) eine NANOG-Suppression beobachtet wurde, lassen vermuten, dass möglicherweise ein Zusammenhang zwischen der Herabregulation von NANOG und dem Proliferationsstopp, welcher gegebenenfalls durch einen Zellzyklusarrest bedingt ist, besteht. Der genaue Zusammenhang von Zellzyklusarrest und NANOG-Inhibition ist jedoch bislang ungeklärt und muss weiter untersucht werden.

Der Transkriptionsfaktor SOX2 zeigte in den Stimulationsversuchen weder nach 24 noch nach 72 Stunden Inkubationszeit eine signifikante Inhibition im Expressionsverhalten, sowohl auf mRNA- als auch auf Proteinebene. Aber die Tatsache, dass SOX2 in der Seminomzelllinie TCam-2 detektierbar war, steht im Widerspruch zu anderen Forschungsergebnissen (de Jong et al. 2008). Allerdings wurde später darauf hingewiesen, dass in der als Seminom charakterisierten Zelllinie auch nicht-seminomatöse Eigenschaften gefunden werden können (Looijenga 2009).

Des Weiteren wurde in der bereits genannten Publikation von You et al. (2009) eine Abhängigkeit der Transkriptionsfaktoren POU5F1 und SOX2 von NANOG in NANOG-siRNA- und Apicidin-Stimulations-Versuchen beschrieben. Dieses Ergebnis spiegelte sich aber nicht in allen Versuchen der genannten Forschergruppe, wie etwa unter Apicidin-Stimulation in niedriger Dosis wieder. Während unter Anwendung hoher Konzentrationen dieses HDACInhibitors eine verminderte Expression aller drei Stammzellfaktoren beobachtet wurde, traf dies bei Verwendung einer geringeren Konzentration nur auf NANOG zu. Daher stellten sie die Vermutung auf, dass zusätzlich zu den bekannten Regelkreisen noch weitere bislang unbekannte Mechanismen unabhängig von NANOG in eine Herabregulation von POU5F1 und 
Diskussion

SOX2 involviert sein müssen (You et al. 2009). Ferner soll darauf hingewiesen werden, dass in früheren Studien ein NANOG-Knockdown an NCCIT-Zellen keinen Effekt an der Expressionsinhibition von POU5F1 und SOX2 zeigte. Als Folge der Ausschaltung von POU5F1 war jedoch eine Abnahme von NANOG und SOX2 zu sehen, und umgekehrt zeigte sich nach SOX2-Knockdown eine reduzierte Expression von NANOG und POU5F1 (Greber et al. 2007), was später als unvollständiger Knockdown gedeutet wurde (You et al. 2009). Auch Ergebnisse nach Esrrb(estrogen-related receptor beta)-Knockout, die eine selektive NANOGInhibition ohne Verminderung der POU5F1-Expression zum Vorschein brachten, eine NANOG-Inhibition jedoch auch POU5F1-Abhängigkeit zuschreiben (van den Berg et al. 2008), lassen vermuten, dass die Regulationsmechanismen der Transkriptionsfaktoren sehr komplex sind und die Regelkreise sowie zusätzliche Einflussfaktoren noch lange nicht endgültig geklärt sind.

Dass Phytoöstrogene Einfluss auf Stammzellfaktoren nehmen, wurde bereits unter GenisteinStimulation beobachtet. Dieses unter anderem in Soja enthaltene Isoflavonoid vermindert die mRNA-Expression von NANOG, nicht jedoch die von POU5F1 und SOX2. Auf Proteinebene wurde für Genistein allerdings eine Depletion von NANOG und POU5F1 beobachtet, was zu der Vermutung geführt hat, dass die Transkriptionsinhibition von NANOG auf die durch Genistein induzierte Reduktion des POU5F1-Proteins zurückzuführen ist (Regenbrecht et al. 2008).

Ferner muss angemerkt werden, dass NANOG und POU5F1 auf mRNA-Ebene eine relativ geringe Repression erfahren, verglichen mit der Proteinexpression. Auch im Mikroarray hat sich gezeigt, dass diese Stammzellfaktoren (mit einer Ausnahme) die Grenze für relevant differentiell regulierte Gene (2-fach) eigentlich nicht erreichen. Sowohl im Western Blot als auch in der immunzytochemischen Färbung waren die Proteine zum Teil aber kaum noch detektierbar. Man könnte zum Einen argumentieren, dass die beiden letzteren Methoden keine quantitativen Ergebnisse geliefert haben. Möglich wäre allerdings auch, dass Regulationsmechanismen wie posttranskriptionelles Gen-Silencing vorliegen.

\subsection{Regulation verschiedener Differenzierungsgene in TGCT-Zelllinien nach Stimulation mit BCE}

Wie in der Mikroarray-Analyse gezeigt werden konnte, werden unter Stimulation der NTERA-2- und TCam-2-Zellen mit dem Belamcanda-chinensis-Extrakt eine Reihe von 
Diskussion

Differenzierungsgene in ihrer Expression reguliert. Im Folgenden soll auf eine Auswahl von Genen, die im Zusammenhang mit Malignomen beziehungsweise der Differenzierung von Zellen in der Literatur Einzug gefunden haben, näher eingegangen werden.

\section{$\underline{\text { Reprimierte Differenzierungsgene in stimulierten NTERA-2-Zellen }}$}

In den mit BCE stimulierten NTERA-2-Zellen hat sich unter anderem eine reduzierte Expression der Gene DAZL (deleted in azoospermia-like) und GDF3 (growth differentiation factor 3) gezeigt. Die Expression dieser Gene wurde in TGCT erforscht, wobei sich herausgestellt hat, dass GDF3, welches auch in primordialen Keimzellen exprimiert ist, in TGCT ebenso wie die Transkriptionsfaktoren NANOG und POU5F1 - verglichen mit gesundem Hodengewebe - in erhöhtem Ausmaß detektierbar ist (Ezeh et al. 2005). DAZL, welches nur in IGCNU, nicht jedoch beispielsweise in Brustkrebszellen exprimiert ist, wird als Marker für den Keimzellursprung dieser Zellen angesehen (Ezeh et al. 2005). Demnach scheinen diese beiden Gene mit der Malignität von Keimzelltumoren des Hodens assoziiert zu sein.

Für CALCA (calcitonin gene-related peptide) hat sich herausgestellt, dass es nicht nur das Wachstum und die Motilität von Prostatakrebszellen stimuliert, sondern auch entscheidende Funktionen im Zusammenhang mit der Angiogenese hat (Dong et al. 2007). EGFL6 (EGFlike-domain, multiple 6), welches ein Mitglied der epidermal growth factor ProteinSuperfamilie ist, begünstigt ebenso - vermutlich durch einen parakrinen Mechanismus Angiogenese und fördert die Migration von Endothelzellen (Chim et al. 2011).

In GLI1(GLI family zinc finger 1)-Knockout-Versuchen konnte gezeigt werden, dass eine Blockierung dieses Transkriptionsfaktors die Proliferation, Invasion und Migration von Krebszellen beeinträchtigt (Das et al. 2009). Ähnliches gilt für ASCL2 (achaete-scute complex homolog 2). Lebermetastasen von kolorektalen Karzinomen weisen eine ASCL2verwandte Stammzellsignatur auf, die wahrscheinlich das metastatische Verhalten der Tumorzellen beeinflussen (Stange et al. 2010).

Eine reduzierte Expression der genannten Gene, wie sie in den NTERA-2-Zellen nach Stimulation mit dem Belamcanda-chinensis-Extrakt gezeigt werden konnte, lässt demnach auf eine tumorinhibitorische Wirkung dieser Substanz schließen.

\section{$\underline{\text { Induzierte Differenzierungsgene in stimulierten NTERA-2-Zellen }}$}

Eine bedeutende Induktion von Differenzierungsgenen konnte in der NTERA-2-Zelllinie nach BCE-Stimulation nur für HAND1 (heart and neural crest derivatives expressed 1) und HMX2 (H6 family homeobox 2) festgestellt werden. Dabei handelt es sich um Gene, denen 
Diskussion

beiden im Rahmen von Differenzierungsvorgängen in Zellen und Geweben Bedeutung zukommt. HAND1 spielt unter anderem im Rahmen der Embryogenese für die Morphogenese entscheidende Rollen (Riley et a. 1998). Außerdem konnte gezeigt werden, dass es in GADD45G(growth arrest and DNA-damage-inducible, gamma)-überexprimierenden NCCITZellen - ebenso wie in POU5F1-Knochout-Zellen - induziert wird und so an dem von GADD45G hervorgerufenen Zellzyklusarrest und der Differenzierung mitbeteiligt ist (Jung M et al. 2010). Neben seiner Bedeutung für die Morphogenese (Wang et al. 2001) ist HMX2 genauso wie HAND1 in Karzinomen reprimiert und eine Induktion scheint mit einer Proliferationsinhibition dieser einher zu gehen (Jin et al. 2009).

$\underline{\text { Reprimierte Differenzierungsgene in stimulierten TCam-2-Zellen }}$

Auch in der TCam-2-Zelllinie waren GDF3, CALCA und EGFL6 unter den reprimierten Genen zu finden. Für ihre Bedeutung im Hinblick auf die Karzinogenese kann daher auf den oberen Abschnitt verwiesen werden.

Desweiteren fand sich bei den stimulierten TCam-2-Zellen eine verminderte Expression von AKT1 (v-akt murine thymoma viral oncogene homolog 1), welches für seine zentrale Rolle im Zusammenhang mit Proliferations- und Überlebens-Pathways in Karzinomen bekannt ist (Carpten et al. 2007).

Das Gleiche gilt für angiopoietin-like 4 (ANGPTL4). Über seine Expression in Malignomen wurde berichtet, dass es die Tumorprogression durch Metastasierung und Vaskulogenese fördert (Nakayama et al. 2011).

So gilt zusammenfassend, ebenso wie für die NTERA-2-Zellen, dass auch in dieser Seminomzelllinie eine reduzierte Expression der genannten Gene nach BCE-Stimulation als tumorinhibitorische Wirkung des Extraktes vermutet werden kann.

\section{$\underline{\text { Induzierte Differenzierungsgene in stimulierten TCam-2-Zellen }}$}

In den TCam-2-Zellen konnten, im Gegensatz zu den NTERA-2-Zellen, einige weitere induzierte Differenzierungsgene detektiert werden. MAFB ( $v$-maf musculoaponeurotic fibrosarcoma oncogene homolog B) beispielsweise induziert Differenzierung (Kelly et al. 2000), gleichzeitig ist es aber auch (durch seine Translokation) als Onkogen in Multiplen Myelomen bekannt (Barillé-Nion et al. 2003). Das Maf-Protein kann insgesamt antagonistische Funktionen in der Onkogenese spielen (abhängig vom zellulären Kontext) und nimmt eine duale Rolle als Onkogen und tumorsuppressor-ähnliches Protein ein (Pouponnot et al. 
Diskussion

2006). NEUROG3 (neurogenin 3) erfüllt insbesondere wichtige Funktionen bei der Spezialisierung von Organen (Zhang YQ et al. 2001; Gasa et al. 2008).

Für die GADD45B-Expression wurde eine Assoziation zum Differenzierungsgrad von Tumoren festgestellt. So war in schlecht differenzierten Tumoren GADD45B (growth arrest and DNA-damage-inducible, beta) in einem deutlich geringeren Ausmaß exprimiert als in gut differenzierten. Deshalb wurde es auch als immunhistochemischer Marker für den Differenzierungsgrad von Tumoren vorgeschlagen (Zenmyo et al. 2010).

Einige der genannten Gene wurden ferner im Rahmen eines transkriptionellen Regelkreislaufes in humanen embryonalen Stammzellen mit NANOG, POU5F1 und SOX2 in Zusammenhang gebracht, in welchem diese drei Transkriptionsfaktoren als Regulatoren gelten, die in aktivem Zustand beispielsweise HAND1 reprimieren (Boyer et al. 2005). Demnach könnte die Induktion dieser Gene in den BCE-stimulierten TGCT-Zelllinien möglicherweise auf die Repression der drei Transkriptionsfaktoren zurückzuführen sein.

Zusammenfassend kann gesagt werden, dass in den TGCT-Zelllinie nach BCE-Stimulation unter den reprimierten Genen eine Reihe von Onkogenen und unter den stärker exprimierten Genen zahlreiche Induktoren der Differenzierung für Zellen und Gewebe zu finden waren. Dies sind Mechanismen, die im Zusammenhang mit Chemotherapeutika und speziell einer zielgerichteten Therapie in der Onkologie gewünscht sind und erforscht werden und beispielsweise für HDAC-Inhibitoren gezeigt werden konnte (You et al. 2009).

\subsection{Kein Hinweis auf Hyperacetylierung von Histonen durch das BCE}

Da unter Stimulation mit dem Phytoöstrogen Genistein eine Expressionsinhibition der Transkriptionsfaktoren NANOG und POU5F1, nicht jedoch für SOX2, beobachtet wurde (Regenbrecht et al. 2008) und Genistein eine Wirkung auf die Hyperacetylierung von Histonen zugeschrieben wird (Kikuno et al. 2008; Majid et al. 2010), wurde im Folgenden untersucht, ob auch die Phytoöstrogene des Belamcanda-chinensis-Extraktes eine derartige Wirkung aufweisen. Inwiefern diese beiden in unterschiedlichen Genistein-Stimulationsversuchen beobachteten Wirkungen im Zusammenhang stehen, ist allerdings ungeklärt, und ein Zusammenhang kann an dieser Stelle nur vermutet werden.

Die Untersuchung auf Hyperacetylierung war auch in Anlehnung an die Publikation über die Depletion der embryonalen Stammzellsignatur durch Histon-Deacetylase-Inhibitoren (You et al. 2009) und die nun beobachteten Gemeinsamkeiten der beiden Stimulanzien, Transkripti- 
Diskussion

onsfaktor- und Proliferationsinhibition möglicherweise im Zusammenhang mit Zellzyklusarrest, von Interesse.

HDAC-Inhibitoren werden besonders in die Richtung gehend erforscht, abnorme epigenetische Veränderungen umzukehren. Hierbei spielt besonders ihre Wirkung auf die Hyperacetylierung von Histonen, bedingt durch Inhibiton der Histon-Deacetylase, mit der Folge einer erhöhten Transkription verschiedener Gene eine Rolle. In der Krebsforschung hat hier vor allem die Induktion von Tumorsuppressorgenen große Bedeutung (Bolden et al. 2006).

Als Positivkontrolle für hyperacetylierte Histone (Histon H4) wurde im Rahmen dieser Arbeit mit den bekannten HDAC-Inhibitoren Valproat und Trichostatin A (TSA) gearbeitet.

Wie sich in der Western-Blot-Analyse gezeigt hat, ist die Hyperacetylierung von Histon H4, ebenso wie die Depletion von NANOG, POU5F1 und SOX2, durch Valproat und TSA reproduzierbar. Im direkten Vergleich wurde folglich der Unterschied zwischen den Effekten des Belamcanda-chinensis-Extraktes und den HDAC-Inhibitoren sichtbar. Während die HDACInhibitoren alle drei Stammzellfaktoren inhibieren und hyperacetyliertes Histon $\mathrm{H} 4$ unter ihrem Einfluss detektierbar ist, führt das Phytoöstrogenextrakt zu keiner Hyperacetylierung und hemmt lediglich die Expression von NANOG und POU5F1.

Dass unter BCE-Stimulation keine Hyperacetylierung beobachtet werden konnte, lässt auch vermuten, dass im Wirkmechanismus des Belamcanda-chinensis-Extraktes Differenzen zu dem von Genistein bestehen. In den genannten Genistein-Ergebnissen wurde allerdings mit Prostatakrebszellen (LNCaP und PC-3) gearbeitet, bei denen eine Hyperacetylierung von Histon H3 und H4 nach entsprechender Behandlung beobachtet wurde (Majid et al. 2010).

Diese unterschiedlichen Aktivitäten der verschiedene Phytoöstrogene lassen darauf schließen, dass man nicht von einem allgemeinen Wirkmechanismus von Phytoöstrogenen sprechen kann. Trotzdem sind die Gemeinsamkeiten - die selektive Inhibition von NANOG und POU5F1, nicht hingegen die von SOX2, wie es für Genistein beschrieben wurde (Regenbrecht et al. 2008), und nun auch für Tectorigenin und das BCE gezeigt werden konnte - durchaus beachtenswert.

\subsection{Hormonrezeptoren in TGCT-Zellen und Inhibition der Stammzellsig- natur in LNCaP-Zellen nach BCE-Stimulation}

Bei den bekannten Wirkmechanismen des Belamcanda-chinensis-Extraktes auf Prostatakrebszellen handelt es sich unter anderem um Änderungen im Expressionsmuster von AR (Thelen et al. 2007), ER- $\beta$ und der IGF-Achse (IGF1R, IGFBP3) (Thelen et al. 2005). Aus diesem 
Diskussion

Grund sollte eine Auswirkung der Phytoöstrogene des Belamcanda-chinensis-Extraktes auf die genannten Hormonrezeptoren und -Pathways in den TGCT-Zelllinien untersucht werden. Für IGCNU-Zellen wurde berichtet, dass diese den Androgenrezeptor (AR) exprimieren (Rajpert-De Meyts und Skakkebaek 1992), im Gegensatz dazu wird angenommen, dass der AR in normalen adulten Keimzellen nicht vorhanden ist (Zhou et al. 2002). In einer aktuellen Studie konnte des Weiteren gezeigt werden, dass der AR besonders in Seminomen auf Grund von durchschnittlich kürzeren CAG-Wiederholungen, im Vergleich zu Kontrollallelen, eine entscheidende Rolle zu spielen scheint. Im Gegensatz dazu wurden in Nicht-Seminomen DNA-Methylierungen im AR-codierenden Genabschnitt gefunden, die mit AR-Inhibition in TGCT assoziiert sind und in Seminomen nicht vorlagen (Davis-Dao et al. 2011).

Für den insulinähnlichen Wachstumsfaktorrezeptor 1 (IGF1R) ist berichtet worden, dass dieser in Seminomen und im normalen Hodengewebe etwa gleich exprimiert ist. Das IGFBindungsprotein 3 (IGFBP3) allerdings scheint in Seminomgeweben inhibiert zu sein. Da IGF1R im gesunden Hoden an der Spermatogenese beteiligt ist, diese jedoch in maligne entarteten Geweben nicht stattfindet, ist es möglich, dass eine unveränderte Expression dieses Rezeptors in Seminomen am Tumorwachstum beteiligt ist. Die Inhibition von IGFBP3, einem Protein, das für die Bindung von IGF1 zuständig ist und somit zu einer geringeren Rezeptorbindung von diesem führt, kommt unter normalen Bedingungen eine tumorinhibitorische Wirkung zu. Durch seine verminderte Expression in fortgeschrittenen Seminomen kommt es möglicherweise zu einem Verlust der Tumorsuppression (Neuvians et al. 2005).

Auch die Östrogenrezeptorexpression in TGCT ist in zahlreichen Arbeiten untersucht worden. Hier hat sich gezeigt, dass der Östrogenrezeptor- $\alpha$ (ER- $\alpha)$ weder in gesundem Hodengewebe, noch in Malignomen des Hodens detektierbar ist. Der Östrogenrezeptor- $\beta$ (ER- $\beta$ ), welchem als Gegenspieler von ER- $\alpha$ eine tumorprotektive Wirkung zugesprochen wird, ist in gesundem Gewebe exprimiert, in Seminomen, EC und gemischten Tumoren inhibiert. Dottersacktumoren und reife Teratome zeigten allerdings eine starke Expression (Pais et al. 2003).

Aus Versuchen an Prostatakarzinomzelllinien sind noch einige weitere Wirkungen von Tectorigenin und dem Belamcanda-chinensis-Extrakt bekannt, wie zum Beispiel auf den ER$\alpha$, die PSA-Expression und -Sekretion. Diese wurden unter Berücksichtigung der Tatsache, dass diese in Hodenkrebszellen nicht vorhanden sind, nicht untersucht (Duffy 2001; Pais et al. 2003).

Die Untersuchungen der Hormonrezeptoren auf mRNA-Ebene in BCE-stimulierten TGCTZelllinien, die mit freundlicher Unterstützung von PD Dr. Thelen (Abteilung Urologie, Uni- 
Diskussion

versitätsmedizin Göttingen) durchgeführt wurden, brachten keine schlüssigen Ergebnisse. Die Ursache dessen ist unklar und liegt möglicherweise in einer geringeren Relevanz dieser Gene in TGCT sowie für deren Viabilität und Malignität. Ein anderer Erklärungsansatz, der nicht unbedingt unabhängig davon ist, könnte mRNA-Instabilität sein. Die geringen Rangeinstufungen von Estradiol und verschiedenen Östrogenantagonisten in der Connectivity Map (s. Tabelle 12) würden insgesamt die Vermutung der geringeren Relevanz dieser Hormonrezeptoren und -Pathways in TGCT untermauern, auch wenn natürlich nicht außer Acht gelassen werden darf, dass die Gensignaturen der cmap mit anderen Zelllinien erstellt worden sind. Die Tatsache, dass Antiöstrogene in der Therapie von Mamma- und Prostatakarzinom, nicht jedoch bei Hodentumoren etabliert sind (Classen et al. 2009), würde wiederum im Einklang mit dieser Hypothese stehen.

Umgekehrt wurde auch beschrieben, dass die genannten Strukturen nicht essentiell für eine proliferationsinhibitorische Wirkung der Isoflavonoide des Belamcanda-chinensis-Extraktes sind, da eine Reduktion der Zellzahl unter Stimulation mit BCE/Tectorigenin für verschiedene Zelllinien beschrieben ist. So wurde neben den Prostatakrebszellen (Thelen et al. 2005) unter anderem in Leukämie- (Lee et al. 2001) und hepatischen Sternzellen (Wu et al. 2010) eine Proliferationsinhibition beobachtet. Auch in Lungenkrebs-, Endothelzell- und SarkomVersuchen wurde eine reduzierte Viabiliät beobachtet, welche auf die mit der EndothelzellInhibition verbundene reduzierte Vaskulogenese zurückgeführt wurde (Jung SH et al. 2003). Außerdem erzielte das Phytoöstrogen Genistein in ER-positiven und in ER-negativen Brustkrebszellinien antiproliferative Effekte, welche daher nicht durch eine direkte Wirkung an Östrogenrezeptoren ausgelöst waren (Murkies et al. 1998).

Wie gezeigt wurde, kommt auch der Stammzellsignatur in Prostatakrebszellen ein malignes Potential zu, welches für die Entwicklung zielgerichteter Therapie eine Rolle spielen könnte. Dabei waren ebenso der Transkriptionsfaktor NANOG (Jeter et al. 2009) in besonderem Maße, sowie POU5F1 und SOX2 (Bae et al. 2010), von Bedeutung. Über die Expression von SOX2 herrscht allerdings Unklarheit, da es nach Bae et al. (2010) in den Prostatakrebszelllinien DU145 und PC3 sowie in Prostatakrebsgewebeproben nachgewiesen werden konnte, nach Jeter et al. (2009) jedoch nicht in den Prostatakrebszellinien DU145, PC3, PPC-1 und LNCaP zu finden war. Da es auch in TGCT verschiedene Meinungen über die Expression von SOX2 gibt (s.o.), scheint die Expression dieses Transkriptionsfaktors sehr variabel und komplex zu sein. 


\section{Diskussion}

Von Interesse war, in BCE-stimulierten LNCaP-Zellen herauszufinden, ob die Wirkung der eingesetzten Phytoöstrogene in dieser Prostatakrebszelllinie, welche in der Erforschung von Hormonrezeptoren und -Signalwegen bereits großen Anklang finden, auch eine Änderung in der Expression der Transkriptionsfaktoren NANOG, POU5F1 und SOX2 hervorrufen, wie es im Rahmen dieser Arbeit in den TGCT-Zellen beobachtet werden konnte.

Die Ergebnisse der relativen mRNA-Expression zeigten einen inhomogenen Effekt, der durch die Überexpression aller drei Transkriptionsfaktoren unter Stimulation mit höheren Konzentrationen $\mathrm{BCE}$ gekennzeichnet war.

Im Western-Blot-Versuch zeigte sich, im Gegensatz zur mRNA-Analyse für NANOG und POU5F1, eine zeit- und konzentrationsabhängige Inhibition, wie sie auch in den TCam-2- und NTERA-2-Zellen beobachtet wurde; SOX2 war nicht detektierbar. Das würde mit der Publikation von Jeter et al. (2009) im Einklang stehen (s.o.). Aufgrund aktuellerer und eingehender Publikationen (Jia et al. 2011) muss allerdings an dieser Stelle vermutet werden, dass die Abwesenheit von SOX2 auf unzureichendem Nachweis in den hier genannten Versuchen beruht. Die Diskrepanz, die in der Expression der Transkriptionsfaktoren auf mRNA- und ProteinEbene beobachtet wurde, ist möglicherweise durch mRNA- oder Proteininstabilität zu erklären. Ein derartiges Phänomen wurde im Hinblick auf den ER- $\alpha$ in den Prostatakrebszellen RWPE-1 beobachtet (Morrissey et al. 2004).

Insgesamt kann angenommen werden, dass es auch in der Prostatakrebszelllinie LNCaP unter BCE-Stimulation zu einer Inhibition der Transkriptionsfaktoren NANOG und POU5F1 kommt.

\subsection{Annäherung an den Wirkmechanismus des Belamcanda-chinensis- Extraktes mit Hilfe der cmap}

Mit Hilfe der online Datenbank Connectivity Map (cmap) ist es möglich, Gemeinsamkeiten von Gensignaturen - induziert durch verschiedene andere Substanzen, die in Zellstimulationsund Mikroarray-Versuchen erstellt wurden - festzustellen (Lamb 2006).

Wie sich in der Suchanfrage an die cmap gezeigt hat, ähnelt die durch das Belamcandachinensis-Extrakt in NTERA-2-Zellen erzeugte Gensignatur stark der von verschiedenen HDAC-Inhibitoren induzierten. Besonders hohe positive Korrelationen wurden mit Vorinostat, CP-690334-01 und Trichostatin A erzielt. Da aber in der Western-Blot-Analyse keine Hyperacetylierung von Histonen (konkret des Histon H4) detektiert werden konnte, ist zu vermuten, dass die Gemeinsamkeiten auf histon-unabhängigen Modulationsmechanismen 
Diskussion

beruhen, die für HDAC-Inhibitoren ebenfalls bekannt sind. So wurde unter anderem eine direkte Hyperacetylierung verschiedener Transkriptionsfaktoren beschrieben (Bolden et al. 2006).

Dass Genistein lediglich eine mittlere/geringe positive Konnektivität von 0,265 erzielte, lässt vermuten, dass die festgestellten Gemeinsamkeiten - Überexpression von NANOG und POU5F1, nicht jedoch von SOX2 (Regenbrecht et al. 2008) - möglicherweise eher Ausnahmen darstellen. Allerdings muss bedacht werden, dass im BCE-Microarray-Versuch eine hohe Konzentration dieser Phytoöstrogene zum Einsatz kam (1000 $\mu \mathrm{g} / \mathrm{ml}$ BCE über 72 Stunden), die in ihrer Wirkung daher vielleicht toxischer sind als $10 \mu \mathrm{M}$ Genistein, welche in den Versuchen der cmap eingesetzt wurden. Außerdem wurden die Signaturen der cmap mit anderen Zelllinien erstellt.

Für die TCam-2-Zellen zeigten sich andere Gemeinsamkeiten als für die NTERA-2-Zellen. Der einzige hoch rangierende HDAC-Inhibitor, mit dritthöchster positiver Korrelation, war CP-690334-01. Die höchste positive Konnektivität zeigte jedoch Lisurid, ein Mutterkornalkaloid und Prolaktin-Hemmer. Bisher sind für dieses Pharmakon keine allgemeinen antikanzerogenen Wirkungen bekannt. Es findet lediglich Einsatz in der Tumortherapie bei der Behandlung von Prolaktinomen. Lisurid ist allerdings neben einer Inhibition der Prolaktinsekretion für eine Reduktion der Tumormasse und Inhibition von Transkription bekannt (Iván et al. 2005), des Weiteren wurden auch Nekrosen unter der Wirkung dieses Arzneimittels beobachtet (Ferrari und Crosignani 1986).

Eine hohe negative Korrelation war in erster Linie für Meticrane festzustellen. Dieses ist ein Diuretikum zur Therapie von arterieller Hypertonie. Über diese Substanz sind allerdings kaum Publikationen zu finden, was es mit derzeitigem Stand unmöglich macht, eine Verbindung zur BCE-induzierten Gensignatur herzustellen.

Auch für die TCam-2-Zellen wurde konkret nach einer Korrelation mit Genistein gesucht. Dieses zeigte eine mittlere/geringe positive Konnektivität von 0,237. Im Gegensatz zu der niedrigen Korrelation im Gesamtranking, war es in der detaillierten Einzeldarstellung der Ergebnisse unter den ersten beiden Substanzen vertreten. Die höchsten positiven Einzelkorrelationen stammten demnach aus Stimulationsversuchen mit Genistein (insgesamt fast alle unter Verwendung von $10 \mu \mathrm{M}$ Genistein).

Wie die in der cmap erzielte negative Korrelation mit Medrysone, einem Cortiosteroid und Doxorubicin, einem Interkalantium, zu deuten ist, bleibt unklar, da beide Substanzen in der 


\section{Diskussion}

Chemotherapie von Malignomen eingesetzt werden und eine Induktion beispielsweise der Stammzellsignatur bislang nicht beschrieben wurde.

Dass sich unterschiedliche Substanzen mit Gemeinsamkeiten für die BCE-induzierten Gensignaturen in NTERA-2- und TCam-2-Zellen gezeigt haben, ist auf verschiedene Weise erklärbar. Zum einen konnte nachgewiesen werden, dass der Wirkmechanismus des Belamcanda-chinensis-Extraktes in den beiden Zelllinien durchaus unterschiedlich ist, trotz der gezeigten Gemeinsamkeiten in Proliferationsinhibition und TranskriptionsfaktorenRepression. Ein Beispiel dafür sind auch die zahlreichen Gene, die im Mikroarray-Versuch für die beide Zelllinien eine differentiell Regulation gezeigt haben (s. Tabelle 8 und Tabelle 9). Da auch unterschiedliche Ausprägungen von Rezeptoren und Pathways für Seminome und Nicht-Seminome bekannt sind (s.o.), wären diese ebenfalls als mögliche verschiedene Angriffspunkte für das BCE denkbar. Zum anderen liefert die Hypothese, dass die Phytoöstrogene des Belamcanda-chinensis-Extraktes möglicherweise über ähnliche epigenetische Mechanismen wie HDAC-Inhibitoren wirken, eine Annäherung. Für diese ist bekannt, dass ihre Effekte teilweise vom Zelltyp abhängig sind (Bolden et al. 2006) und verschiedene Zielstrukturen von HDAC-Inhibitoren in TGCT unterschiedlich ausgeprägt sind. So ist die DNA-Methyltransferase DNMT1 beispielsweise nicht in Seminomen exprimiert, im embryonalen Karzinom, welches zu den Nicht-Seminomen zählt, jedoch hochreguliert (Omisanjo et al. 2007).

\subsection{Ausblick}

$\mathrm{Zu}$ der Reihe von Tumoren, für die antikanzerogene Wirkungen nach Stimulation mit Tectorigenin und/oder dem Belamcanda-chinenis-Extrakt beschrieben worden sind, können nun auch Zelllinien aus malignen Keimzelltumoren des Hodens hinzugezählt werden. Für manche Malignome wurde das Extrakt oder Bestandteile des Extraktes aufgrund der beobachteten pharmakotherapeutisch bedeutenden Effekte als potentielle Tumortherapie in Aussicht gestellt. Ob diese Substanzen jedoch eines Tages Einzug als (supportive) Tumortherapie speziell an TGCT - finden werden, ist fraglich, da besonders für maligne Keimzelltumoren des Hodens aktuell gute etablierte Therapiemöglichkeiten zur Verfügung stehen. Einen denkbaren Einsatz könnten sie daher eher in therapieresistenten Fällen oder als Rezidivprophylaxe finden. 


\section{Zusammenfassung}

\section{Zusammenfassung}

Die epidemiologische Verteilung von hormonabhängigen Tumoren sowie die große Beliebtheit von Phytopharmaka in der Bevölkerung haben in jüngster Zeit einige Studien hervorgebracht, die die Wirkung von Phytoöstrogenen auf maligne Neubildungen zum Ziel hatten. In verschiedenen Malignomen wie Prostatakarzinom und Leukämie konnte dabei gezeigt werden, dass Isoflavonoide des Belamcanda-chinensis-Extraktes (BCE) eine Proliferationsinhibition und onkogene Modulation in Tumorzellen erzielen. Diese Arbeit sollte Aufschluss darüber liefern, inwiefern derartige Wirkungen auch in malignen Keimzelltumoren des Hodens (TGCT), repräsentiert durch die Seminomzelllinie TCam-2 und die Nicht-Seminomzelllinie NTERA-2, zu beobachten sind. Dafür wurden die beiden Zelllinien über Zeiträume von 24-72 Stunden mit verschiedenen Konzentrationen Tectorigenin bzw. BCE stimuliert. Neben der Viabilität im Proliferationsassay wurden RNA- und Proteinexpressionen untersucht.

Es konnte gezeigt werden, dass nach Phytoöstrogen-Stimulation neben einer zeit- und konzentrationsabhängigen Proliferationshemmung eine Regulation der Stammzellsignatur in den TGCT-Zelllinien, gekennzeichnet durch Repression der Transkriptionsfaktoren NANOG und POU5F1, auftritt. Interessanterweise war die BCE-induzierte Regulation von Stammzellgenen in TGCT-Zelllinien unabhängig von Hormonrezeptoren und der epigenetischen Regulation von Histonproteinen durch Acetylierung. In weitergehenden Genexpressionsanalysen konnte gezeigt werden, dass in den TGCT-Zelllinien durch Phytoöstrogen-Stimulation unterschiedliche Differenzierungsgene induziert werden und Onkogene eine Repression erfahren.

Unter Zuhilfenahme der Connectivity Map hat sich gezeigt, dass man nicht von „einem“ Wirkmechanismus des Belamcanda-chinensis-Extraktes in TGCT-Zelllinien sprechen kann, da verschiedene Korrelationen für die stimulierten NTERA-2- und TCam-2-Zelle gefunden wurden, und der Wirkmechanismus somit vermutlich vom Zelltyp abhängig ist. In beiden TGCT-Zelllinien zeigte sich aber eine hohe positive Konnektivität mit HDAC-Inhibitoren, was die Hypothese der möglichen epigenetischen Modifikation durch das BCE wiederum bestätigt, wobei hierfür ein anderer Mechanismus als die Acetylierung von Histonproteinen wahrscheinlich ist. Weitergehende Untersuchungen zum exakten Wirkmechanismus von Phytoöstrogenen in TGCT könnten dazu dienen, dass diese Substanzgruppe bei Therapieresistenz oder als Rezidivprophylaxe in der Behandlung von TGCT zum Einsatz kommt. 


\section{Anhang}

\subsection{Abbildungsverzeichnis}

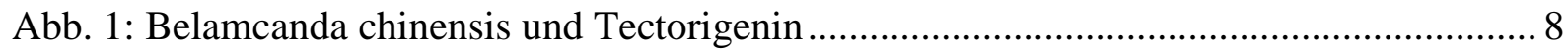

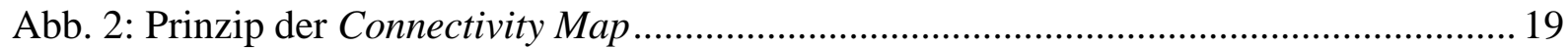

Abb. 3: Proliferation der TGCT-Zelllinien NTERA-2 und TCam-2 nach Stimulation mit

Tectorigenin für 24 und $48 \mathrm{~h}$.

Abb. 4: Proliferation der TGCT-Zelllinien NTERA-2 und TCam-2 nach Stimulation mit BCE für 24 und $72 \mathrm{~h}$.

Abb. 5: mRNA-Expression von NANOG in NTERA-2- und TCam-2-Zellen nach Stimulation mit BCE für 24 und $72 \mathrm{~h}$.

Abb. 6: mRNA-Expression von POU5F1 in NTERA-2- und TCam-2-Zellen nach Stimulation mit BCE für 24 und $72 \mathrm{~h}$. .35

Abb. 7: mRNA-Expression von SOX2 in NTERA-2- und TCam-2-Zellen nach Stimulation mit BCE für 24 und $72 \mathrm{~h}$.

Abb. 8: Proteinexpression der Stammzellfaktoren in den TGCT-Zelllinien NTERA-2 und

TCam-2 nach 24 und 72 h BCE-Stimulation.

Abb. 9: Immunzytochemische Darstellung von NANOG und POU5F1 in TGCT-Zelllinien nach $24 \mathrm{~h}$ Tectorigenin-Stimulation.

Abb. 10: Mikroarray-Expressionsanalyse in TGCT-Zelllinien nach BCE-Stimulation. 40

Abb. 11: Mikroarray-Expressionsanalyse der Stammzellsignatur in TGCT-Zelllinien nach BCE-Stimulation.

Abb. 12: Proteinexpression der Stammzellfaktoren in der Prostatakrebszellinie LNCaP nach

24 und 72 h BCE-Stimulation. 44

Abb. 13: mRNA-Expression der Stammzellfaktoren in LNCaP-Zellen nach Stimulation mit

BCE für 24 und $72 \mathrm{~h}$.

Abb. 14: mRNA-Expression der Stammzellfaktoren in TGCT-Zelllinien nach Stimulation mit HDAC-Inhibitoren für $24 \mathrm{~h}$.

Abb. 15: Proteinexpression der Stammzellfaktoren in den TGCT-Zelllinien NTERA-2 und

TCam-2 nach 24 h BCE- bzw. HDACi-Stimulation. .48

Abb. 16: Übereinstimmungen von BCE-stimulierten NTERA-2-Zellen mit Vorinostat-

Signaturen in der cmap. 50

Abb. 17: Übereinstimmungen von BCE-stimulierten NTERA-2-Zellen mit Trichostatin-A- 
Anhang

Abb. 18: Übereinstimmungen von BCE-stimulierten NTERA-2-Zellen mit Genistein-

Signaturen in der cmap.

Abb. 19: Übereinstimmungen von BCE-stimulierten TCam-2-Zellen mit Lisurid-Signaturen in der cmap.

Abb. 20: Übereinstimmungen von BCE-stimulierten TCam-2-Zellen mit CP-690334-01-

Signaturen in der cmap.

Abb. 21: Übereinstimmungen von BCE-stimulierten TCam-2-Zellen mit Medrysone-

Signaturen in der cmap.

Abb. 22: Übereinstimmungen von BCE-stimulierten TCam-2-Zellen mit Genistein-Signaturen in der cmap. .54

\subsection{Tabellenverzeichnis}

Tabelle 1: WHO Klassifikation der Hodentumoren und ihre Häufigkeit, modifiziert nach Eble

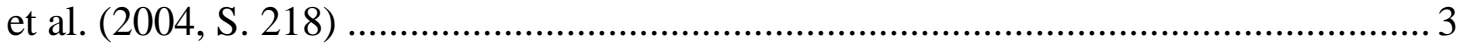

Tabelle 2: Real-Time-PCR - Sequenzen der eingesetzten Primer........................................ 15

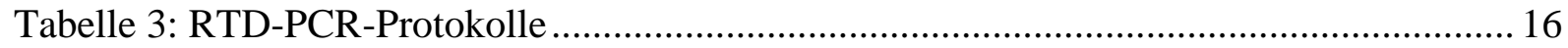

Tabelle 4: Western Blot - Primärantikörper ................................................................. 23

Tabelle 5: Immunzytochemie - Primärantikörper ............................................................. 24

Tabelle 6: Verwendete Chemikalien, Enzyme, Puffer, Kits ............................................... 24

Tabelle 7: Verwendete Einwegartikel und Geräte …......................................................... 26

Tabelle 8: Differentielle Expression von Differenzierungsgenen in TCam-2-Zellen nach BCE-

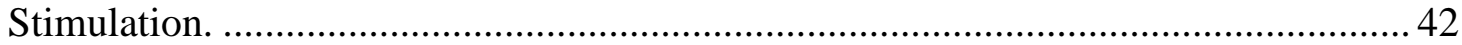

Tabelle 9: Differentielle Expression von Differenzierungsgenen in NTERA-2-Zellen nach BCE-Stimulation.

Tabelle 10: Übersicht über die ersten sechs Ränge der „permuted results“ (Stimulanzienzentrierte Übersicht) für die NTERA-2-Zellen in der cmap.

Tabelle 11: Übersicht über die ersten acht Ränge der „permuted results“ (Stimulanzienzentrierte Übersicht) für die TCam-2-Zellen in der cmap.

Tabelle 12: Konnektivitäten von BCE zu Stimulanzien, die mit Östrogen in Verbindung stehen. 
Literaturverzeichnis

\section{Literaturverzeichnis}

Abate-Shen C (2003): Homeobox genes and cancer: new OCTaves for an old tune. Cancer Cell $\underline{4}, 329-330$

Adlercreutz H (1995): Phytoestrogens: epidemiology and a possible role in cancer protection. Environ Health Perspect $\underline{103}, 103-112$

Avilion AA, Nicolis SK, Pevny LH, Perez L, Vivian N, Lovell-Badge R (2003): Multipotent cell lineages in early mouse development depend on SOX2 function. Genes Dev $\underline{17}, 126-140$

Bae K-M, Su Z, Frye C, McClellan S, Allan RW, Andrejewski JT, Kelley V, Jorgensen M, Steindler DA, Vieweg J et al. (2010): Expression of pluripotent stem cell reprogramming factors by prostate tumor initiating cells. J Urol $\underline{183}, 2045-2053$

Barillé-Nion S, Barlogie B, Bataille R, Bergsagel PL, Epstein J, Fenton RG, Jacobson J, Kuehl WM, Shaughnessy J, Tricot G (2003): Advances in biology and therapy of multiple myeloma. Hematology Am Soc Hematol Educ Program 2003, 248-278

Belpomme D, Irigaray P, Sasco AJ, Newby JA, Howard V, Clapp R, Hardell L (2007): The growing incidence of cancer: role of lifestyle and screening detection (Review). Int J Oncol $\underline{30}, 1037-1049$

Benjamini Y, Hochberg Y (1995): Controlling the False Discovery Rate: A Practical and Powerful Approach to Multiple Testing. J R Statist Soc B 무, 289-300

Ben-Porath I, Thomson MW, Carey VJ, Ge R, Bell GW, Regev A, Weinberg RA (2008): An embryonic stem cell-like gene expression signature in poorly differentiated aggressive human tumors. Nat Genet $\underline{40}, 499-507$

Berg JW (1975): Can nutrition explain the pattern of international epidemiology of hormonedependent cancers? Cancer Res $\underline{35}$, 3345-3350

Bolden JE, Peart MJ, Johnstone RW (2006): Anticancer activities of histone deacetylase inhibitors. Nat Rev Drug Discov $\underline{5}, 769-784$ 
Literaturverzeichnis

Boyer LA, Lee TI, Cole MF, Johnstone SE, Levine SS, Zucker JP, Guenther MG, Kumar RM, Murray HL, Jenner RG et al. (2005): Core transcriptional regulatory circuitry in human embryonic stem cells. Cell $\underline{122}, 947-956$

Carpten JD, Faber AL, Horn C, Donoho GP, Briggs SL, Robbins CM, Hostetter G, Boguslawski S, Moses TY, Savage S et al. (2007): A transforming mutation in the pleckstrin homology domain of AKT1 in cancer. Nature $\underline{448}, 439-444$

Cheers G: Botanica, 1. Auflage; Könemann Verlagsgesellschaft mbH, Köln 1998

Chim SM, Qin A, Tickner J, Pavlos N, Davey T, Wang H, Guo Y, Zheng MH, Xu J (2011): EGFL6 promotes endothelial cell migration and angiogenesis through the activation of extracellular signal-regulated kinase. J Biol Chem 286, 22035-22046

Chomczynski P, Sacchi N (1987): Single-step method of RNA isolation by acid guanidinium thiocyanate-phenol-chloroform extraction. Anal Biochem 162, 156-159

Clark AT (2007): The stem cell identity of testicular cancer. Stem Cell Rev $\underline{3}, 49-59$

Classen M, Diehl V, Kochsiek K, Hallek M, Böhm M, Schmiegel W: Innere Medizin, 6. Auflage; Urban \& Fischer Verlag/Elsevier GmbH, München 2009

Das S, Harris LG, Metge BJ, Liu S, Riker AI, Samant RS, Shevde LA (2009): The hedgehog pathway transcription factor GLI1 promotes malignant behavior of cancer cells by upregulating osteopontin. J Biol Chem 284, 22888-22897

Davis-Dao CA, Siegmund KD, Vandenberg DJ, Skinner EC, Coetzee GA, Thomas DC, Pike MC, Cortessis VK (2011): Heterogenous effect of androgen receptor CAG tract length on testicular germ cell tumor risk: shorter repeats associated with seminoma but not other histologic types. Carcinogenesis $\underline{32}, 1238-1243$

de Jong J, Stoop H, Gillis AJM, Hersmus R, van Gurp RJHLM, van de Geijn G-JM, van Drunen E, Beverloo HB, Schneider DT, Sherlock JK et al. (2008): Further characterization of the first seminoma cell line TCam-2. Genes Chromosomes Cancer 47, 185-196 
Literaturverzeichnis

Dong Y-L, Reddy DM, Green KE, Chauhan MS, Wang H-Q, Nagamani M, Hankins GDV, Yallampalli C (2007): Calcitonin gene-related peptide (CALCA) is a proangiogenic growth factor in the human placental development. Biol Reprod $\underline{76}, 892-899$

Duffy MJ (2001): Clinical uses of tumor markers: a critical review. Crit Rev Clin Lab Sci $\underline{38}$, 225-262

Eble JN, Sauter G, Epstein JI: Pathology and Genetics of Tumours of the Urinary System and Male Genital Organs. World Health Organization, Lyon (Frankreich) 2004

Ezeh UI, Turek PJ, Reijo RA, Clark AT (2005): Human embryonic stem cell genes OCT4, NANOG, STELLAR, and GDF3 are expressed in both seminoma and breast carcinoma. Cancer $\underline{104}, 2255-2265$

Ferrari C, Crosignani PG (1986): Medical treatment of hyperprolactinaemic disorders. Hum Reprod 1 (8), 507-514

Gasa R, Mrejen C, Lynn FC, Skewes-Cox P, Sanchez L, Yang KY, Lin C-H, Gomis R, German MS (2008): Induction of pancreatic islet cell differentiation by the neurogenin-neuroD cascade. Differentiation $\underline{76}, 381-391$

Gentleman RC, Carey VJ, Bates DM, Bolstad B, Dettling M, Dudoit S, Ellis B, Gautier L, Ge Y, Gentry J et al. (2004): Bioconductor: open software development for computational biology and bioinformatics. Genome Biol $\underline{5(10)}$, R80

Glazier MG, Bowman MA (2001): A review of the evidence for the use of phytoestrogens as a replacement for traditional estrogen replacement therapy. Arch Intern Med 161, 1161-1172

Greber B, Lehrach H, Adjaye J (2007): Silencing of core transcription factors in human EC cells highlights the importance of autocrine FGF signaling for self-renewal. BMC Dev Biol $\underline{7}$ : 46

Hayes-Lattin B, Nichols CR (2009): Testicular cancer: a prototypic tumor of young adults. Semin Oncol 36, 432-438 
Literaturverzeichnis

Hoei-Hansen CE, Rajpert-De Meyts E, Daugaard G, Skakkebaek NE (2005): Carcinoma in situ testis, the progenitor of testicular germ cell tumours: a clinical review. Ann Oncol $\underline{16}$, $863-868$

Huyghe E, Matsuda T, Thonneau P (2003): Increasing incidence of testicular cancer worldwide: a review. J Urol 170 (1), 5-11

Irizarry RA, Hobbs B, Collin F, Beazer-Barclay YD, Antonellis KJ, Scherf U, Speed TP (2003): Exploration, normalization, and summaries of high density oligonucleotide array probe level data. Biostatistics $\underline{4}, 249-264$

Ito H, Onoue S, Yoshida T (2001): Isoflavonoids from Belamcanda chinensis. Chem Pharm Bull $\underline{49}, 1229-1231$

Iván G, Szigeti-Csúcs N, Oláh M, Nagy GM, Góth MI (2005): Treatment of pituitary tumors: dopamine agonists. Endocrine 28 (1), 101-110

Jacobsen R, Bostofte E, Engholm G, Hansen J, Olsen JH, Skakkebaek NE, Moller H (2000): Risk of testicular cancer in men with abnormal semen characteristics: cohort study. BMJ $\underline{321}$, 789-792

Jeter CR, Badeaux M, Choy G, Chandra D, Patrawala L, Liu C, Calhoun-Davis T, Zaehres H, Daley GQ, Tang DG (2009): Functional evidence that the self-renewal gene NANOG regulates human tumor development. Stem Cells $\underline{27}$, 993-1005

Jia X, Li X, Xu Y, Zhang S, Mou W, Liu Y, Liu Y, Lv D, Liu C-H, Tan X et al. (2011): SOX2 promotes tumorigenesis and increases the anti-apoptotic property of human prostate cancer cell. J Mol Cell Biol $\underline{3}, 230-238$

Jin B, Yao B, Li J-L, Fields CR, Delmas AL, Liu C, Robertson KD (2009): DNMT1 and DNMT3B modulate distinct polycomb-mediated histone modifications in colon cancer. Cancer Res $\underline{69}, 7412-7421$ 
Literaturverzeichnis

Jung M, Peterson H, Chavez L, Kahlem P, Lehrach H, Vilo J, Adjaye J (2010): A data integration approach to mapping OCT4 gene regulatory networks operative in embryonic stem

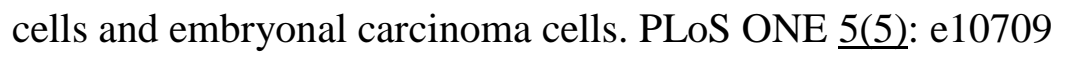

Jung SH, Lee YS, Lee S, Lim SS, Kim YS, Ohuchi K, Shin KH (2003): Anti-angiogenic and anti-tumor activities of isoflavonoids from the rhizomes of Belamcanda chinensis. Planta Med $\underline{69}, 617-622$

Kallas A, Pook M, Maimets M, Zimmermann K, Maimets T (2011): Nocodazole treatment decreases expression of pluripotency markers Nanog and Oct4 in human embryonic stem cells. PLoS ONE $\underline{6, I V}$, e19114

Kang SW, Kim MC, Kim CY, Jung SH, Um BH (2008): The rapid identification of isoflavonoids from Belamcanda chinensis by LC-NMR and LC-MS. Chem Pharm Bull $\underline{56}$, $1452-1454$

Kelly LM, Englmeier U, Lafon I, Sieweke MH, Graf T (2000): MafB is an inducer of monocytic differentiation. EMBO J $\underline{19}, 1987-1997$

Kennedy AR (1995): The evidence for soybean products as cancer preventive agents. J Nutr $\underline{125}, 733-743$

Kikuno N, Shiina H, Urakami S, Kawamoto K, Hirata H, Tanaka Y, Majid S, Igawa M, Dahiya R (2008): Genistein mediated histone acetylation and demethylation activates tumor suppressor genes in prostate cancer cells. Int J Cancer $\underline{123}$, 552-560

Krege S, Beyer J, Souchon R, Albers P, Albrecht W, Algaba F, Bamberg M, Bodrogi I, Bokemeyer C, Cavallin-Ståhl E et al. (2008): European consensus conference on diagnosis and treatment of germ cell cancer: a report of the second meeting of the European Germ Cell Cancer Consensus group (EGCCCG): part I. Eur Urol 53, 478-496

Kushi LH, Doyle C, McCullough M, Rock CL, Demark-Wahnefried W, Bandera EV, Gapstur S, Patel AV, Andrews K, Gansler T (2012): American Cancer Society Guidelines on nutrition 
Literaturverzeichnis

and physical activity for cancer prevention: reducing the risk of cancer with healthy food choices and physical activity. CA Cancer J Clin $\underline{62}, 30-67$

Lamb J, Crawford ED, Peck D, Modell JW, Blat IC, Wrobel MJ, Lerner J, Brunet J-P, Subramanian A, Ross KN et al. (2006): The Connectivity Map: using gene-expression signatures to connect small molecules, genes, and disease. Science $\underline{313}$, 1929-1935

Lee KT, Sohn IC, Kim YK, Choi JH, Choi JW, Park HJ, Itoh Y, Miyamoto K (2001): Tectorigenin, an isoflavone of Pueraria thunbergiana Benth., induces differentiation and apoptosis in human promyelocytic leukemia HL-60 cells. Biol Pharm Bull 24, 1117-1121

Linke J, Loy V, Dieckmann K-P (2005): Prevalence of testicular intraepithelial neoplasia in healthy males. J Urol $\underline{173}, 1577-1579$

Liu N, Lu M, Tian X, Han Z (2007): Molecular mechanisms involved in self-renewal and pluripotency of embryonic stem cells. J Cell Physiol 211, 279-286

Looijenga LHJ (2009): Human testicular (non)seminomatous germ cell tumours: the clinical implications of recent pathobiological insights. J Pathol $\underline{218}, 146-162$

Majid S, Dar AA, Shahryari V, Hirata H, Ahmad A, Saini S, Tanaka Y, Dahiya AV, Dahiya R (2010): Genistein reverses hypermethylation and induces active histone modifications in tumor suppressor gene B-Cell translocation gene 3 in prostate cancer. Cancer $\underline{116}$, 66-76

McLachlan JA, Newbold RR, Li S, Negishi M (1998): Are estrogens carcinogenic during development of the testes? APMIS $\underline{106}, 240-244$

Morrissey C, Bektic J, Spengler B, Galvin D, Christoffel V, Klocker H, Fitzpatrick JM, Watson RWG (2004): Phytoestrogens derived from Belamcanda chinensis have an antiproliferative effect on prostate cancer cells in vitro. J Urol $\underline{172}$, 2426-2433

Mosmann T (1983): Rapid colorimetric assay for cellular growth and survival: application to proliferation and cytotoxicity assays. J Immunol Methods $\underline{65}$, 55-63 
Literaturverzeichnis

Murkies AL, Wilcox G, Davis SR (1998): Clinical review 92: Phytoestrogens. J Clin Endocrinol Metab $\underline{83}, 297-303$

Nakayama T, Hirakawa H, Shibata K, Nazneen A, Abe K, Nagayasu T, Taguchi T (2011): Expression of angiopoietin-like 4 (ANGPTL4) in human colorectal cancer: ANGPTL4 promotes venous invasion and distant metastasis. Oncol Rep $\underline{25}$, 929-935

Neuvians TP, Gashaw I, Hasenfus A, Hacherhäcker A, Winterhager E, Grobholz R (2005):

Differential expression of IGF components and insulin receptor isoforms in human seminoma versus normal testicular tissue. Neoplasia $\underline{7}, 446-456$

Omisanjo OA, Biermann K, Hartmann S, Heukamp LC, Sonnack V, Hild A, Brehm R, Bergmann M, Weidner W, Steger K (2007): DNMT1 and HDAC1 gene expression in impaired spermatogenesis and testicular cancer. Histochem Cell Biol 127, 175-181

Pais V, Leav I, Lau K-M, Jiang Z, Ho S-M (2003): Estrogen receptor-beta expression in human testicular germ cell tumors. Clin Cancer Res $\underline{9}, 4475-4482$

Pal R, Ravindran G (2006): Assessment of pluripotency and multilineage differentiation potential of NTERA-2 cells as a model for studying human embryonic stem cells. Cell Prolif $\underline{39}$, $585-598$

Park ET, Gum JR, Kakar S, Kwon SW, Deng G, Kim YS (2008): Aberrant expression of SOX2 upregulates MUC5AC gastric foveolar mucin in mucinous cancers of the colorectum and related lesions. Int J Cancer $\underline{122}$, 1253-1260

Pleskacova J, Hersmus R, Oosterhuis JW, Setyawati BA, Faradz SM, Cools M, Wolffenbuttel KP, Lebl J, Drop SL, Looijenga LH (2010): Tumor risk in disorders of sex development. Sex Dev $\underline{4}, 259-269$

Pouponnot C, Sii-Felice K, Hmitou I, Rocques N, Lecoin L, Druillennec S, FelderSchmittbuhl M-P, Eychène A (2006): Cell context reveals a dual role for Maf in oncogenesis. Oncogene 25, 1299-1310 
Literaturverzeichnis

Rajpert-De Meyts E, Skakkebaek NE (1992): Immunohistochemical identification of androgen receptors in germ cell neoplasia. J Endocrinol $\underline{135}, \mathrm{R} 1-4$

Raman JD, Nobert CF, Goldstein M (2005): Increased incidence of testicular cancer in men presenting with infertility and abnormal semen analysis. J Urol 174, 1819-1822

Regenbrecht CR, Jung M, Lehrach H, Adjaye J (2008): The molecular basis of genisteininduced mitotic arrest and exit of self-renewal in embryonal carcinoma and primary cancer cell lines. BMC Med Genomics 1: 49

Riley P, Anson-Cartwright L, Cross JC (1998): The Hand1 bHLH transcription factor is essential for placentation and cardiac morphogenesis. Nat Genet $\underline{18}, 271-275$

Schottenfeld D, Warshauer ME, Sherlock S, Zauber AG, Leder M, Payne R (1980): The epidemiology of testicular cancer in young adults. Am J Epidemiol 112, 232-246

Shao ZM, Alpaugh ML, Fontana JA, Barsky SH (1998): Genistein inhibits proliferation similarly in estrogen receptor-positive and negative human breast carcinoma cell lines characterized by P21WAF1/CIP1 induction, G2/M arrest, and apoptosis. J Cell Biochem $\underline{69}$, 44-54

Sharpe RM, Skakkebaek NE (1993): Are oestrogens involved in falling sperm counts and disorders of the male reproductive tract? Lancet $\underline{341}, 1392-1395$

Silverberg E (1982): Cancer in young adults (ages 15 to 34). CA Cancer J Clin $\underline{32}$, 32-42

Smyth GK (2004): Linear Models and Empirical Bayes Methods for Assessing Differential Expression in Microarray Experiments. Stat Appl in Genet Mol Biol 3: 3

Sobin LH, Gospodarowicz MK, Wittekind C. TNM Classification of Malignant Tumours. 7. Auflage; John Wiley \& Sons Ltd, West Sussex (UK) 2009

Stang A, Katalinic A, Dieckmann K-P, Pritzkuleit R, Stabenow R (2010): A novel approach to estimate the German-wide incidence of testicular cancer. Cancer Epidemiol 34, 13-19 
Literaturverzeichnis

Stange DE, Engel F, Longerich T, Koo BK, Koch M, Delhomme N, Aigner M, Toedt G, Schirmacher P, Lichter P et al. (2010): Expression of an ASCL2 related stem cell signature and IGF2 in colorectal cancer liver metastases with 11p15.5 gain. Gut $\underline{59}, 1236-1244$

Stephen RA (1962): The clinical presentation of testicular tumours. Br J Urol 34, 448-453

Stettner M, Kaulfuss S, Burfeind P, Schweyer S, Strauss A, Ringert R-H, Thelen P (2007): The relevance of estrogen receptor-beta expression to the antiproliferative effects observed with histone deacetylase inhibitors and phytoestrogens in prostate cancer treatment. Mol Cancer Ther $\underline{6}, 2626-2633$

Thelen P, Scharf J-G, Burfeind P, Hemmerlein B, Wuttke W, Spengler B, Christoffel V, Ringert R-H, Seidlová-Wuttke D (2005): Tectorigenin and other phytochemicals extracted from leopard lily Belamcanda chinensis affect new and established targets for therapies in prostate cancer. Carcinogenesis $\underline{26}, 1360-1367$

Thelen P, Peter T, Hünermund A, Kaulfuss S, Seidlová-Wuttke D, Wuttke W, Ringert R-H, Seseke F (2007): Phytoestrogens from Belamcanda chinensis regulate the expression of steroid receptors and related cofactors in LNCaP prostate cancer cells. BJU Int $\underline{100}, 199-203$

van den Berg DLC, Zhang W, Yates A, Engelen E, Takacs K, Bezstarosti K, Demmers J, Chambers I, Poot RA (2008): Estrogen-related receptor beta interacts with Oct4 to positively regulate Nanog gene expression. Mol Cell Biol 28, 5986-5995

Venkataramani V, Rossner C, Iffland L, Schweyer S, Tamboli IY, Walter J, Wirths O, Bayer TA (2010): Histone deacetylase inhibitor valproic acid inhibits cancer cell proliferation via down-regulation of the alzheimer amyloid precursor protein. J Biol Chem $\underline{285}$, 10678-10689

Wagner H, Bauer R, Xiao P, Chen J, Nenninger A: Rhizoma belamcandae sinensis - Shegan in: Chinese drug monographs and analysis 2 (11); Verlag für Ganzheitliche Medizin Dr. Erich Wühr GmbH, Kötzting/Bayer. Wald 1999, 1-13

Wang W, Chan EK, Baron S, Van de Water T, Lufkin T (2001): Hmx2 homeobox gene control of murine vestibular morphogenesis. Development $\underline{128}, 5017-5029$ 
Literaturverzeichnis

Wobbes T, Schraffordt Koops H, Oldhoff J (1980): The relation between testicular tumours, undescended testes, and inguinal hernias. J Surg Oncol 14, 45-51

Wu J-H, Wang Y-R, Huang W-Y, Tan R-X (2010): Anti-proliferative and pro-apoptotic effects of tectorigenin on hepatic stellate cells. World J Gastroenterol 16, 3911-3918

Yamaki M, Kato T, Kashihara M, Takagi S (1990): Isoflavones of Belamcanda chinensis. Planta Med $\underline{56}, 335$

You JS, Kang JK, Seo D-W, Park JH, Park JW, Lee JC, Jeon YJ, Cho EJ, Han J-W (2009): Depletion of embryonic stem cell signature by histone deacetylase inhibitor in NCCIT cells: involvement of Nanog suppression. Cancer Res $\underline{69}, 5716-5725$

Zenmyo M, Tanimoto A, Sakakima H, Yokouchi M, Nagano S, Yamamoto T, Ishido Y, Komiya S, Ijiri K (2010): Gadd45 $\beta$ expression in chondrosarcoma: a pilot study for diagnostic and biological implications in histological grading. Diagn Pathol 5: 69

Zhang YQ, Mashima H, Kojima I (2001): Changes in the expression of transcription factors in pancreatic AR42J cells during differentiation into insulin-producing cells. Diabetes $\underline{50}, 10$ 14

Zhang Y-Y, Wang Q, Qi L-W, Qin X-Y, Qin M-J (2011): Characterization and determination of the major constituents in Belamcandae Rhizoma by HPLC-DAD-ESI-MS(n). J Pharm Biomed Anal 56, 304-314

Zhou Q, Nie R, Prins GS, Saunders PTK, Katzenellenbogen BS, Hess RA (2002): Localization of androgen and estrogen receptors in adult male mouse reproductive tract. J Androl $\underline{23}$, $870-881$ 


\section{Danksagung}

Der größte Dank gebührt meinem Doktorvater PD Dr. Stefan Schweyer für die Bereitstellung des interessanten Themas und die ausgezeichnete Betreuung, sowohl während der experimentellen Phase im Labor, als auch während der Abfassung dieser Dissertationsarbeit.

Neben den technischen Assistentinnen Anke Klages und Nicole Kerl, die mir im Labor bei technischen Fragen immer hilfsbereit zur Seite standen, gilt mein Dank außerdem allen Mitarbeiterinnen und Mitarbeitern der Abteilung Pathologie der Universitätsmedizin Göttingen, durch die ich immer Unterstützung erfahren habe sowie dem Abteilungsleiter Prof. Dr. HeinzJoachim Radzun.

Ein ganz spezieller Dank gebührt allen Partnern und Kollegen, die auch über die Abteilungsgrenzen hinaus zum Gelingen dieser Arbeit beigetragen haben. Für die Mitbenutzung von Geräten danke ich der Abteilung Neuropathologie, Abteilung Humangenetik und der Abteilung Urologie. PD Dr. Paul Thelen und Marion Striepe aus der Abteilung Urologie gebührt außerdem großer Dank für die Kooperation im Zusammenhang mit der Prostatakrebszelllinie und der Analyse von Hormonrezeptoren und -Pathways. Dr. Vivek Venkataramani und der Abteilung Molekulare Psychiatrie danke ich für die Hilfe bei der Etablierung der WesternBlot-Methode.

Zu guter Letzt möchte ich meiner Familie sowie der Familie Alflen für die Hilfe bei Korrekturarbeiten und jegliche Art von Unterstützung danken. 